Daniel Martín Serjio
Barredo
Oller
Hernández
Ibánez
Alonso
González

\title{
La Comunicación y el Periodismo de Ecuador frente a los desafíos contemporáneos
}

Prólogo: Ángel Páez, PhD, Universidad del Zulia, Venezuela Epílogo: Amaro La Rosa, Universidad Femenina del Sagrado Corazón, Perú

Cuadernos Artesanos de Latina / 74

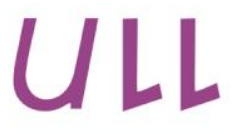

Universidad de La Laguna

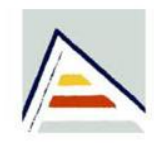

Universitat d'Alacant Universidad de Alicante
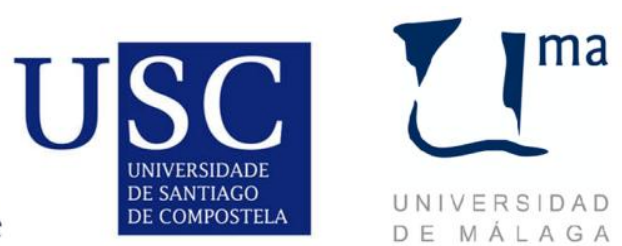

UNIVERSIDAD $D E M A L A G A$

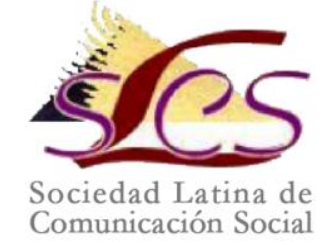


CAC \# 74 - Cuadernos Artesanos de Comunicación - Comité Científico

Presidencia: José Luis Piñuel Raigada (UCM)

Secretaría: Concha Mateos (URJC)

- Bernardo Díaz Nosty (Universidad de Málaga, UMA)

- Carlos Elías (Universidad Carlos III de Madrid, UC3M)

- Javier Marzal (Universidad Jaume I, UJI)

- José Luis González Esteban (Universitas Miguel Hernández de Elche)

- José Luis Terrón (Universidad Autónoma de Barcelona, UAB)

- José Miguel Túñez (Universidad de Santiago, USC)

- Juan José Igartua (Universidad de Salamanca, USAL)

- Marisa Humanes (Universidad Rey Juan Carlos, URJC)

- Miguel Vicente (Universidad de Valladolid, UVA)

- Miquel Rodrigo Alsina (Universidad Pompeu Fabra, UPF)

- Núria Almiron (Universidad Pompeu Fabra, UPF)

- Ramón Reig (Universidad de Sevilla, US)

- Ramón Zallo (Universidad del País Vasco, UPV-EHU)

- Victoria Tur (Universidad de Alicante, UA).

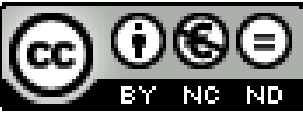

* Queda expresamente autorizada la reproducción total o parcial de los textos publicados en este libro, en cualquier formato o soporte imaginables, salvo por explícita voluntad en contra del autor o autora o en caso de ediciones con ánimo de lucro. Las publicaciones donde se incluyan textos de esta publicación serán ediciones no comerciales y han de estar igualmente acogidas a Creative Commons. Se hará constar esta licencia y el carácter no venal de la publicación. * La responsabilidad de cada texto es de su autor o autora.

* La responsabilidad de cada texto es de su autor o autora. 


$\begin{array}{ccc}\text { Daniel } & \text { Martín Oller } & \text { Sergio Hernández } \\ \text { Barredo Ibáñez } & \text { Alonso } & \text { González }\end{array}$

\section{La Comunicación y el Periodismo de Ecuador frente a los desafíos contemporáneos}

Cuadernos Artesanos de Latina / 74

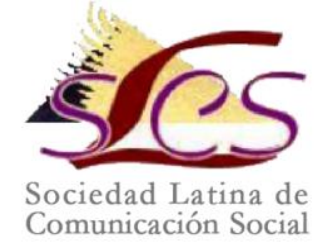


$74^{\circ}$ - La Comunicación y el Periodismo de Ecuador frente a los desafíos contemporáneos, Daniel Barredo Ibáñez, Martín Oller Alonso y Sergio Hernández Gonzalez| Precio social: 8,50€ - Precio librería: $11,05 €$.

Editores: Javier Herrero y Alberto Ardèvol Abreu Diseño: F. Drago

Ilustración de portada: Fragmento del cuadro de la serie Cosmoarte, de Pedro González.

Imprime y distribuye: F. Drago. Andocopias S. L.

c/ La Hornera, 41. La Laguna. Tenerife.

Teléfono: 922250554 | fotocopiasdrago@,telefonica.net

Edita: Sociedad Latina de Comunicación Social - edición no venal

- La Laguna (Tenerife), 2015 - Creative Commons

(http://www.revistalatinacs.org/09/Sociedad/estatutos.html)

Catálogo: http://www.cuadernosartesanos.org

Protocolo de envío de manuscritos con destino a CAC: http://www.cuadernosartesanos.org/protocolo.html

Descargar $p d f$ :

http://www.cuadernosartesanos.org/\#74

ISBN - 13: $978-84-15698-90-6$

DL: TF $-1.030-2014$

DOI: $10.4185 / \mathrm{CAC} 74$ 
Este libro está dedicado, y es un homenaje sincero y modesto, al Dr. Romeo Rodríguez, Rector de la Escuela Superior Politécnica de Chimborazo, y a la Lic. Carola Donoso, comunicadora de la Escuela Superior Politécnica de Chimborazo, fallecidos trágicamente el día 22 de noviembre de 2013 en un accidente de tráfico.

Con cariño, os recuerdan vuestros amigos:

Daniel Barredo / Sergio Hernández / Martín Oller 


\title{
La Comunicación y el Periodismo de Ecuador frente a los desafíos contemporáneos
}

\author{
Daniel Barredo, Sergio Hernández, Martín Oller
}

\begin{abstract}
En la última década, se han dado importantes pasos en la comunicación del Ecuador. Las iniciativas de los gobiernos de Rafael Correa para regular el sistema comunicacional, la inauguración de medios públicos, y la reorganización del paradigma con una cada vez mayor presencia de los medios comunitarios, son algunos de los debates a los que asiste la República andina y que hacen del contexto ecuatoriano uno de los más interesantes para los investigadores en el ámbito de la comunicación.
\end{abstract}

Pero a pesar de esta ebullición de leyes, de nuevas prácticas periodísticas, de reformas y emprendimientos, la Academia ecuatoriana destaca por la escasez de contribuciones que analicen con rigurosidad este escenario simbólico: según el índice SCImago, entre 1996 y 2013 solo se produjeron en el país andino 10 documentos citables vinculados a la comunicación.

En este Cuaderno Artesano se ofrecen siete capítulos, con los cuales se pretende abordar la complejidad del Ecuador desde los ámbitos del Periodismo o el Derecho. Es este un intento de explicar en qué estado se encuentra la comunicación ecuatoriana, con el fin de aportar claves que ayuden a entender un contexto sobre el cual se ha escrito tan poco.

\section{Palabras clave}

Comunicación ecuatoriana; LOC; Rafael Correa; Ecuador; cultura periodística.

\section{Forma de citar este libro}

Barredo Ibáñez, Daniel et alt. (2014): La Comunicación y el Periodismo de Ecuador frente a los desafios contemporáneos Cuaderno Artesano de Comunicación, 73, La Laguna (Tenerife): Latina. 


\section{Índice}

Palabras de bienvenida

Prólogo, por Ángel Páez

Introducción, por Daniel Barredo y Martín Oller

CAPÍTULO I: El milagro ecuatoriano: pautas para entender el Ecuador del siglo XXI

Daniel Barredo, Roxana Silva y Cheryl Martens

CAPÍTULO II: Políticas públicas en comunicación y sistemas mediáticos. El caso de Ecuador Palmira Chavero y Martín Oller

CAPÍTULO III: Ley Orgánica de Comunicación y comunicación responsable José María Pérez Zúñiga y Daniel Barredo

CAPÍTULO IV: El periodismo ecuatoriano en entredicho. Descenso de credibilidad y nuevas perspectivas comunicacionales Daniel Barredo, José María Pérez Zúñiga, Rocío Vivas y Montserrat Fernández

CAPÍTULO V: El periodismo cultural: análisis de un subcampo periodístico en el contexto del periodismo de investigación Pamela Cruz

CAPÍTULO VI: Algunos problemas de la comunicación institucional 143 digital. Un estudio de las instituciones educativas más prestigiosas del Ecuador

Daniel Barredo,Jenny Basantes, Ernesto Bonilla, Juan Pablo Trámpuz y Silvia Vega 
CAPÍTULO VII: La comunicación y la vinculación en la universidad 161 ecuatoriana. Propuesta de creación del Centro Universitario de Jóvenes Emprendedores (CUJE) en la Universidad de las Américas (UDLA), Ecuador

Martín Oller, Palmira Chavero, Rafael Jorda y Xavier Oviedo

Epílogo, por Amaro La Rosa 


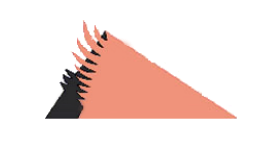

\title{
Palabras de bienvenida
}

\begin{abstract}
A Eugenio Santacruz y Espejo se lo considera el precursor del 1 periodismo en Ecuador. Tanto así, que la fecha de publicación de la primera edición de las "Primicias de la Cultura de Quito" ha sido marcada en el calendario para conmemorar cada año el "Día del Periodismo Ecuatoriano".
\end{abstract}

Pero lo realizado por el ilustre pensador dista mucho del trabajo periodístico de estos días. No había entonces un manejo de fuentes, ni labor reporteril, ni contraste de la información ni ley de comunicación. Lo suyo era un acto reflexivo y cívico respaldado en una ansiada libertad de expresión.

El periodismo de opinión inauguró el oficio en este país y en la mayoría de países porque el derecho a expresarse no sólo es el motor primario del periodista sino un pilar de la democracia.

Este libro pone bajo la lupa los desafíos de una profesión en permanente proceso de adaptación, en un país en el que desde el Estado se reclama a la información como un bien público. El concepto de adaptación se entiende como la capacidad de acomodarse a las condiciones de un entorno. Pero una cosa es ajustarse al mercado y a las nuevas plataformas de difusión y otra muy distinta es la revisión de conceptos primarios como las libertades. Las universidades también se adaptan.

Por ejemplo, en la Universidad de Waterloo en Canadá, los estudiantes pueden optar por una carrera en Dialéctica que los entrena para hablar en público en ámbitos políticos, empresariales y hasta religiosos. La Universidad de Columbia en EE.UU. abrió en 2010 un Centro de Periodismo Digital con una inversión de 15 
millones de dólares. En Ecuador, los estudiantes de periodismo se entrenan en las nuevas tecnologías, en las técnicas narrativas y en la formación del criterio editorial. Pero el reto incluye ahora intentar tomarle el pulso a una novel Ley Orgánica de Comunicación y a la estructura de regulación que la acompaña.

Ciertamente hay un futuro para la comunicación y el periodismo en el Ecuador. Pero los desafíos contemporáneos nos dejan ver que los cronistas del mañana tendrán que ser seguramente, y al mismo tiempo, más innovadores y mucho más rigurosos.

¿Cuáles son los valores del periodismo que realmente importan? En estos desafíos contemporáneos y futuros resulta vital que ni la comunicación ni el periodismo tengan como eje principal a la conveniencia. En todo el mundo los hospitales universitarios salvan vidas y los consultorios legales universitarios defienden los derechos de poblaciones vulnerables. Pero pensar que un periódico estudiantil destape casos de corrupción es una ficción futurista. Espejo fue un visionario y, aunque el proyecto no prosperó y murió en la cárcel, nos heredó un oficio ese 5 de enero de 1792. Quizás es tiempo de emularle entendiendo los retos de hoy, asumiendo los riesgos del oficio y trazando los caminos del mañana.

José Velásquez, $\mathrm{MsC}$ Decano de la Facultad de Comunicación Universidad de las Américas (Ecuador) 


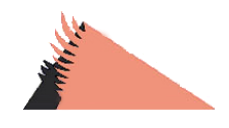 \\ Prólogo}

$\mathrm{E}$

STA MAGNÍFICA OBRA sobre la comunicación y el periodismo se convierte en una interesante radiografía de la sociedad ecuatoriana (muy cercana a los países de la región latinoamericana), al tiempo que ella misma se traduce en un esfuerzo por transformar una cultura investigativa caracterizada, como lo apuntan sus autores, por un paradigma académico irregular, la publicación de contribuciones irrelevantes y escasamente citables, la existencia de unas universidades identificadas por ser centros de docencia, donde se otorgaba una escasa importancia a la generación de conocimiento, las deficientes condiciones sociolaborales del investigador en comunicación, la deficiente situación del acceso a recursos bibliográficos de primer nivel, la falta de interés de los investigadores locales por insertarse en redes académicas internacionales, la falta de conexión entre los tres ejes habituales de la universidad (investigación / docencia / vinculación con la sociedad) y la falta de una investigación de base y de una cultura social de la investigación.

La obra muestra evidencias de los intentos que ha hecho Ecuador por avanzar hacia una sociedad que centra su desarrollo en la ciencia y, en este caso, en la ciencia de la comunicación. En el Capítulo I, Daniel Barredo, Roxana Silva y Cheryl Martens abordan el debatido término del milagro ecuatoriano, que en concreto se traduce en un elevado apoyo que situaba a los habitantes de la República andina como los segundos más satisfechos en la región con sus administradores.

En el capítulo sobre políticas públicas en comunicación y sistemas mediáticos, Palmira Chavero y Martín Oller caracterizan el sistema 
mediático ecuatoriano, tratando de orientar la discusión desde las diferencias entre la libertad de prensa, que es igual a la libertad que tienen los poderosos para fijar la agenda de temas en la opinión pública, versus la libertad de expresión de los ciudadanos en democracia.

Con el tema de la Ley Orgánica de Comunicación José María Pérez Zúniga y Daniel Barredo muestran las distintas opciones que existen sobre el papel del Estado en la regulación de los medios. El trabajo se presenta justo en un momento en el que en el mundo se debate sobre la neutralidad de la red, que es un principio que establece que todos los contenidos que circulan por Internet deben recibir tratos igualitarios y no deben discriminarse según origen, uso o aplicación. En otras palabras, es la última fase de la eterna discusión sobre la regulación de los medios de comunicación ${ }^{1}$.

En el capítulo "El periodismo ecuatoriano en entredicho. Descenso de credibilidad y nuevas perspectivas comunicacionales" Daniel Barredo, José María Pérez Zúniga, Rocio Vivas y Montserrat Fernández se presentan como integrados a favor de las posibilidades de interacción con las instituciones que ofrecen las TICs, pasando a un segundo plano la mediación de los medios, en un contexto de menor credibilidad de los mismos.

En el trabajo de Pamela Cruz se ofrece una perspectiva innovadora del periodismo cultural como un campo específico del periodismo de investigación en el que se proponen nuevas preocupaciones como la indagación de los diálogos culturales y la difusión de productos integrales narrados por sus propios actores culturales.

En el capítulo "Algunos problemas de la comunicación institucional digital. Un estudio de las instituciones educativas más prestigiosas del Ecuador", Daniel Barredo, Jenny Basantes, Ernesto Bonilla, Juan Carlos

\footnotetext{
${ }^{1}$ Fernández, Paola (2014). Neutralidad de la red: tensiones para pensar la regulación de internet. Question: revista especializada en periodismo y comunicación, 1: 42, http://perio.unlp.edu.ar/ojs/index.php/question/article/view/2131 [recuperado 15/12/2014].
}

${ }^{2}$ Apocalípticos e integrados es un libro de Umberto Eco, publicado en 1965. 
Trámpuzy Silvia Vega apuestan por una tesis muy polémica: "Internet estimula a las instituciones la posibilidad de contactar a sus públicos estratégicos sin filtrado o intermediación, siempre y cuando se optimicen las oportunidades sugeridas por las TICs"; sin embargo, se destaca que en el desarrollo de la investigación, se muestran evidencias empíricas que respaldan tal aseveración.

Y para cerrar con broche de oro y probar que el libro no se limita a la simple retórica y a la presentación de evidencias empíricas, Martín Oller, Palmira Chavero, Rafael Jorda y Xavier Oviedo comparten con nosotros la experiencia de la propuesta de creación del Centro Universitario de Jóvenes Emprendedores (CUJE) en la Universidad de las Américas (UDLA), Ecuador, creado como estrategia de vinculación con el mercado laboral, el cual permite realizar prácticas pre -profesionales a los estudiantes dentro de la universidad.

Maracaibo, Venezuela, 13 de diciembre de 2014 Ángel Páez, $\mathrm{PhD}$ Universidad del Zulia, Venezuela 



\title{
N \\ Introducción
}

\section{Un escenario en transformación: la Comunicación ecuatoriana del siglo XXI}

\begin{abstract}
Tumerosas circunstancias hacían de Ecuador uno de los 1 países del mundo en donde menos se publicaba. A partir de los gobiernos de la Revolución Ciudadana, en cambio, se han activado iniciativas muy concretas para conseguir una reacción en la investigación. En las páginas siguientes enumeramos algunas de las circunstancias que nos hemos topado en los últimos dos años, tras realizar estancias investigativas en centros tanto públicos, como privados.
\end{abstract}

\section{Ecuador: la investigación en formación}

Durante los dos últimos años, hemos trabajado en varios centros académicos, tanto de la capital, como de las provincias del Ecuador, tanto de carácter público, como privado ${ }^{3}$. En el transcurso de estas estancias, hemos experimentado numerosas deficiencias que lastran la investigación en Comunicación, a pesar de que también hemos notado algunos beneficios de un paradigma que, en estos

\footnotetext{
${ }^{3}$ En concreto, hemos trabajado como investigadores Prometeos -un programa de contratación de expertos de alto nivel - en instituciones públicas como la Escuela Superior Politécnica de Chimborazo (Riobamba, Ecuador); el Centro Internacional de Estudios Superiores de Comunicación para América Latina, el Instituto de Altos Estudios Nacionales y la Universidad Central del Ecuador (Quito, Ecuador). En los últimos meses, nos desempeñamos en una institución privada, la Universidad de las Américas (Quito, Ecuador).
} 
momentos, está en proceso de transformación. Las siguientes páginas son un extracto de todas estas observaciones; citemos, por ejemplo, los siguientes:

a. La situación de un paradigma académico irregular. La mayor parte de los esfuerzos interpretativos se concentraban en el Centro Internacional de Estudios Superiores de Comunicación para América Latina, el cual -creado en XX-prácticamente aglutinaba la mayor parte de la producción del país, sea a través de la divulgación de investigaciones propias, sea a través de iniciativas como Chasqui, Revista Latinoamericana de Comunicación, o bien la colección de libros editados por el propio centro.

b. La amplia trayectoria en el ensayo académico, así como la publicación de contribuciones irrelevantes y escasamente citables. Quizá por ese apego por géneros académicos de carácter teórico, entre 1996 y 2013 únicamente se produjeron 10 documentos citables, según leemos en SCImago:

\begin{tabular}{|c|c|c|c|c|c|c|c|c|c|c|c|c|c|c|c|c|c|}
\hline \multicolumn{11}{|c|}{ Publicaciones en Comunicación del Ecuador $(1996-2013)$, según SCImago } \\
\hline $\mathbf{1 9}$ & $\mathbf{1 9}$ & $\mathbf{1 9}$ & $\mathbf{1 9}$ & $\mathbf{2 0}$ & $\mathbf{2 0}$ & $\mathbf{2 0}$ & $\mathbf{2 0}$ & $\mathbf{2 0}$ & $\mathbf{2 0}$ & $\mathbf{2 0}$ & $\mathbf{2 0}$ & $\mathbf{2 0}$ & $\mathbf{2 0}$ & $\mathbf{2 0}$ & $\mathbf{2 0}$ & $\mathbf{2 0}$ & $\mathbf{2 0}$ \\
$\mathbf{9 6}$ & $\mathbf{9 7}$ & $\mathbf{9 8}$ & $\mathbf{9 9}$ & $\mathbf{0 0}$ & $\mathbf{0 1}$ & $\mathbf{0 2}$ & $\mathbf{0 3}$ & $\mathbf{0 4}$ & $\mathbf{0 5}$ & $\mathbf{0 6}$ & $\mathbf{0 7}$ & $\mathbf{0 8}$ & $\mathbf{0 9}$ & $\mathbf{1 0}$ & $\mathbf{1 1}$ & $\mathbf{1 2}$ & $\mathbf{1 3}$ \\
\hline 0 & 0 & 0 & 0 & 0 & 0 & 0 & 0 & 0 & 0 & 0 & 1 & 1 & 0 & 0 & 1 & 2 & 5 \\
\hline \multicolumn{11}{|c|}{ Fuente: elaboración propia } \\
\hline
\end{tabular}

Curiosamente, si se observa la tabla anterior, el $80 \%$ de la producción de alto nivel se registró entre 2011 y 2013.

c. La existencia de unas universidades identificadas por ser centros de docencia, donde se otorgaba una escasa importancia a la generación de conocimiento.

d. Las deficientes condiciones sociolaborales del investigador en Comunicación, entre las cuales enumeramos los sueldos bajos, la gran carga académica que en algunos casos superaba las dieciséis horas de clase semanales, etcétera.

\footnotetext{
${ }^{4}$ Datos consultados el 08/12/2014 de

http:/ $/$ www.scimagojr.com/countryrank.php?area $=3300 \&$ category $=3315 \&$ re gion $=$ all \&year $=$ all\&order $=$ it $\&$ min $=0 \& \min$ type $=$ it
} 
e. La deficiente situación del acceso a recursos bibliográficos de primer nivel, en tanto que algunos de los repositorios universitarios -según hemos podido observar en muchos centros- están o estaban desactualizados y/o restringían la consulta de bases de datos de primer orden.

f. La falta de interés de los investigadores locales por insertarse en redes académicas internacionales, o bien la falta de recursos para participar en eventos como congresos, simposios o talleres en otros países. En ese sentido, hemos percibido algunos factores socioculturales -como el egoísmo o el individualismo - que bloquean la interacción.

g. La falta de conexión entre los tres ejes habituales de la universidad (investigación / docencia / vinculación con la sociedad), y la falta de incentivo de iniciativas que pudieran activar o reactivar uno de los ejes a través del otro.

h. La falta de una investigación de base, con la escasa existencia de medidas para retener el talento (como por ejemplo becas propias del centro académico), y la falta de orientaciones para desarrollar trabajos de tesis con estándares de calidad internacional.

i. La falta de una cultura social de la investigación, con medios o departamento de comunicación incapaces de encontrar un hecho noticioso en la divulgación científica.

Todos estos indicadores, expuestos en las líneas precedentes, señalan un escenario en fase de desarrollo, donde predomina una cultura investigativa con numerosas carencias pero que, sin embargo, cuenta con el impulso renovador generado desde instancias gubernamentales. Son problemas, sí, que dificultaban una producción académica de calidad, con alta visibilidad internacional. Pero consideramos que, con sus luces y sus sombras, la Revolución Ciudadana está provocando una activación de la cuestión investigativa, primero ante el establecimiento de diagnósticos que 
palían el concurso de las circunstancias anteriores; y, segundo, ante la organización de soluciones muy concretas -como el Proyecto Prometeo, por ejemplo, o la categorización de las universidadesque buscan conseguir una reacción positiva de parte de los centros académicos.

Queda mucho camino por recorrer, aunque en nuestra opinión, gracias a la revolución educativa hay, al menos, camino. Somos ahora los investigadores quienes debemos responder a los estímulos tanto de las universidades como del gobierno, ante la cada vez mayor demanda de la investigación en un país donde se publicaba $\tan$ poco.

Los artículos que se muestran en las páginas siguientes son un reflejo de las investigaciones que, en conjunto con otros investigadores nacionales e internacionales, hemos ido generando en los últimos meses. Queda mucho camino por recorrer, pero algo se ha avanzado ya. Y a continuación, una muestra.

Quito, 11 de diciembre de 2014

Daniel Barredo Ibáñez, PhD

Universidad de las Américas (Ecuador)

Martín Oller Alonso, PhD

Universidad de las Américas (Ecuador) 


\title{
I
}

\section{E1 milagro ecuatoriano: pautas para entender el Ecuador del siglo XXI}

\author{
Daniel Barredo Ibáñez: Universidad de las Américas, Ecuador \\ Roxana Silva. Consejo Nacional Electoral, Ecuador \\ y Cheryl Martens. Universidad de las Américas, Ecuador
}

\section{Introducción}

$\mathrm{D}$ ESDE la victoria electoral de Rafael Correa en 2006, Ecuador ha experimentado numerosas transformaciones sociales, económicas, educativas y culturales, entre otras (Hawkins, 2011; Becker, 2012; 2013; Polga, 2013; Arévalo, 2014). Es cierto que la Revolución Ciudadana -el proceso político que cobija ideológicamente al presidente ecuatoriano -, ha sido criticada por la personalización del movimiento en la figura del presidente (De la Torre, 2013), o por mantener un régimen basado en el "autoritarismo competitivo" (Levitsky y Loxton, 2013: 107), a pesar de que en menos de una década el "apoyo a la democracia" ha aumentado en Ecuador en 13 puntos porcentuales (Latinobarómetro, 2013: 7). Pero no olvidemos que Ecuador, en 2013, tenía la tasa de desempleo más baja de América Latina, con un 4,6\% de la población activa (CEPAL, 2013: 56), además de que según asegura esta fuente en la página 77, entre 2000 y 2012 se redujo la indigencia en casi ocho puntos porcentuales, y la pobreza en alrededor de dieciocho puntos. Pero al margen del bienestar económico -que a menudo suele simplificarse por el alza de los precios de las materias primas (Arsel y Ávila, 2012)-, uno de los 
principales avances del Ecuador ha sido la integración de los sectores excluidos en la sociedad:

"Ecuador es una historia de éxito, con uno de los países que tenía mayor grado de apartheid entre la población blanca, la mestiza y la autóctona. Correa ha logrado incluir en la ciudadanía a sectores históricamente excluidos y su éxito se basa en ello. La democracia para los ecuatorianos no es tanto el funcionamiento de las instituciones, sino la inclusión social y el acceso a un mayor grado de dignidad ciudadana en el acceso a bienes tangibles"

(Latinobarómetro, 2013: 10)

En las siguientes páginas, explicaremos algunos de los componentes principales del llamado milagro ecuatoriano, un término muy polémico que ha sido ampliamente discutido por muchos miembros tanto de la sociedad de ese país, como de los países vecinos (Rodríguez Garavito, 2014, 24 de febrero; Carrión, 2014, 9 de junio; Mantilla, 2014, 16 de abril; Salamea, 2014, 26 de abril), y que asimismo cuenta con partidarios que ensalzan las transformaciones que mencionábamos al comienzo de este trabajo (Falconí, 2014, 31 de enero; ANDES, 2014, 19 de marzo) $)^{5}$. Consideramos que, mediante una revisión de algunos de esos factores estructurales que han caracterizado a los gobiernos de la Revolución Ciudadana en estos siete años (2007 - 2014), podemos ofrecer algunas consideraciones para situar de una forma más precisa el debate sobre un gobierno que, en 2013, aprobaba el $73 \%$ de los ecuatorianos (Latinobarómetro, 2013: 37), un elevado apoyo que situaba a los habitantes de la República andina como los segundos más satisfechos en la región con sus administradores.

\section{Los primeros tiempos de la Revolución: quita de deuda y fiscalidad}

\footnotetext{
${ }^{5}$ También destacamos, entre esas voces afirmativas las que aparecen en el vídeo El Milagro Ecuatoriano, publicado por la Secretaría Nacional de Comunicación. Consultado el 4 de diciembre de 2014 de https://www.youtube.com/watch?v=8pjiAs38UDs
} 
Desde mediados de los años setenta, como señala Arias (2006: 1), los gestores del Ecuador fueron endeudando progresivamente al país a través de la adquisición de créditos procedentes del "capital financiero internacional". Esto tuvo irremediables consecuencias sobre diversos indicadores del desarrollo social, sea en ámbitos como la salud o la educación, sea en la construcción de infraestructuras (Arias, 2006: 4 - 5). Rafael Correa, al llegar al poder en 2006, propuso un "cambio de modelo (Luna, 2014: 2), y una de sus primeras iniciativas fue la creación de la Comisión para la Auditoría Integral del Crédito Público, una comitiva encargada de revisar los diferentes tipos de deuda asumidos por la República andina en las últimas tres décadas ${ }^{6}$. Hawkins (2011: 42) describe cómo esta comisión detectó "numerosas irregularidades" durante los procesos de concesión de los créditos; tras la revisión de esas anomalías, los esfuerzos de esa Comisión consiguieron reducir la deuda externa con los bancos estadounidenses de 3,2 billones de dólares a 1 billón. La quita de deuda trajo algunas consecuencias, sobre todo en lo que se refiere a las relaciones de Ecuador con otros países, porque no se entendió el interés del gobierno ecuatoriano por democratizar y transparentar los créditos adquiridos, ni la necesidad de emprender mejoras laborales y fiscales. Una de las consecuencias más obvia fue la retirada progresiva de la especulación financiera internacional procedente bien de EEUU, bien de Europa-, y un relativo aislamiento que motivó la integración progresiva de Ecuador dentro de ese llamado "mundo multipolar" (Ellner, 2012: 104) descrito por Chávez. Es decir, el país andino tuvo que enfrentar la búsqueda de aliados que respetasen el proceso revolucionario, tanto al interior de América Latina - no por casualidad la sede de la Unión de Naciones Suramericanas[UNASUR] se ha inaugurado recientemente en Ecuador (TeleSUR, 2014, 3 de diciembre)-, como al exterior, con el establecimiento de alianzas con países como China, a los que se ha concedido la posibilidad de explotar los recursos del país (Polga, 2013: 137). Precisamente la explotación de los recursos fue otro de los puntos de discordia con la inversión extranjera de carácter especulativo; Rafael Correa optó por recuperar la iniciativa estatal en

\footnotetext{
${ }^{6}$ Según aclaran en su página web: http:/ $/$ www.auditoriadeuda.org.ec/index.php?option $=\mathrm{com}$ content\&view $=\mathrm{ar}$ ticle\&catid $=35 \&$ id $=44 \&$ Itemid $=55$ (consulta: 03/12/2014).
} 
el aprovechamiento de esos recursos, e inició una importante nacionalización de las “industrias extractivas" (Arsel y Ávila, 2012: 209), a través de las cuales el Estado ecuatoriano consiguió aumentar enormemente la recaudación fiscal. A partir de 2010, los beneficios petroleros se incrementaron del 13\% al 87\%, según explica Becker (2012: 73), gracias a la nueva lógica de reparto de las ganancias establecida por el gobierno de la Revolución Ciudadana. La estatización de parte de esas industrias extractivas tuvo numerosos beneficios, sobre todo con las políticas redistributivas de la riqueza desarrolladas por el Estado. Según Pérez (2010: 4), el mandatario ecuatoriano pretendía obtener "legitimidad" con estas lógicas de redistribución, pero esta autora observaba que no había "señales de mecanismos adecuados de petición y rendición de cuentas". Unos años después de estas reformas económicas, en 2013, casi seis de cada diez ecuatorianos, esto es, el $57 \%$ de la población aseguraba disfrutar de una "buena situación económica" (Latinobarómetro, 2013: 46). Con todo, hay tres factores que enumera Polga (2013: 141) que apuntalan el escenario económico del Ecuador:

a) Los débitos que se están comprometiendo con China.

b) El aumento de casi un 20\% de empleados públicos entre 2007 y 2012.

c) Y la subordinación del país a las rentas petroleras.

Uno de los mayores problemas del Ecuador, en las décadas anteriores, era la corrupción, un fenómeno que tenía indudables efectos sobre la estabilidad democrática, según describe Seligson (2003: 96). Solo la década anterior de la victoria electoral de Correa estuvo precedida por una gran inestabilidad política (Arévalo, 2014). Estos vaivenes, en un plano macro, estaban marcados por la aplicación de políticas neoliberales que, de acuerdo con Hawkins (2011), iniciaron en Chile en la década de los setenta y en los otros países de la región a partir de los ochenta. Pero desde un punto de vista nacional, también había factores asociados como la red clientelar, la falta de procesos públicos transparentes, el intercambio habitual de favores, etcétera. Correa, consciente de la necesidad de instaurar un nuevo paradigma representativo, "rompió en pedazos las frágiles y desprestigiadas instituciones políticas del Ecuador" (De 
la Torre, 2013: 36). Junto a la transformación de las viejas instituciones ecuatorianas, la estabilidad política se ha conseguido a través de actos simbólicos que recuperan el protagonismo estatal, como la expulsión del ejército estadounidense de Manta (Becker, 2013: 46) ${ }^{7}$. Asimismo, se ha impulsado la formación del electorado ecuatoriano, y se ha aprovechado la dolarización establecida en el año 2000, la cual "tuvo éxito en la reducción de la inflación, consolidación de la estabilidad macroeconómica y el crecimiento" (Arévalo, 2014: 130).

Al hablar de corrupción, deberíamos más bien mencionar los diferentes tipos o ámbitos en que tiende a darse. En primer lugar, la judicial, que -según leemos en estudios como el de Basabe -Serrano (2013) - presenta todavía ciertas deficiencias. En segundo lugar, la corrupción fiscal, la cual ha sido una de las principales inquietudes del Estado ecuatoriano. Año a año, el Servicio de Rentas Internas ha ido incrementando el número de contribuyentes o de impuestos; Polga (2013: 139) describe cómo solo entre 2011 y 2012 se consiguió un aumento en la recaudación de alrededor de un 18\% a través de la carga impositiva. De igual modo que en otros ámbitos, hay todavía algunos datos que generan la impresión de que la fiscalidad está en proceso de desarrollo; se calcula que solo "el fraude aduanero", por ejemplo, es de aproximadamente el 46 del dinero que se recauda (Núñez, 2012: 56). Sin embargo, y sin dejar de reconocer las deficiencias que puede presentar todavía el sistema, el incentivo de la recaudación fiscal de los gobiernos de Correa ha servido para "crear nuevos programas sociales" (Hawkins, 2011: 42).

\section{Una Revolución en un escenario de escasa participación}

La Revolución Ciudadana, como fenómeno social, se enfrenta a un grave desafío: la falta de una cultura de participación en la esfera pública ecuatoriana, motivada tanto por "la débil cultura política de la población” (Luna, 2014: 4), como por la falta de interés por los asuntos que suceden en los ámbitos de la política (Coronel y Mier,

\footnotetext{
${ }^{7}$ Aunque como señala Dosh (2003) el gobierno ecuatoriano sigue colaborando con los EEUU en algunos aspectos, como por ejemplo en la lucha contra el narcotráfico.
} 
2011). Es cierto que los casos de corrupción tan característicos de las décadas anteriores consiguieron retraer y desincentivar la movilización ciudadana (Tibocha y Jaramillo, 2008), implementando un clima de enorme desconfianza entre los electores y los elegidos. Quizá por ello una de las preocupaciones de los gobiernos de Correa ha sido generar una mayor cultura de transparencia y participación, al calor de instrumentos como la Ley Orgánica Electoral, Código de la Democracia, de 9 de abril de 2009. Se han activado numerosas iniciativas institucionales para conseguir estimular la interacción entre los ciudadanos y sus representantes. Desde el Consejo Nacional Electoral, por ejemplo, la Dra. Roxana Silva Consejera Principal de la institución- entre 2013 y 2014 puso en marcha dos plataformas que, en el caso de Voto Transparente, buscaban precisamente involucrar a los ecuatorianos en el control y monitoreo de las campañas electorales (Barredo y Silva, 2014), y en el caso de la Red Ciudadanía Participativa, pretendía servir como canal de contacto entre la sociedad y los mandatarios. Precisamente, al estudiar Voto Transparente, percibimos que la infraestructura se veía influenciada por la escasa movilización social y por factores como la brecha digital que existe en el Ecuador (Barredo y Silva, 2014). Otro de los factores que tienden a restringir la participación, es la educación, una de las bases transformadoras más importantes de la Revolución Ciudadana. Si en el 2001 solo 18 de cada 100 ecuatorianos estaban en la universidad (Luna, 2014: 7), en el año 2008 se aprobó la nueva Constitución, en la que se consagró la educación como un derecho, por lo que las matrículas universitarias pasaron a ser gratuitas (ANDES, 2013, 15 de abril). La trascendencia y el valor de la educación como un vector de cambio, se observa asimismo en la dotación de fondos gubernamentales dedicados a este apartado. Entre el 2000 y el 2012, Ecuador multiplicó casi por cuatro su gasto público en educación (CEPAL, 2013: 67). Todas estas cifras no solo redundan en la inversión en infraestructura y equipamiento, sino que se han incentivado programas específicos de contratación de recursos humanos de alto nivel -como el Proyecto Prometeo $^{8}-$, y se han aprobado multitud de reglamentos y

\footnotetext{
${ }^{8}$ Este programa gubernamental promueve la contratación de investigadores y docentes de alto nivel, tanto ecuatorianos como extranjeros; hasta noviembre de 2014, se habían aprobado 912 proyectos de investigadores procedentes de
} 
legislaciones para fomentar un cambio del imaginario de la enseñanza: las instituciones de Educación Superior han de convertirse, progresivamente, en centros de investigación. Ya no basta con promover que un mayor número de personas accedan a la educación universitaria, sino que hay que convertir a los centros académicos en centros neurálgicos de la producción de conocimiento, según reconocía René Ramírez, presidente del Consejo de Educación Superior:

"Lo que tenemos que tener claro es que un profesor que solo transmite conocimiento no es universitario, es de escuela o colegio. Si algo le caracteriza al docente universitario es que hace investigación y genera nuevo conocimiento y ese profesorado en un buen porcentaje no ha existido en el Ecuador"

(ANDES, 2012, 9 de noviembre)

Las palabras de Ramírez, en parte ciertas, no recogían algunos matices importantes, como las malas condiciones laborales de los docentes ecuatorianos -también mejoradas a partir de la implementación de la Ley Orgánica del Servicio Público de 6 de octubre de 2010-, o las exigencias que se presumían al docente universitario tan solo una década atrás; CONEA (2003: 27 - 28), el anterior organismo acreditador de la calidad universitaria, resumía la función investigadora de las instituciones de educación superior en apenas dos rasgos globales (poseer una "organización adecuada" y un "personal especializado y cualificado"), con unos criterios muy abstractos, cuyo cumplimiento parecía más optativo que obligatorio. En ese contexto subrayamos la aprobación de la Ley Orgánica de Educación Superior [LOES], de 12 de octubre de 2010, en donde se establecen algunos componentes que pueden resultar contradictorios, como por ejemplo la "garantía de la libertad de cátedra e investigativa" (art. 146). Escribimos contradictorios, sobre todo a la luz de la existencia del Consejo de Evaluación, Acreditación y

48 nacionalidades, según se explica en su página web http://prometeo.educacionsuperior.gob.ec/logros-achievements/ (consulta: 04/12/2014). 
Aseguramiento de la Calidad de la Educación Superior (CEAACES) ${ }^{9}$, un organismo encargado de puntuar el desarrollo de las actividades de las instituciones de educación superior. El CEAACES, dentro de sus procesos de categorización de los centros académicos, limita enormemente la capacidad productiva de los investigadores ecuatorianos, al imponer como principal exigencia la publicación en referentes internacionales -como Elsevier o Thomson Reuters- alejado de las posibilidades reales de la Academia nacional. De los 295 documentos citables de las Ciencias Sociales ecuatorianas que se produjeron entre 1996 y 2013, 59 se publicaron únicamente en 2013, lo que representa un aumento considerable con respecto de 2012, en que se editaron 35 documentos $^{10}$. Paradójicamente, a pesar de la exigencia gubernamental de publicar en revistas de alto impacto, en 2013 Ecuador solo tenía una revista indexada en SCImago en Ciencias Sociales: Chasqui, Revista Latinoamericana de Comunicación, y posicionada entre las publicaciones menos relevantes ${ }^{11}$. Otro de los hechos discordantes de la LOES es la exigencia del título de doctorado o $\mathrm{PhD}$ (artículo 150.a) para ejercer la titularidad en las universidades, sobre todo si pensamos que en 2012, solo 7 instituciones de educación superior ecuatorianas estaban autorizadas para ofertar programas de doctorado, de las cuales cuatro aún no estaban creadas (Ecuadoruniversitario.com, 2012, 30 de diciembre). Dos años antes, en 2010, el 1\% de los docentes de las universidades públicas tenía el título de doctor, por el $2 \%$ de los docentes de las privadas (Revista LÍDERES.ec, 2012, 1 de octubre). La respuesta del gobierno ecuatoriano a estas problemáticas ha sido incentivar la formación de los recursos humanos, como se asegura en el Acuerdo No. 2012- 029 de Política Pública de la SENESCYT para el Fomento del Talento Humano en Educación Superior. Además de la integración de los investigadores Prometeos en los centros universitarios públicos, el

\footnotetext{
${ }^{9}$ Es un organismo encargado de evaluar la calidad de la educación superior, según se explica en su página web: http://www.ceaaces.gob.ec/sitio/mision/ (consulta: 04/12/2014).

${ }^{10}$ Según consta en el Índice SCImago:

http:/ / www.scimagojr.com/countrysearch.php? country $=\mathrm{EC} \& a \mathrm{rea}=3300$ (consulta: 04/12/2014).

${ }^{11}$ En concreto en el cuarto cuartil, con un SJR marginal de 0,1: http://www.scimagojr.com/journalsearch.php?q=5700153643\&tip=sid\&clea $\underline{\mathrm{n}=0}$ (consulta: 04/12/2014).
} 
organismo responsable de la investigación en el Ecuador promueve numerosas becas para cursar estudios en el exterior. Con todo, Galarza (2014: 108), al analizar los montos asignados para hombres o mujeres, ha calificado a los programas de becas como "inequitativos", ya que no se tienen en cuenta algunos criterios relevantes para el reparto de los fondos, como el caso de las mujeres con hijos; asimismo, y como se hace eco Luna (2014, 8 de marzo), menos del 10\% de las becas van a parar a las "Ciencias Sociales, Educación y Arte y Cultura”. Otro aspecto interesante dentro del estímulo de la Educación Superior ha sido la bajada de los tipos de interés para los llamados créditos educativos (Falconí, 2014, 31 de enero).

\section{La reforma de la comunicación: hacia la comunicación responsable}

Las reformas legislativas desarrolladas en los siete años de gobierno de la Revolución Ciudadana han sido numerosas, y han afectado a todos los ámbitos de la vida pública, comenzando con la propuesta y la aprobación de la Constitución de 2008, una de las "constituciones más radicales del mundo" (Lalander, 2010: 16) por su apuesta por lo social. Pero uno de los instrumentos legales que más nos interesa, por su relevancia y novedad, ha sido la Ley Orgánica de Comunicación [LOC], aprobada en el año 2013, un cuerpo legislativo que desilusionó a algunos de los sectores intervinientes en su creación (Ramos y Gómez, 2014), pero que sin embargo resulta de gran importancia por su capacidad para integrar a públicos tradicionalmente excluidos (artículo 14), por su invitación a la participación social en los medios de comunicación (artículo 13), y por su apuesta por la transparencia (artículo 16). Ramos y Gómez (2014: 307) critican a la LOC por la cantidad de "actores gubernamentales" presentes en los procesos de regulación de la comunicación, sobre todo en las dos instituciones creadas para viabilizar los presupuestos contenidos en esta ley: el Consejo de Regulación y Desarrollo de la Información [CORDICOM], y la Superintendencia de la Información y Comunicación [SUPERCOM]. Dentro del confuso debate que se ha generado en prácticamente todas las esferas representativas ecuatorianas, 
creemos que la aprobación de la LOC es un punto de partida para reflejar en la gestión simbólica los cambios que se están produciendo en el país. Al observar la comunicación de dos de las instituciones más importantes del Ecuador, concluimos que existía una distancia profunda entre la sociedad y esas instituciones (Barredo, 2014). Y, en ese sentido, consideramos que la LOC puede resultar determinante para conseguir una comunicación más responsable, según hemos expuesto en un artículo complementario a este:

"La intervención de la Administración resulta necesaria, primero, porque la actividad informativa es un servicio público, desde el momento que, por aplicación del principio de territorialidad, el uso del espacio radioeléctrico está sometido a concesión administrativa; y, segundo, porque los profesionales de la comunicación y, fundamentalmente, los medios, no han sabido ejercer su actividad de acuerdo a los valores jurídicos y éticos que protegen el ejercicio de este derecho fundamental"

(Pérez Zúñiga y Barredo, en evaluación)

¿Y qué motivos pueden aducirse para la "necesaria" intervención del Estado? A nivel latinoamericano, Ramos (2012: 66) ha alertado de una "cruzada mediática de corte corporativo" que atenta contra el desarrollo de las democracias progresistas del continente. A nivel ecuatoriano, la regulación de las épocas anteriores no ha evitado las duras condiciones sociolaborales de los periodistas de este país (Abad, 2010), la poca presencia de la sociedad en los medios de comunicación o el escaso conocimiento de los medios públicos (Ayala y Calvache, 2009), la falta de libertad de los periodistas contratados por las organizaciones informativas que dependían de fuertes corporaciones (Abad, 2010), e incluso la poca credibilidad de los medios de comunicación (Vásconez, 2011; Rodrigo, 2012; Checa Godoy, 2012; Barredo, Pérez Zúñiga, Vivas y Fernández, 2014). Otro aspecto que recoge la LOC, y que resulta esencial, es el reconocimiento de la diversidad del Ecuador, cuya falta ha sido denunciaba en artículos previos (Viteri, 1997). La pluralidad cultural y social y lingüística ha sido una de las obsesiones del gobierno de la 
Revolución Ciudadana, como demuestra el hecho de que se hayan puesto en marcha dos Planes Nacionales del Buen Vivir, en donde -en nuestra opinión- se ha intentado integrar institucionalmente la cosmovisión y el pensamiento indígena, los cuales estructuran buena parte del imaginario cultural ecuatoriano, aunque no todo él. Algunos autores, como Vanhulst y Beling (2014: 59), señalan la "apropiación política" de este concepto, en tanto que detectan contradicciones entre el discurso oficial y el discurso antropológico. También, en ese sentido, contrasta la supuesta "ocupación estatal" (Hawkins, 2011: 44) de zonas habitadas por indígenas en aras del extractivismo petrolero, o la minimización de organizaciones como la CONAIE (De la Torre, 2013: 41 -42). Pero a menudo estos autores olvidan la principal demanda que se le hace internamente a los Estados de los países en vías de desarrollo: "cumplir con el desarrollo socioeconómico" (Arsel y Ávila, 2012: 223), lo que en gran medida impulsa la necesidad de explotar los recursos minerales. Hay que resaltar, asimismo, que las organizaciones indígenas dependen, en general, de grandes organizaciones políticas ecuatorianas (Becker, 2011), y, como recalca este autor, esas organizaciones en ocasiones no actúan con sentido de Estado. Dentro de la falta de reconocimiento de la diversidad social, cabe subrayar la progresiva integración del colectivo LGBTIQ en la vida pública ecuatoriana; en ese aspecto, Lind, Heintz y Keating (2013: 530), al comparar el discurso de la Revolución con las políticas implementadas durante la misma, han percibido un "Estado homofóbico y un Estado homoproteccionista". Pero por primera vez en la historia del Ecuador, hay que reconocer que se han aprobado las uniones de hecho entre las parejas del mismo sexo, si bien esta aprobación aún no recoge el derecho de esas parejas a adoptar niños (Constante, 2014, 18 de septiembre). La Revolución, como un proceso en construcción, presenta niveles de disenso entre sus miembros, incluso entre sus miembros más importantes. Así, por ejemplo, cabe resaltar la aprobación de las uniones de hecho con las declaraciones del propio presidente en las que se manifestaba en contra del matrimonio entre homosexuales o lesbianas (El Telégrafo, 2013, 31 de mayo), en un país donde la Iglesia tiene un enorme poder, y donde se calcula que unos ocho de cada diez habitantes son católicos (Tibocha y Jaramillo, 2008: 23 - 24). En 
cuanto a la integración de las mujeres en la vida pública, Ecuador ha sido uno de los países que, junto a Bolivia, ha apostado más fuertemente por "la paridad política" (Archenti y Tula, 2014: 51). Hay autores que, como Ellner (2012: 108), destacan la amplitud de los procesos de inclusión de la mujer en las distintas esferas públicas ecuatorianas, si bien otros autores, en cambio, reprochan la falta de aplicación de las legislaciones en la cotidianidad de las mujeres (Bernal, 2011).

\section{Conclusiones}

Quizá una de las transformaciones más notables que ha promovido Rafael Correa ha sido la recuperación del prestigio de la política: del "que se vayan todos" de 2005 (Luna, 2014: 4), el país ha avanzado hacia el fomento de espacios de integración de la ciudadanía dentro de las esferas del poder. Obviamente, hay algunos huecos o insuficiencias dentro del proceso; pero incluso los autores que critican el supuesto "autoritarismo" presidencial (De la Torre, 2013: 35), señalan en la misma línea su "proyecto redistributivo". En los sistemas democráticos, la controversia forma parte del devenir de los líderes o de las instituciones; más, si cabe, en un proceso tan complejo y con tantas aristas como el ecuatoriano, un contexto fuertemente inestable donde entre 1996 y 2006, como recuerdan Tibocha y Jaramillo (2008: 23), "ningún presidente elegido por sufragio universal ha podido llevar a buen término su mandato". Estamos de acuerdo con Becker (2013: 46), en que a menudo se clasifica a los gobiernos latinoamericanos $-\mathrm{y}$, sobre todo, al ecuatoriano - bajo etiquetas superficiales como "izquierda "buena" o moderada e izquierda "mala" o nacionalista y radical". Estos estereotipos, lastimosamente, se reproducen desde muchos sectores políticos, académicos y periodísticos; y a través de la minimización, se simplifican las realidades y las dimensiones de un país. La Revolución Ciudadana -o incluso el socialismo, como explica Lalander (2010: 9) - no es un concepto anclado estáticamente, sino que su interés radica en su progresivo andamiaje. También es cierto que a menudo se olvida que el conjunto de reformas emprendidas apenas han abarcado un lapso muy pequeño, tan solo siete años de la historia del Ecuador, lo cual es un gran hándicap para constituir 
soluciones integrales a problemas que duran desde hace décadas o centurias:

"Al ser cuestionados por no emprender cambios más rápidos y radicales, los defensores del proyecto de Correa aseguraron que era imposible solucionar en cinco años problemas que se alargaban desde hacía cinco siglos de explotación y opresión. Otros sostenían que el tratamiento del gobierno a los sectores más marginados de la sociedad era indicativo de las principales prioridades de la administración" $"$.

(Becker, 2012: 74)

El milagro ecuatoriano tampoco puede explicarse únicamente por la fragilidad del sistema de partidos, y por el "boom mineral" (Levitsky y Loxton, 2013: 126) que sin duda ha ayudado a mejorar la calidad de vida de los ecuatorianos. Detrás de dicho milagro, hay un extenso conjunto de factores contextuales, ya que de otra manera no hubiese sido posible abarcar una cantidad tan elevada de transformaciones. La Revolución Ciudadana tampoco debe confundirse únicamente con el presidente Correa, sino que ha de entenderse como un fenómeno colectivo, como el resultado de un proceso de reivindicaciones históricas y culturales. Está por ver cuál va a ser el desarrollo de la Revolución en los próximos años, y si será posible enderezar las contradicciones que se han ido mostrando a lo largo de este trabajo; desde luego, la caída drástica de los precios del petróleo (El Universo, 2014, 14 de noviembre), augura un nuevo escenario relacional y, posiblemente, un cambio de etapa: la Revolución Ciudadana está ante uno de sus mayores desafíos para asegurar la supervivencia de los avances sociales cosechados en esta década.

\section{Referencias bibliográficas}

${ }^{12}$ La traducción es de los autores. La cita literal, en ingles, afirma lo siguiente: "When criticized for not making more rapid and radical changes, proponents of Correa's project argued that it was impossible to solve in five years problems that were a result of five centuries of exploitation and oppression. Others contended that how the government treated the most marginalized sectors of society was indicative of the administration's ultimate priorities" (Becker, 2012: 74). 
Abad, Gustavo (2010). Cultura periodística, censura y autocensura en Ecuador. Quito: FLACSO.

ANDES (2013, 15 de abril). En Ecuador la educación superior gratuita es un derecho garantizado en la Constitución; en Chile lo reclaman en las calles. Recuperado el 5 de diciembre de 2014 de http://www.andes.info.ec/es/sociedad/ecuador -practica gratuidad -educacion -superior - mientras -chile -anhelan.html

ANDES (2014, 19 de marzo). Las claves del milagro ecuatoriano, según el académico estadounidense William Black. Recuperado el 4 de diciembre de 2014 de

http://www.andes.info.ec/es/noticias/claves -milagro -ecuatoriano -segun -academico -estadounidense -william -black.html

ANDES (2012, 9 de noviembre). El nuevo reglamento de docencia universitaria busca que los profesores generen conocimiento. Recuperado el 4 de diciembre de 2014 de http://www.andes.info.ec/es/sociedad/8660.html

Archenti, Nélida y Tula, María Inés (2014). Cambios normativos y equidad de género. De las cuotas a la paridad en América Latina: los casos de Bolivia y Ecuador. América Latina Hoy, 66, 47 - 68.

Arévalo, Guillermo Alexander (2014). Ecuador: economía y política de la revolución ciudadana, evaluación preliminar. Apuntes del CENES, 33(58), 109 - 134.

Arias, Hugo (2006). Auditoría ciudadana de la deuda ecuatoriana. En Primer Simposio Internacional sobre Deuda Pública, Auditoría Populary Alternativas de Ahorro e Inversión para los Pueblos de América Latina, Caracas, Venezuela.

Arsel, Murat y Ávila, Natalia (2012). "Stating" Nature's Role in Ecuadorian Development: Civil Society and the Yasuní -ITT Initiative. Journal of Developing Societies, 28(2), 203 - 227.

Ayala, Alexandra y Calvache, María Belén (2009). Percepción sobre los medios públicos en Ecuador. Quito: CIESPAL.

Basabe -Serrano, Santiago (2013). Explicando la corrupción judicial 
en las cortes intermedias e inferiores de Chile, Perú y Ecuador. Perfiles Latinoamericanos, 42, $79-108$.

Barredo Ibáñez, Daniel (2014). El Modelo Integrado de Evaluación de la Comunicación Organizacional en Ecuador: un estudio exploratorio a partir del diagnóstico de la ESPOCH y de CIESPAL (2013 -2014). index.comunicación, 1(4), 173 - 208.

Barredo Ibáñez, Daniel y Silva, Roxana (2014). Interacción institucional, participación ciudadana y transparencia. La iniciativa del Voto Transparente en el Ecuador (2013 - 2014). Chasqui, Revista Latinoamericana de Comunicación, 126, 4 - 13.

Barredo Ibáñez, Daniel; Pérez Zúñiga, José María; Vivas, Rocío; y Fernández, Montserrat (2014). La crisis del periodismo ecuatoriano: algunas reflexiones a partir de una encuesta en Riobamba y Quito (2013 - 14). En Actas del VI Congreso Internacional Latina de Comunicación Social, Tenerife, Universidad de la Laguna.

Bernal, Gabriela (2011). "Reconocimiento formal, discriminación real: los derechos de las mujeres en Ecuador en 2011". En PADH (Comp.). Informe sobre Derechos Humanos Ecuador (2011) <pp. 123 126>. Quito: Universidad Andina Simón Bolívar.

Becker, Marc (2011). Correa, Indigenous Movements, and the Writing of a New Constitution in Ecuador. Latin American Perspectives, 38(1), 47 - 62.

Becker, Marc (2012). Building a Plurinational Ecuador: Complications and Contradictions. Socialism and Democracy, 26(3), 72 $-92$.

Becker, Marc (2013). The Stormy Relations between Rafael Correa and Social Movements in Ecuador. Latin American Perspectives, 40(3), $43-62$.

Carrión, Goivanni (2014, 9 de junio). El milagro ecuatoriano. Recuperado el 4 de diciembre de 2014 de http://www.eluniverso.com/opinion/2014/06/09/nota/3079471/ milagro -ecuatoriano 
Checa - Godoy, Antonio (2012). La Banca y la propiedad de los medios: el caso de Ecuador. Revista Latina de Comunicación Social, 67, 125 - 147. Consultado el 01/09/2014 de:

http://www.revistalatinacs.org/067/art/950 Sevilla/06 Checa.html

CEPAL (2013). Anuario Estadístico de América Latina y el Caribe. Santiago de Chile: Naciones Unidas.

CONEA (2003). La calidad de la Universidad Ecuatoriana. Principios, características y estándares de calidad. Quito: CONEA.

Constante, Soraya (2014, 18 de septiembre). Ecuador crea un registro de parejas de hecho. Recuperado el 4 de diciembre de 2014 de

http://sociedad.elpais.com/sociedad/2014/09/18/actualidad/1410 $\underline{991430 \quad 619743 . h t m l}$

Coronel, Gabriela y Mier, Aura (2011). Impacto del Twitter en Ecuador, caso 30S. Recuperado el 1 de diciembre de 2014 de http://www.iiis.org/CDs2011/CD2011CSC/CISCI 2011/PapersP df/CA806GT.pdf

De la Torre, Carlos (2013). Technocratic Populism in Ecuador. Journal of Democracy, 24(3), 33 - 46.

Dosh, Paul (2013). Indigenous Movements and Failed Electoral Partnerships in Ecuador. Latin American Perspectives, 40(3), 255 256.

Ecuadoruniversitario.com (2012, 30 de diciembre). En 2013 se ampliará la oferta de doctorados $\mathrm{PhD}$ en el Ecuador. Recuperado el 4 de diciembre de 2014 de http://ecuadoruniversitario.com/directivos $-\mathrm{y}-$ docentes/legislacion/ley -organica - de -la-educacion-superior/en -2013 -se -ampliara -la -oferta -de -doctorados - phd -en -el ecuador/

Ellner, Steve (2012). The Distinguishing Features of Latin America's New Left in Power: The Chávez, Morales and Correa Governments. Latin American Perspectives, 39(1), 96 - 114.

El Telégrafo (2013, 31 de mayo). Correa se opone a las adopciones 
por parte de parejas del mismo sexo. Recuperado el 4 de diciembre de 2014 de http://www.telegrafo.com.ec/noticias/informacion general/item/correa -se -opone - a -las -adopciones - por - parte de-parejas - del -mismo -sexo.html

El Universo (2014, 14 de noviembre). Petróleo cayó ayer al nivel más bajo desde hace 4 años. Recuperado el 4 de diciembre de 2014 de

http://www.eluniverso.com/noticias/2014/11/14/nota/4221006/ petroleo -cayo - ayer -nivel -mas -bajo -hace -4 -anos

Falconí, Fernando (2014, 31 de enero). El milagro ecuatoriano (I). Recuperado el 4 de diciembre de 2014 de http://www.telegrafo.com.ec/opinion/columnistas/item/el _ $\underline{\text { milagro -ecuatoriano }-\mathrm{i} . \mathrm{html}}$

Galarza, María Teresa (2014). Los programas de becas internacionales de la Secretaría de Educación Superior, Ciencia, Tecnología e Innovación del Ecuador frente a las realidades de las familias monoparentales. Aportes Andinos, 34, 104 - 118.

Hawkins, Daniel (2011). The Influence of Organized Labour in the Rise to Power of Lula in Brazil and Correa in Ecuador. LABOUR, Capital and Society, 44(2), 26 - 55.

Lalander, Rickard (2010). Socialist Decentralization in the Andes? Explorative Reflections on Radical Democracy and 21st Century Neo -Constitutionalism. En Simposio Internacional Independencia y Dependencia en América Latina, 200 años después, Estocolmo, Universidad de Estocolmo.

Latinobarómetro (2010). Informe 2010. Recuperado el 4 de diciembre de 2014 de http://www.latinobarometro.org/documentos/LATBD INFORM E LATINOBAROMETRO 2010.pdf

Latinobarómetro (2013). Informe 2013. Recuperado el 4 de diciembre de 2014 de

http://www.latinobarometro.org/documentos/LATBD INFORM E LB 2013.pdf

Levitsky, Steven y Loxton, James (2013). Populism and competitive 
authoritarianism in the Andes. Democratization, 20(1), 107 - 136.

Lind, Amy; Heintz, Mary Ellen y Keating, Christine (2013).

Navigating The Left Turn. International Feminist Journal of Politics, 15(4), $515-533$.

Luna, Milton (2014). La educación en el Ecuador 1980 - 2007. Revista Iberoamericana de Educación, 65(1), 1 - 15.

Luna, Milton (2014, 8 de marzo). Menos becas para CC.SS.

Recuperado el 4 de diciembre de 2014 de http://www.elcomercio.com/opinion/menos -becas -cc-ss.html

Mantilla, Sebastián (2014, 16 de abril). El milagro ecuatoriano. Recuperado el 4 de diciembre de 2014 de http://www.elcomercio.com/opinion/milagro -ecuatoriano.html

Montesino, José Leopoldo (2007). La economía ecuatoriana del siglo XXI y sus perspectivas de comercio internacional con países del Asia Pacífico. Si Somos Americanos. Revista de Estudios Transfonterizos, IX(1), $71-107$.

Núñez, Fausto Marcelo (2012). Corrupción: tendencias globales y el fraude aduanero. Caso ecuatoriano<tesis de maestría>. Quito: Universidad Andina Simón Bolívar.

Pérez Zúñiga, José María y Barredo, Daniel (en evaluación). La Ley Orgánica de Comunicación del Ecuador: algunas reflexiones sobre la comunicación como servicio público y la comunicación responsable.

Polga, John (2013). Ecuador: estabilidad institucional y la consolidación de poder de Rafael Correa. Revista de Ciencia Política, 33(1), $135-160$.

Pérez, Pilar (2010). El Presidente Rafael Correa y su política de redención. Ecuador Debate, 80, 77 - 94.

Ramos, Isabel (2012). La contienda política entre los medios privados y el gobierno de Rafael Correa. Utopía y Praxis Latinoamericana, 17(58), $65-76$.

Ramos, Juan y Gómez, Ava (2014). Sujetos, objetos, decisiones y 
evasiones - el proceso de aprobación de la Ley de Comunicación en Ecuador. Intercom, Revista Brasileira de Ciências da Comunicação, 37(1), $283-310$.

RevistaLÍDERES.ec (2012, 1 de octubre). La formación de más PHD genera retos al Ecuador. Recuperado el 4 de diciembre de 2014 de http://www.revistalideres.ec/informe -semanal/PHD Ecuador -Senescyt - universidad 0 784121594.html

Rodrigo, Iván (2012). Calidad informativa: credibilidad de medios y periodistas en el Ecuador. ComHumanitas, 3(3), 53 - 69.

Rodríguez Garavito, César (2014, 24 de febrero). ¿El milagro ecuatoriano?. Recuperado el 4 de diciembre de 2014 de http://www.elespectador.com/opinion/el -milagro -ecuatoriano columna -477090

Salamea, Marco (2014, 26 de abril). ¿Cuál es el "MILAGRO" ecuatoriano? Recuperado el 4 de diciembre de 2014 de http://www.elmercurio.com.ec/428519-cual -milagro ecuatoriano/\#.VIDpyjGG-YU

Seligson, Michael (2003). Corrupción y democracia. Revista de Ciencias Sociales, 14, $20-30$.

TeleSUR (2014, 3 de diciembre). Presidentes inaugurarán Torre Unasur en Ecuador. Recuperado el 04/12/2014 de http://www.telesurtv.net/news/Presidentes -inauguraran -Torre Unasur -en -Ecuador -20141203 -0020.html

Tibocha, Ana María y Jaramillo, Mauricio (2008). La Revolución Democrática de Rafael Correa. Análisis Político, 64, 22 - 39.

Vanhulst, Julien y Beling, Adrian E. (2014). Buen vivir: Emergent discourse within or beyond sustainable development? Ecological Economics, 101, 54 - 63.

Viteri, Carlos (1997). Ecuador: un país ficticio. Íconos, Revista de Ciencias Sociales, 2, 51 - 58.

Vásconez, Irene (2011). La credibilidad de los medios de comunicación en el Ecuador: reflejo de un periodismo de calidad. ComHumanitas, 1(1), 173 - 182. 


\section{Agradecimientos}

Los autores agradecen expresamente a la Universidad de las Américas, por prestar indirectamente fondos para realizar este proyecto. Asimismo, sus resultados fueron presentados en el marco del VI Congreso Internacional Latina de Comunicación Social, celebrado en Tenerife (España) en el mes de diciembre de 2014 bajo el título Participación ciudadana y transparencia institucional. Algunas consideraciones sobre el milagro ecuatoriano (2007 - 2014). 


\section{Políticas públicas en comunicación y sistemas mediáticos. E1 caso de Ecuador}

Palmira Chavero. Facultad Latinoamericana de Ciencias Sociales, Ecuador

Martín Oller. Universidad de las Américas, Ecuador

\section{Introducción}

TRADICIONALMENTE en los estudios de comunicación, a la

1 hora de analizar el sistema mediático de un país, se ha acudido a la propuesta realizada por Hallin y Mancini (2004), en la que establecen tres tipos ideales de sistemas mediáticos en función de la interacción que se produce entre el mercado, el Estado y los medios de comunicación. Según la propuesta de estos autores, la configuración de un sistema mediático concreto es el resultado de determinadas características:

a) Industria de la prensa. Al estudiar este aspecto se tiene en cuenta el momento y la manera en que se produce el nacimiento del mercado de los medios de comunicación, la consolidación del mismo, el alcance de las tiradas y el perfil de los consumidores de los medios. La financiación de los medios o el grado de libertad de expresión son algunas de las variables a estudiar en este apartado. 
b) Paralelismo político. En este punto cabe estudiar la relación que existe entre los medios de comunicación y el sistema político. En este sentido, conviene analizar si estamos ante unos medios con rasgos de la prensa de partido, una totalmente independiente a cualquier adscripción política o se trata de otra modalidad intermedia.

c) Profesionalización y autonomía de los periodistas. No se trata aquí de analizar sólo el nivel de formación de los profesionales de la comunicación, sino todo lo que rodea a la propia profesión: autonomía para ejercerla, intrusismo, capacidad de actuar como lobby, regulación, colegiación o asociacionismo, existencia y respeto a los códigos deontológicos, etc. La escasez de asociacionismo es, para algunos autores, consecuencia de la falta de profesionalización (Ortega y Humanes, 2000: 165).

d) Papel del Estado. En su función de garante del cumplimiento de algunos derechos fundamentales como el de acceso a la información, los Estados tienen la posibilidad de intervenir de distintas maneras: directa (como propietario de los medios de comunicación y afines) e indirecta (concediendo las frecuencias del espectro radioeléctrico o como legislador en esta materia).

La combinación de estos factores da origen, según los autores, a tres tipos de sistemas mediáticos. El primero de ellos es el Liberal o del Atlántico Norte, típico de países como Estados Unidos, Canadá, Gran Bretaña o Irlanda y caracterizado por un volumen medio de tiradas, una prensa eminentemente comercial y autónoma y buenos niveles de profesionalización. El segundo modelo es el Democrático Corporativo, presente en los países del Norte de Europa y con volúmenes importantes de tirada, una prensa comercial neutral y altos niveles de profesionalización. Por último, el sistema de Pluralismo Polarizado, típico de los países del Mediterráneo, se caracteriza por una tirada media, niveles relativamente bajos de profesionalización con un alto paralelismo político y la intervención del Estado en el sector mediático. 
Sin embargo, estos modelos no sólo tienen la limitación de tratarse de tipos ideales a los que cabría incorporar matices, sino que sus propios autores reconocen que los modelos podrían estar cambiando, en especial por el giro que modelos mediáticos como el estadounidense comenzaba a dar hacia sistemas con características del Sur de Europa. Además de esto, la propuesta de Hallin y Mancini (2004) adolece, en lo que para este artículo interesa, de estar basada en países europeos y norteamericanos que, si bien comparten características con América Latina, gozan de una democracia relativamente consolidada y quedan lejos de la idiosincrasia latinoamericana. Otros autores como Oller y Meier (2012) u Oller y Barredo (2013) hablan de "Culturas periodísticas intermedias" para definir el periodismo en países poscoloniales, con regímenes políticos no democráticos y subdesarrollados que difiere de los estándares occidentales (propuesta que se ajusta mucho más al estudio contextualizado que pretendemos realizar).

\subsection{Las críticas al modelo de Hallin y Mancini}

Aunque tradicionalmente se ha utilizado este modelo de análisis y su aplicabilidad ha sido demostrada para muchos países, los modelos propuestos por Hallin y Mancini (2004) adolecen de un excesivo funcionalismo, pues la realidad ha demostrado que los medios de comunicación no son una parte autónoma del sistema social. Según una lógica funcionalista, el modelo liberal funcionaría de manera autónoma, pero los propios autores del libro Sistemas mediáticos comparados, al hablar de "contratendencias", se cuidan advirtiendo de que el modelo liberal no es la tendencia a seguir. No en vano, el propio modelo liberal es cuestionado en el momento en que una de las "contratendencias" observadas ha sido la creciente polarización mediática y el consiguiente alineamiento político de los medios de comunicación en el país donde el modelo liberal encontraba su máximo exponente, Estados Unidos. Por otro lado, esta propuesta refleja un excesivo énfasis en la "instrumentalización" de los medios como consecuencia de su politización, aunque otros autores han demostrado que los medios de comunicación pueden llegar a actuar siguiendo sus propias lógicas e intereses (Chavero et al., 2013). 
En los últimos años, otros investigadores han destacado las debilidades de la propuesta realizada por Hallin y Mancini en 2004. Para Alburquerque (2012), uno de los factores de influencia es la crisis del modelo tradicional de periodismo independiente de los últimos años, influenciada fundamentalmente por la irrupción de los medios digitales (blogueros progresistas). Otro de los factores que atribuye este autor es la dependencia excesiva del punto de vista occidental, posición que empieza a ponerse en cuestionamiento a diferentes niveles. Una de las revisiones que propone Alburquerque es la reconceptualización del "paralelismo político", concepto que puede tener dos niveles de análisis. En primer lugar, atendiendo a la relación entre los partidos y los medios, que ha de tener en cuenta tres variables de análisis: organización (tipo de vínculo entre el partido y el medio: administración directa, control informal), metas partidarias (grado en el que las posiciones del partido y el medio coinciden) y el apoyo que brinda el partido (coherencia entre las preferencias partidarias de los medios y de los lectores). En segundo lugar, la relación que se da entre los sistemas de partidos y los sistemas de medios, esto es, la relación existente entre los lectores de un medio y los votos recibidos por los partidos con los que se asocia a ese medio.

Otra de las advertencias sobre el modelo es que la propuesta inicial está realizada a partir del estudio de 18 países con unas determinadas características. Sin embargo, quedarían fuera de él países y regiones del mundo con características y procesos históricos diferentes, como el caso de los países de América Latina (Pfetsch, 2013). Incluso en investigación, como afirma Mellado (2009), los aspectos más preocupantes en periodismo en esta región es que se ha convertido en un producto y conocimiento híbrido entre las perspectivas norteamericanas y europeas.

Estas peculiaridades e idiosincrasia propia hacen que no sea posible realizar una extrapolación directa de los modelos de Hallin y Mancini a todos los países. Los países latinoamericanos quedan incluidos en las denominadas "democracias de tercera ola" (Huntington, 1991), países que comienzan el proceso de democratización en la década de los 70; la juventud de estas 
democracias, en combinación con el peso de los regímenes autoritarios previos son elementos que terminan por influir en el sistema mediático.

En el caso de Ecuador, según el Índice de Democracia, elaborado por The Economist Intelligence Unit ${ }^{13}$, en 2012 Ecuador ocupaba el puesto 87 (de un total de 167) con una puntuación de 5,78 en una escala de 0 a 10), lo que le sitúa en la categoría de "régimen híbrido". Atendiendo a las categorías de medición de la democracia, la puntuación de Ecuador es la siguiente:

Tabla 1. - Índice de Democracia 2012. Datos para Ecuador

\begin{tabular}{|l|l|l|l|l|l|l|l|}
\hline & $\begin{array}{l}\text { Proceso } \\
\text { electoral y } \\
\text { pluralismo }\end{array}$ & $\begin{array}{l}\text { Funcionamiento } \\
\text { del gobierno }\end{array}$ & $\begin{array}{l}\text { Participación } \\
\text { política }\end{array}$ & $\begin{array}{l}\text { Cultura } \\
\text { política }\end{array}$ & $\begin{array}{l}\text { Libertades } \\
\text { civiles }\end{array}$ & $\begin{array}{l}\text { Puntuación } \\
\text { Media }\end{array}$ & $\begin{array}{l}\text { Puesto } \\
\text { en el } \\
\text { ranking }\end{array}$ \\
\hline Ecuador & 7,83 & 4,64 & 5 & 4,38 & 7,06 & 5,78 & 87 \\
\hline
\end{tabular}

Fuente: The Economist Intelligence Unit, 2012

En 2006 (primera elaboración de este Índice), la puntuación de Ecuador era de 5,64. Los datos de este índice indican que, aunque muchos países latinoamericanos están avanzando en democratización, en la región siguen existiendo muchos países con democracias débiles (14 países de la región quedan dentro de la categoría "democracias defectuosas"), al tiempo que existen países con democracias completas (Uruguay), reflejo de la heterogeneidad de América Latina y de la presencia de importantes diferencias entre los países.

Existen, en definitiva, diversas razones por las que se hace necesario presentar un modelo de análisis alternativo al occidental. Siguiendo a Alburquerque (2010):

${ }^{13}$ El Índice de Democracia de la Unidad de Inteligencia The Economist es uno de los más utilizados para medir la calidad de la democracia. Este índice tiene cinco dimensiones de medición: proceso electoral y pluralismo, libertades civiles, funcionamiento del gobierno, participación política y cultura política. En función del resultado, los países son clasificados en cuatro tipos: democracias completa; democracias defectuosas; regímenes híbridos y regímenes autoritarios. 
a) La extrapolación directa de los modelos de análisis inicial contribuye a mantener el punto de vista de Occidente para el análisis, al tomar como referencia las democracias occidentales.

b) Los modelos de Hallin y Mancini están realizados en base a democracias estables y maduras, característica que no se cumple para los países latinoamericanos. En el caso de Ecuador, en la primera década del siglo XXI hubo seis golpes (o intentos) de estado.

c) Ausencia de una perspectiva dinámica más compleja, que tenga en cuenta un panorama de transición con una meta democrática que no tiene por qué ser la propuesta por Occidente.

d) Los modelos de periodismo propuestos requieren de un ambiente político competitivo y estabilidad institucional, premisas que pueden darse (o no) en distinto grado.

La importancia de la configuración del sistema mediático reside en el doble rol que éste desempeña: de agente económico y de agente ideologizante (De Moraes, 2013: 41). Esto es así debido a sus propias características, que sistematiza este mismo autor:

1. Su capacidad de fijar sentidos e ideologías, formar opiniones y trazar líneas predominantes del imaginario social: elabora y difunde contenidos, imponiendo sus reglas propias sin permitir otras opciones, modificaciones o visiones.

2. Apropiación de diferentes léxicos al servicio de sus objetivos particulares, incorporándolos en los discursos dominantes.

3. Refuerzo del mercado como el eje organizativo de la sociedad, presentándosecomo el actor capaz de regular la vida contemporánea.

4. Control selectivo de las informaciones y medidas de valor que circulan socialmente, silenciando o descontextualizando aquello que pueda convertirse en análisis crítico (De Moraes, 2013: 20ss.). 


\section{El sistema mediático de América Latina}

Para un análisis adecuado del sistema mediático es necesario, por tanto, tener en cuenta el contexto propio latinoamericano en general y ecuatoriano en particular. En su historia mediática, América Latina cuenta con algunas características comunes (Becerra, 2014: 63):

1- Lógica comercial como protagonista del funcionamiento de las industrias culturales.

2- Ausencia de servicios públicos no gubernamentales y uso de los medios de gestión estatal como órganos propagadores del discurso gubernamental.

3- Procesos de concentración de la propiedad del sistema de medios.

4- Centralización de la producción de contenidos informativos y de entretenimientos en los principales puntos urbanos de cada país.

5- Sistemas poco regulados pero fuertemente controlados por la relación que mantuvieron con los gobiernos (Becerra, 2014: 63). En América Latina, "el conflicto entre actores industriales y gobiernos expresa el quiebre de un modelo que Fox y Waisbord describieron con una paradoja: "el modelo comercial del audiovisual latinoamericano fue en muchos casos al mismo tiempo no regulado y fuertemente controlado" (Ibíd.: 69).

Históricamente, los Estados latinoamericanos han tenido dificultad para poner en marcha políticas claras de medios, a lo que hay que unir que el modelo populista favoreció en los 40 y 50 el desarrollo de las culturas subalternas y de las industrias culturales (Mastrini y Becerra, 2001). En el mercado de los medios, los países latinoamericanos fueron pioneros en la introducción de la televisión, no así en el desarrollo de las tecnologías; es en los 60 cuando se consolida el proceso de modernización económica y renovación cultural, fundamentalmente por la entrada de capital extranjero (ibíd.). "La gestión de los medios tuvo un desarrollo familiar, patriarcal y artesanal hasta la extensión del factor informacional, como medular en la estructura económica, coincidente con el 
crecimiento de la envergadura económica de los medios y su integración en un sistema global comercial" (ibíd., 2001: 3). En los años 60 se consolida un modelo de televisión fundamentalmente privada, con producción concentrada en grandes ciudades y gran presencia de capital extranjero. En algunos países comenzaba a aparecer la televisión pública, pero aún con bajos niveles de penetración y basada en la propaganda política del gobierno.

Si atendemos a las publicaciones diarias en Ecuador, es a finales del S.XIX cuando se consolidan. En 1860 se fundó El Telégrafo, el primer periódico de circulación nacional; en el siglo XX nacieron dos de los diarios con mayor circulación: ElComercio (1906) y El Universo (1922). Según datos de 2010, existen unos 35 diarios a nivel local, nacional y regional. En el ámbito de la radio y teledifusión, según los datos de la Superintendencia de Telecomunicaciones, en diciembre de 2010 existían 1.205 radioemisoras en onda corta, AM y FM, y 444 canales de televisión, incluyendo las estaciones matrices y repetidoras de señal abierta en VHF y UHF, tanto de propiedad privada como pública y comunitaria. Según la misma institución, el $83 \%$ de las televisiones eran de propiedad privada, el $17 \%$ de servicio público y las comunitarias no tenían representación $(0 \%)$. En cuanto a las radios, el $89 \%$ son de naturaleza privada, el 10,8\% de servicio público y apenas el $0,2 \%$ comunitarias. En 2007, con la llegada de Rafael Correa a la presidencia, se crean los medios públicos Ecuador TV, Radio Pública de Ecuador (reemplaza a la Radio Nacional) y El Telégrafo (incautado por el Estado a un exbanquero ${ }^{14}$ ). Además, se crea el diario gubernamental El Ciudadano y la Agencia Pública de Noticias del Ecuador y Sudamérica (Andes) y en 2010 nace el diario público PP, El Verdadero, impreso en las instalaciones de El Telégrafo (Unesco, 2011).

En paralelo al desarrollo del mercado de los medios, el debate sobre el estado de la comunicación en América Latina sigue su curso. En su congreso de 2002, la Asociación Latinoamericana de Investigadores en Comunicación estableció algunas metas para el

${ }^{14}$ La Agencia de Garantías de Depósito se lo había incautado a Fernando Aspiazu, expropietario del Banco El Progreso. 
debate sobre la comunicación en América Latina (Marques de Melo, 2010: 27$)^{15}$ :

a) Afrontar la comunicación como un proceso social, incentivando estudios sobre el comportamiento de los emisores y los efectos.

b) Disponer de autonomía teórica, fomentando la crítica metodológica. Generar conocimientos capaces de mejorar la calidad de los productos mediáticos que demanda la sociedad.

c) Recuperar el conocimiento empírico con sus tres dimensiones: autóctono, mestizo y popular.

Los retos en el contexto comunicativo latinoamericano parecen, por tanto, claros: pluralismo, repartición de frecuencias y habilitación de espacios para los diferentes tipos de medios de comunicación (Hervieu, 2010). Cumplir con estos retos supone avanzar en la denominada "democratización de la comunicación", que pretende revertir la situación actual generalizada de concentración y poder mediático. Para alcanzar la democratización de la comunicación, Macaroff (2010) propone actuar en tres líneas de trabajo: fortalecer los diversos tipos de medios de comunicación, entre ellos los públicos; trabajar en la formación de audiencias críticas y mejorar las prácticas periodísticas.

En la actualidad, las características que definen al "cuarto poder", siguiendo a Pascual Serrano (2013) en De Moraes (2013: 68) son:

- Es un apéndice de los grupos económicos empresariales (por lo general los dueños de los medios son emporios empresariales, ni siquiera especializados en comunicación).

- Llega a tener más poder que los tres poderes tradicionales ${ }^{16}$

\footnotetext{
${ }^{15}$ Autores como Marques de Melo defienden la tesis de la sociedad de la información entendida como una práctica para alcanzar la sociedad del conocimiento, en la que se defiende que no basta con una dotación de equipamientos técnicos, sino que se hace necesario poner en marcha procesos cognitivos que lleguen a toda la población y que permitan la construcción de una nueva sociedad entre todos los ciudadanos, poniendo fin a los procesos autoritarios en América Latina (Marques de Melo, 2010: 35 ss.).
} 
- No tiene legitimidad democrática, no es elegido por ninguna institución democrática, lo que lo convierte en un poder fáctico.

- Ha logrado importantes niveles de impunidad.

- No está sometido a controles económicos como el resto de poderes.

- No tiene ningún contrapoder, como sí tienen los otros tres poderes.

\section{La Ley Orgánica de Comunicación de Ecuador}

Hasta la llegada al gobierno de Rafael Correa (Alianza País ${ }^{17}$ ), la actividad periodística en Ecuador se regía por la Ley del Ejercicio Profesional del Periodista, de 1975, que obligaba a la titulación y colegiación. En 2004, por iniciativa ciudadana, se aprobó la Ley Orgánica de Transparencia y Acceso a la Información Pública (LOTAIP), aunque su aplicación no ha resultado todo lo eficiente que se esperaba. En 2008 se aprueba la nueva Constitución, y en ella se reconocen los derechos de acceso a la información y libertad de expresión. A partir de ese momento, el Gobierno da un plazo de un año para aprobar una Ley Orgánica de Comunicación; el proyecto se debatió en la Asamblea Nacional desde el 21 de noviembre de 2009, pero de forma interrumpida y con discrepancias.

Entretanto, en 2009, el Gobierno limita la exoneración del pago de IVA a la importación de papel periódico, con lo que Correa se gana el descontento de los propietarios de los medios impresos. En diciembre de 2009, el proyecto de ley se somete a una evaluación de la Comisión Interamericana sobre Derechos Humanos (CIDH) a petición del Gobierno. De esta manera, se consigue consenso para excluir cualquier censura directa. En 2010 se produce un primer debate y, a partir de ahí, el proceso se estanca, con la dimisión

\footnotetext{
${ }^{16}$ En el caso de Ecuador, cuenta con cinco poderes: a los tres tradicionales se les suma el Electoral y el de Transparencia y Control Social.

${ }^{17}$ Alianza País, más que un partido político, es definido como un movimiento político, que nace en 2006 y cuyo presidente es Rafael Correa.
} 
incluida de Betty Carrillo, presidenta de la Comisión Parlamentaria (Checa, 2012).

Ante la falta de consenso para la nueva ley de comunicación, Correa decide incorporar algunas preguntas relativas a este proyecto en el referéndum constitucional y la consulta popular que se realiza el 7 de mayo de 2011 (con un total de 10 preguntas). La pregunta fue planteada en los siguientes términos:

“¿Está usted de acuerdo con que la Asamblea Nacional, sin dilaciones dentro del plazo establecido en la Ley Orgánica de la Función Legislativa, expida una Ley de Comunicación que cree un Consejo de Regulación que regule la difusión de contenidos de la televisión, radio y publicaciones de prensa escrita que contengan mensajes de violencia, explícitamente sexuales o discriminatorios; y que establezca criterios de responsabilidad ulterior de los comunicadores o medios emisores?"

Los resultados para esta pregunta fueron los siguientes:

Tabla 2. - Resultados de la pregunta 9 de la consulta popular, referida a la Ley de Comunicación

\begin{tabular}{l|l|l} 
Opción & Votos & Porcentaje \\
\hline Sí & 3.882 .379 & 44,96 \\
\hline No & 3.630 .263 & 42,04 \\
\hline Voto nulo & 454.337 & 5,26 \\
\hline Voto en blanco & 667.397 & 7,73 \\
\hline Total & 8.634 .376 & $100 \%$ \\
\hline
\end{tabular}

Fuente: elaboración propia a partir de los datos publicados en el Registro Oficial el 13 de julio de 2011.

Con estos resultados, se trabaja el proyecto de ley existente y se aprueba en la Asamblea Nacional el 25 de junio de 2013, con 108 votos de los 135 asambleístas presentes (en total, 137): los de Alianza País y 3 independientes. Hasta ese momento se habían incrementado las críticas al proceso y crece el enfrentamiento entre el Presidente y los medios de comunicación; una de las críticas al texto final es la inclusión de la figura del linchamiento mediático (Art. 26) la creación de la Superintendencia de la Información y la 
Comunicación, entes cuya creación no se habían debatido en el proceso (Almeida, 2014).

En este proceso, la UNESCO hizo algunas recomendaciones a partir del proyecto de ley. En el plano jurídico, algunas de estas sugerencias fueron la creación de un órgano regulador independiente, la independencia editorial de intereses políticos y comerciales, la titulación obligatoria, la penalización de la difamación y el desacato, el derecho a la rectificación y el establecimiento de mecanismos de responsabilidad civil, la transparencia de las instituciones pública, el fomento de la participación ciudadana o la asunción de responsabilidad ulterior en caso de limitar la liberta de expresión (Unesco, 2011. 64ss.).

Contra estas recomendaciones (que dejaban ver un apoyo -con mejoras- al proyecto de ley), la organización liberal Fundamedios advierte de algunos riesgos (Ricaurte, citado en Checa, 2012: 48): a) Imposición de normas de responsabilidad ulterior que actúan como censura previa, b) profesionalización forzosa c) amplio y discrecional régimen de sanciones d) creación de un amplio y difuso Sistema Nacional de Comunicación e) Consejo Nacional de Información y Comunicación con potestad para sancionar e incluso cerrar medios y f) registro de medios que cumple las veces de un permiso de funcionamiento previo.

Si analizamos el texto final aprobado por la Asamblea Nacional, los puntos principales (y controvertidos) que recoge la Ley Orgánica de Comunicación vigente en Ecuador desde 2013 pueden resumirse de la siguiente manera:

\section{Redistribución del espectro radioeléctrico (Art. 106).} Continuando la línea marcada por otros países de América Latina, Ecuador apuesta por una redistribución de las frecuencias que fomente los medios comunitarios y los medios públicos (inexistentes éstos en Ecuador hasta 2008), en detrimento de los medios de comunicación privados, hasta ahora dueños de más del $90 \%$ de las frecuencias radioeléctricas, según los datos de la auditoría de frecuencias elaborado por la Comisión pertinente del Consejo Nacional de Radiodifusión y Televisión (Conartel). 
La redistribución que marca la ley tendrá que terminar de la siguiente manera: 33\% del espectro para medios privados, 33\% para medios públicos y $34 \%$ del espectro para los medios comunitarios. Éste es, sin duda, uno de los grandes retos y desafíos de los organismos encargados de realizar la redistribución, revertir el mapa mediático para que una parte del $90 \%$ de medios privados dejen de operar y cedan espacio a los medios comunitarios, que apenas tienen una presencia del 3\% (incluyendo medios escritos). Para lograrlo, el Art. 106 establece que "se alcanzará de forma progresiva y principalmente mediante la asignación de frecuencias todavía disponibles; la reversión de frecuencias por incumplimiento de las normas técnicas, jurídicas para su funcionamiento o fines para los que les fueron concesionadas y su posterior redistribución; la distribución de frecuencias que regresan al Estado conforme a lo dispuesto por la ley y la distribución equitativa de frecuencias y señales que permitirá la digitalización de los sistemas de transmisión de radio y televisión. En todos estos casos, la distribución de frecuencias y señales priorizará al sector comunitario hasta lograr la distribución equitativa que establece este artículo". Sin embargo, lo cierto es que un año y medio después de la entrada en vigor de la Ley de Comunicación la nueva asignación de frecuencias a medios comunitarios ha sido prácticamente nula; los medios incautados hasta la fecha continúan en manos del Estado, que hace un uso de ellos más cercano a lo oficialista que a lo público.

2. Creación de órganos de regulación (Art. 47 al Art.59). La LOC da origen al Consejo de Regulación y Desarrollo de la Información y la Comunicación (Cordicom) y a la Superintendencia de la Información y la Comunicación (Supercom), esta última aun más polémica que el primero. El Cordicom es el órgano encargado de regular: el acceso a la información, los contenidos y franjas horarias, además de autorizar (mediante informe vinculante) la concesión de frecuencias y elaborar estudios sobre el comportamiento de la comunidad en relación a los contenidos mediáticos. Para sus funciones se sirve de los reglamentos que el propio órgano 
elabora en cada una de las áreas; hasta finales de 2014 había emitido diez reglamentos.

Los miembros del Cordicom $^{18}$ son un representante de la Función Ejecutiva (presidente), un representante de los Consejos Nacionales de Igualdad, un representante del Consejo de Participación Ciudadana y Control Social, un representante de los Gobiernos Autónomos Descentralizados y uno del Defensor del Pueblo.

La Superintendencia de la Información y Comunicación es, según la define la propia ley (Art.55), "el organismo técnico de vigilancia, auditoría, intervención y control, con capacidad sancionatoria, de administración desconcentrada con personalidad jurídica, patrimonio propio y autonomía administrativa, presupuestaria y organizativa, que cuenta con amplias atribuciones para hacer cumplir la normativa de regulación de la información y comunicación". Entre sus funciones, velar por el cumplimiento de la ley y los reglamentos y aplicar las sanciones correspondientes.

3. Derecho a la reserva de la fuente (Art. 40) y derecho al secreto profesional (Art. 41), asumiendo una de las recomendaciones realizadas por la Unesco, con la que se protege la actividad profesional del periodista: "El derecho a la reserva de fuentes está legalmente protegido en la Constitución, sin embargo, un caso reciente evidenció la posible vulneración de este derecho. La futura ley de comunicación debería especificar, con menciones claras y taxativas, los casos excepcionales en los que no se reconocerá este derecho. Una capacitación de los distintos actores del Poder Judicial en relación a la doctrina y jurisprudencia interamericana en esta área sería también recomendable" (Unesco, 2011: 64).

${ }^{18}$ Los integrantes iniciales del Cordicom pueden consultarse en http://www.eluniverso.com/noticias/2013/07/28/nota/1214086/integrantes -consejo -regulacion. En 2014 uno de ellos dejó el cargo y fue sustituido. 
4. Derecho a la rectificación (Art. 23) y derecho a la réplica (Art.24), con los cuales se intenta proteger al ciudadano contra las malas prácticas periodísticas. Con respecto a la primera, los medios tienen la obligación de publicar las rectificaciones pertinentes en las 72 horas siguientes a la presentación de la reclamación, en una publicación con las mismas características, dimensiones, espacio/duración y sección en la que se publicó la información errada. Ese mismo plazo de 72 horas es el que disponen las personas o colectivos que consideren afectados sus derechos a la dignidad, honra o reputación a ejercer su derecho de réplica.

5. Defensor de las audiencias (At. 73), figura creada para defender los intereses de las audiencias y los lectores con la que deben contar todos los medios de carácter nacional, previo nombramiento por el Consejo de Participación Ciudadana y Control Social. El defensor de las audiencias debería entrar en funciones en enero de 2015, pero sólo en el último trimestre de 2014 se comenzaron a debatir los requisitos, atribuciones, salario, relación de dependencia, etc. En octubre de 2014, el Consejo de Regulación y Desarrollo de la Información y la Comunicación aprobó el reglamento para esta figura, en el que sin embargo no quedan claros aspectos importantes como los requisitos para la selección de los defensores de las audiencias y de los lectores. Ese mismo mes, el Cordicom emitió un informe en el que indicaba los 61 medios nacionales que deben contar con la figura del defensor de las audiencias. La elección de esta figura, según queda establecido en la ley, ha de ser por concurso público. Según lo establecido por el Cordicom en la resolución correspondiente, son 61 los medios de comunicación de carácter nacional: 34 radios, 20 canales de televisión y 7 medios impresos. Para tal identificación, se tomaron en cuenta los medios nacionales con cobertura de más del 30\% de la población del país con llegada al menos a dos regiones del país y los que cuentan con más de 6 repetidoras (los audiovisuales). En el caso de las radios se contabilizaron aquellas emisoras con redes permanentes de radio AM, FM y Onda Corta. Para los medios impresos, se tomaron en consideración los medios nacionales 
con ediciones regionales, los medios diarios de tirada superior a los 8.000 ejemplares y con cobertura a más del 30\% de la población del país.

6. Linchamiento mediático (Art. 26). Es una de las mayores polémicas de la Ley Orgánica de Comunicación, que sin embargo queda fuera del posterior Reglamento que desarrolla la ley (enero 2014). Establece la prohibición de difundir información que "de manera directa o a través de terceros, sea producida de forma concertada y publicada reiterativamente a través de uno o más medios de comunicación con el propósito de desprestigiar a una persona natural o jurídica o reducir su credibilidad pública".

7. Profesionalización de la actividad periodística (Art. 42 a 44). La LOC establece que "las actividades periodísticas de carácter permanente realizadas en los medios de comunicación, en cualquier nivel o cargo, deberán ser desempeñadas por profesionales en periodismo o comunicación, con excepción de las personas que tienen espacios de opinión y profesionales o expertos de otras ramas que mantienen programas o columnas especializadas" (Art.42). Esta obligatoriedad no afecta, sin embargo, a las personas que trabajen en lenguas de nacionalidades o pueblos indígenas.

La disposición transitoria 16 establece un plazo de seis años para cumplir con esta titulación, al tiempo que compromete a los medios de comunicación y entidades públicas a colaborar con el proceso de profesionalización facilitando las necesidades de los trabajadores.

8. Regulación de contenidos. Uno de los aspectos más conflictivos a nivel internacional en una ley de comunicación reside en la regulación de contenidos mediáticos, lo que supone un límite a la libertad de expresión. En el caso de la normativa ecuatoriana, la ley prohíbe (Art.62) la difusión de "contenidos discriminatorios que tenga por objeto o resultado menoscabar o anular el reconocimiento, goce o ejercicio de los derechos 
humanos reconocidos en la Constitución y en los instrumentos internacionales", así como los contenidos que sean apología o incitación a prácticas o actos violentos basado en mensajes discriminatorios. También se prohíben los contenidos violentos (Art. 67) y la difusión en horario no adulto de contenidos sexualmente explícitos (Art.68).

\section{Características del sistema mediático de América Latina - Ecuador}

La coyuntura histórica, económica, social y política de América Latina $-\mathrm{y}$, con ella, Ecuador- ha ido configurando un sistema mediático del que se desprenden las siguientes características:

1. Fuertes niveles de concentración empresarial

Tal y como se adelantaba, las características del sistema mediático ecuatoriano están influidas por el proceso histórico del país y de la región. "América Latina es una región que desde sus épocas coloniales mantiene una extrema relación de dependencia con los centros de poder. Dictaduras, desaparecidos y crisis dan cuenta de la dificultad de las clases hegemónicas regionales para articular un modelo de acumulación que integre al conjunto de las sociedades. [...] El alto grado de concentración de la propiedad de los medios, en manos de las elites económicas y políticas, ha clausurado hasta ahora las opciones de un desarrollo más democrático. La concentración de la riqueza en muy pocas manos marca que éste, desgraciadamente, no es sólo un problema del sector audiovisual" (Mastrini y Becerra, 2001: 17).

A la hora de hacer política pública, uno de los desafíos consiste en la heterogeneidad, es decir, "en encontrar políticas públicas no uniformadoras, políticas públicas que planteen la heterogeneidad de lo público y, por tanto, que sean capaces de posibilitar la presencia, la visibilidad de la diversidad social" (Martín Barbero, 2008: 11).

Venezuela, Bolivia, Ecuador y Argentina son los países más activos en políticas públicas contra la concentración de los medios. "Entre las medidas favorables al derecho a la 
comunicación se incluyen nuevas leyes de radiodifusión; el fortalecimiento de medios estatales y públicos; el apoyo a medios alternativos y comunitarios; el fomento de la producción audiovisual independiente; las garantías de mayor ecuanimidad en el acceso a las tecnologías; el énfasis en la generación y distribución de contenidos regionales y locales y la integración cultural en bases cooperativas y no mercantiles. Los más significativos: 1) ley de servicios de comunicación audiovisual de Argentina 2) ley de radiodifusión comunitaria de Uruguay 3) Ley de Cinematografía Nacional de Venezuela 4) Red de radios de los pueblos originarios en Bolivia 5) creación de canales estatales de televisión que ofrecen otras lógicas de programación informativa, cultural $y$ de entretenimiento: Encuentro (Argentina), Vive Tv (Venezuela), Ecuador TV, Telesur" (de Moraes, 2013: 2)

Los principales grupos mediáticos en América Latina son Grupo Clarín (Argentina), Organizaciones Globo (Brasil), Grupo Televisa (México) y Grupo Cisneros (Venezuela), pero también hay otros grupos locales como Garafulic (Bolivia), Caracol (Colombia) y Azteca (México). También es importante la inversión extranjera, como la del Grupo Prisa (Trejo, 2010: 25). El comportamiento de estos grandes grupos es similar al de los actores de la escala global: "son grupos multimedia con ramificaciones a otras actividades comunicacionales (telecomunicaciones, informática, industria gráfica) pero también a otras ramas de la industria y el comercio. Estos grupos tienen negocios cruzados entre sí, a la vez que tejen y destejen alianzas internacionales con los actores de mayor peso en el mercado planetario" (Mastrini y Becerra, 2001: 8 ss.).

"América Latina se asemeja cada vez más a un gran latifundio mediático, dominado por los poderosos grupos transnacionales de la comunicación y sus interlocutores regionales" (Mora, 2010: 169). De Moraes utiliza la imagen de un árbol para representar al sistema mediático, cuyas ramas serían los sectores de información y comunicación, unidos por un hilo conductor invisible que los entrelaza generando 
un circuito común de elaboración, irradiación y comercialización de contenidos, que finalmente quedan en manos de un reducido número de corporaciones (De Moraes, 2013: 19).

Siguiendo la tendencia global en el mercado de la comunicación, en Ecuador nos encontramos conglomerados de empresas de distinto tipo que cuentan entre sus bienes con medios de comunicación -tampoco aquí lo bancos están alejados de la propiedad de los medios-. La crisis bancaria 1999 -2001 evidenció cómo los medios eran utilizados en defensa de intereses financieros (Checa -Godoy, 2012). En el espectro radioeléctrico, 19 familias controlan 298 de las 384 frecuencias de TV abierta y 45 familias el dominio de un $60 \%$ de las más de mil concesiones de radio AM y FM (Alaniz, 2013: 8). Durante décadas el único medio público era Radio Nacional, creada en 1961, único portavoz gubernamental durante años.

Antes de la aprobación de la Ley Orgánica de Comunicación, eran ocho grandes grupos de comunicación los propietarios de los medios de comunicación, según los datos arrojados por la Comisión de Auditoría de Frecuencias de Radio y Televisión: Grupo Eljuri, Grupo Isaías, Grupo Vivanco, Grupo Egas, Grupo Alvarado, Grupo Mantilla, Grupo Pérez y Grupo Martínez (Unesco, 2011).

Desde la llegada de Correa (2007), son varias las medidas que se toman para limitar la concentración mediática. En primer lugar, se prohíbe a banqueros tener acciones en los medios de comunicación. Así lo establece el artículo 312 de la Constitución de 2008:

Art. 312. - "Las instituciones del sistema financiero privado, así como las empresas privadas de comunicación de carácter nacional, sus directores y principales accionistas, no podrán ser titulares, directa ni indirectamente, de acciones y participaciones, en empresas ajenas a la actividad financiera $O$ 
comunicacional, según el caso. Los respectivos organismos de control serán los encargados de regular esta disposición, de conformidad con el marco constitucional y normativo vigente.

Se prohíbe la participación en el control del capital, la inversión o el patrimonio de los medios de comunicación social, a entidades o grupos financieros, sus representantes legales, miembros de su directorio y accionistas.

Cada entidad integrante del sistema financiero nacional tendrá una defensora o defensor del cliente, que será independiente de la institución y designado de acuerdo con la ley".

La Constitución ofrece un plazo de un año para revertir la propiedad mediática de los bancos: (disposición transitoria 29):

"Las acciones y participaciones que posean las instituciones del sistema financiero privado, así como las empresas de comunicación privadas de carácter nacional, sus directores y principales accionistas, en empresas distintas al sector en que participan, se enajenarán en el plazo de un año contado a partir de la aprobación de esta reforma en referendo.

Las participaciones accionarias de las personas jurídicas del sector financiero, sus representantes legales y miembros de directorio y accionistas que tengan participación en el capital pagado de medios de comunicación social, deberán ser enajenadas en el plazo de dos años a partir de la entrada en vigencia de esta Constitución.

Nota: Primer inciso sustituido por reforma aprobada en el referéndum y consulta popular de 7 de Mayo de 2011, dada por Resolución del Consejo Nacional Electoral No. 00, publicada en Registro Oficial Suplemento 490 de 13 de Julio de 2011”. 
Después de varios intentos por parte de la Junta Bancaria de cambiar la noma y de algunas resoluciones contradictorias del propio gobierno, finalmente se obliga a los banqueros a acatar la norma, por la que se ven afectados 118 accionistas (Checa Godoy, 2012).

En segundo lugar, se incautan algunos medios de comunicación, dentro de la política ya expuesta de incautación de bienes a exbanqueros realizada por la Agencia de Garantías de Depósitos (ADG) como consecuencia de la crisis financiera de 1999. Entre todos los bienes que se incautaron, algunos eran medios de comunicación: Gamma TV, TC Televisión y Cablenoticias, además de dos emisoras de radio (Carrusel y Super k) y dos revistas (El Agro y La Onda). En la actualidad, estos medios incautados siguen siendo administrados por el Estado, aunque se espera formen parte de la redistribución del espectro radioeléctrico.

En tercer lugar, la redistribución del espectro radioeléctrico en tercios, de manera que un 33\% del espectro quede para medios públicos, un $33 \%$ para medios privados y el $34 \%$ para los medios comunitarios.

El objetivo principal de estas medidas es romper la tendencia global hacia la concentración de la propiedad de los medios de comunicación, a fin de evitar que los medios contribuyan "más bien a un orden de gobernabilidad de corte autoritario, legitimando intereses y acciones de élites muy particulares, imponiendo decisiones de manera no participativa, aunque con la apariencia de consensuales y legitimadas. Por consiguiente, los medios participan como obstáculos para una gobernabilidad más ampliamente participativa o democrática. A su vez, en una especie de círculo vicioso, en este proceso de concentración -económica y políticalos medios consolidan cada vez más su estatus de poderes fácticos, lo que les permite participar en un orden hegemónico, produciendo consenso para un proceso de desarrollo del que se benefician unos pocos aunque con una fachada 'democrática"' (Sánchez Ruiz, 2007 citado en Trejos, 2010: 48).

- Otra de las consecuencias de los altos niveles de concentración es la discriminación a las minorías sociales, lo que se traduce 
en un incremento de la exclusión de algunos sectores sociales y colectivos en situación de especial vulnerabilidad, además de la perpetuación de la invisibilidad a la que se somete a estos colectivos. "Mientras más se concentran las estaciones televisoras o las audiencias de las cadenas, menos diversidad existe en la televisión de cada país" (Trejo, 2010: 39). Algunos autores extienden esa influencia incluso a los niveles de confianza en la democracia, afirmando que existe una "mayor confianza por la democracia en los países que tienen menos índices de concentración televisiva" (Trejo, 2010: 46). En una encuesta realizada a líderes políticos latinoamericanos en 2002, el 65,2\% de ellos reconoció en los medios de comunicación el segundo mayor poder fáctico, sólo superado por los grupos económicos y financieros y muy por delante de los poderes constitucionales (Caputo, 2004 citado en Sánchez, 2009).

La concentración mediática no es importante sólo para edificar y consolidar la democracia, sino también para la conformación de la cultura política que toda democracia necesita (Trejo, 2010: 21).

2. Lo anterior no está reñido, sin embargo, con unrelanzamiento de los medios comunitarios y otras herramientas para alcanzar una comunicación alternativa.

La comunicación alternativa es definida como "una herramienta para la comunicación en el campo popular, sin dejar de lado la militancia social, quedando implícito que periodistas $\mathrm{y} / \mathrm{o}$ comunicadores deben estar dentro del conflicto, siempre con una clara tendencia a democratizar la palabra y la información"19. En Ecuador, la Agencia Latinoamericana de Información (Alai) apuesta por la "conformación de un nuevo tejido comunicacional, democrático, amplio, descentralizado y pluricultural, en sintonía con los procesos de transformación social" (De Moraes, 2013: 114).

En este contexto, conviene destacar el importante papel de las agencias alternativas en red en América Latina por sus características

\footnotetext{
${ }^{19}$ Acepción propuesta por el Foro de Medios Alternativos de la Argentina en el Encuentro Nacional de Medios Alternativos el 9, 10 y 11 de octubre de 2004 en Neuquén (Argentina) y recogida en De Moraes (2013: 103).
} 
(De Moraes, 2013: 19ss.): 1) Entienden la comunicación como bien común y derecho humano, que no puede ser apropiado ni distorsionado por las ambiciones económicas y políticas de las corporaciones 2) Denuncian y combaten la concentración monopólica de los medios 3) Buscan valorar temas sociales y renovar las prácticas periodísticas, a través de métodos más flexibles y colaborativos 4) Politizan el uso de las tecnologías, divulgando, lo máximo posible, informaciones veraces y contenidos que contribuyan a acentuar la variedad de mundos que el mundo contiene.

El auge de otro tipo de comunicación (y medios) pone de manifiesto un cambio -a menos un intento de alcanzarloen los papeles que tradicionalmente han desempeñado cada uno de los actores de la esfera pública en Ecuador. En palabras de Abad, "los medios y los partidos ya no miran a la sociedad, es la sociedad la que los mira y los juzga"

(Abad, 2006: 5).

3. Intervención del Estado. En los años 70 ya algunos países latinoamericanos (Venezuela, México) hablaron de la democratización de la comunicación, con conceptos como servicio público, acceso y participación, condena al desequilibrio en el flujo informativo internacional, derecho a la información o derecho a la réplica (Mastrini y Becerra, 2001: 5). Pero con los 80 y el auge global de las políticas liberales vino el fracaso de estas políticas democratizadoras. En los últimos años se ha retomado este discurso y se están aprobando o debatiendo leyes de comunicación en un gran número de países lationamericanos: Argentina en 2009, Venezuela en 2004, Uruguay en 2007, Ecuador 2013, México debate en 2013, Bolivia realizó cambios constitucionales que alcanzan al sector de los medios; en Brasil y Chile desde hace varios años existen iniciativas de la sociedad civil con un apoyo tenue del sistema político. En casi todos estos países hay consenso en reservar más del 30\% de las licencias audiovisuales para el sector no lucrativo de la sociedad (Becerra, 2014: 68). 
Las leyes de Venezuela y Ecuador sí aluden al control de los contenidos, no así las de Argentina y Uruguay, que se limitan al acceso a las licencias por parte de organizaciones sin ánimo de lucro. La intervención del Estado en el reparto de emisoras de televisión viene a cambiar el panorama televisivo en 2008, que se completa en el caso de Ecuador por la creación de medios públicos y oficialistas y la incautación de varios medios de comunicación, así como la Agencia de Noticias del Ecuador y Suramérica (Andes), agencia de noticias pública creada en 2009. Además de eso, el Gobierno de Rafael Correa cuenta con un espacio semanal de rendición de cuentas ("Enlace ciudadano", de obligada retransmisión para las cadenas públicas, que sin embargo traspasa la barrera de la rendición de cuentas y se convierte por momentos en espacios de publicidad gubernamental) y las cadenas nacionales, espacios dedicados a dar a conocer las obras del gobierno.

En este punto, conviene diferenciar entre lo público y lo estatal: lo público está hecho de Estado, pero también de sociedad (Martín Barbero, 2008). Esta misma lógica cabría aplicar a los medios de comunicación: medios públicos no son medios del Estado, sino medios al servicio de toda la sociedad.

Además de la generación de políticas públicas y el reparto del espectro radioeléctrico, existen otras formas de intervención del Estado, como la publicidad oficial. En Ecuador, aunque no se cuenta con datos oficiales, el gobierno es en los últimos años el mayor anunciante: 5,8 millones de dólares en 2009 según algunas estimaciones (Abad, 2010), 60 millones en 2010, 10 de los cuales habrían sido inversión de Presidencia, según otras (Checa, 2012). En 2009, el presidente anunció que no invertiría publicidad institucional en medios con cuentas en paraísos fiscales, lo que originó la movilización del accionariado de algunos medios de comunicación.

4. Baja profesionalización en el sector, entendida ésta no sólo como el nivel de formación de los periodistas, sino también 
como su grado de autonomía, asociacionismo o intrusismo en el ejercicio de la profesión.

América Latina es el continente que menos invierte en publicidad (3,8\%, frente a 44,2\% de América del Norte o al $27,4 \%$ de Europa) en la primera parte del S.XXI (Marques de Melo, 2010: 46). Para entender la repercusión de este dato, conviene recordar que los ingresos por publicidad son la principal fuente económica para el sector mediático privado, la que le permite operar con cierto margen en el mercado, pero también le vincula a otro tipo de intereses económicos e influye en el ejercicio diario de la profesión.

Según los datos de una encuesta realizada a 372 periodistas ecuatorianos en 2008 y 2009, el 41,4\% de los periodistas reconocía haber sufrido presiones o censura en alguna o bastantes ocasiones (Abad, 2010), lo cual refleja la ausencia de independencia en el desarrollo de la profesión.

Si en los 90 el salario mínimo establecido por el Gobierno para los periodistas ecuatorianos era de 99 dólares mensuales (el $72,4 \%$ de la muestra declaraba cobrar menos de 400 dólares; el 17,3\% entre 400 y 800 dólares mensuales) (Virtue, 1994); en la actualidad, el 48\% cobra entre 340 y 650 dólares mensuales, el $18 \%$ entre 651 y 900 dólares y hay un $15 \%$ de periodistas que cobran menos del salario mínimo establecido en Ecuador (341 dólares), según los datos del Consejo de Regulación y Desarrollo de la Información y la Comunicación ${ }^{20}$.

A mediados de los años 90, los principales problemas que declaraban los periodistas ecuatorianos eran, en este orden: falta de independencia (presiones de los propietarios o de intereses políticos, bajos salarios, profesionalización y formación, acceso a las noticias, problemas éticos, seguridad

\footnotetext{
${ }^{20}$ Datos disponibles en http://www.cordicom.gob.ec/resultados - de -laencuesta -nacional -de -profesionalizacion -a -los -trabajadores - de -la comunicacion/ (Recuperado el 10/12/2014)
} 
personal, oportunidades de trabajo y ausencia de solidaridad entre compañeros (Virtue, 1994).

La formación de los periodistas no contiene sólo técnicas comunicativas, sino también conocimiento sobre el contexto político, económico, social, geopolítico (Ramonet, en De Moraes, 2013: 96).

En Ecuador el proceso de profesionalización del periodismo está llevando a la certificación de los perfiles ocupacionales ${ }^{21}$ de las personas que ejercen esta actividad ${ }^{22}$, que en la actualidad asciende a 17.000 en todas las áreas de comunicación en Ecuador ${ }^{23}$. El CORDICOM, junto a SENESCYT ${ }^{24}$, SECAP $^{25}$ y SETEC $^{26}$ han realizado durante el segundo semestre de 2014 un proceso de "reconocimiento público, documentado y formal de la capacidad laboral demostrada por un trabajador, efectuado con base en la evaluación de sus competencias en su desempeño laboral y sin estar necesariamente sujeto a la culminación de un proceso educativo. En el Ecuador, este reconocimiento formal de las competencias implica la expedición por parte de una institución autorizada (Organismo de

${ }^{21}$ Hay una clasificación de 6 categorías de perfiles ocupacionales: 1) Presentador locutor para radio y/o televisión; 2) Trabajador de piso de televisión; 3) Fotógrafo de medios y multimedia; 4) Coordinador técnico de programación para medios comunitarios; 5) Camarógrafo de noticias y 6) Productor de contenidos para medios comunitarios.

${ }^{22}$ El CORDICOM realizó una encuesta a escala nacional desde el 3 al 17 de julio de 2014 sobre el nivel de formación que tienen los trabajadores en comunicadores, los periodistas y los trabajadores vinculados y conexos de la comunicación (http://www.cordicom.gob.ec/caminemos -juntos -hacia -la profesionalizacion/) (Recuperado el 21/09/14).

${ }^{23}$ Según los datos ofrecidos por el Cordicom y disponibles en http://www.telegrafo.com.ec/politica/item/ecuador -tiene -17-mil personas -que -trabajan -en -el -area - de -la -comunicacion.html. (Recuperado el 09/12/20149.

${ }^{24}$ Secretaría Nacional de Educación Superior, Ciencia, Tecnología e Innovación (http://www.educacionsuperior.gob.ec/).

${ }^{25}$ Servicio Ecuatoriano de Capacitación Profesional (http://www.secap.gob.ec/).

${ }^{26}$ Secretaría Técnica de Capacitación y Formación Profesional (http://www.secretariacapacitacion.gob.ec/). 
Evaluación de la Conformidad ${ }^{27}$ ) de una certificación que confirma documentalmente la competencia"28 (Oller y Chavero, 2014).

5. Escasa penetración de las TICs, bajas tiradas de prensa y gran consumo de la televisión, lo que lo convierte en un mercado eminentemente audiovisual.

Según datos del Instituto Nacional de Estadísticas de Ecuador (2012), el 31\% de los ecuatorianos dice leer la prensa, frente al $46,7 \%$ de los adolescentes que dedica de 1 a 5 horas semanales a informarse por televisión y al 35,4\% que dedica el mismo tiempo a informarse por internet (Marín et al., 2013). Según algunos estudios, el 26\% de los ecuatorianos dedica más de tres horas diarias a ver la televisión y el 13\% entre dos y tres horas diarias (Mitau, 2011).

En la configuración del espectro radioeléctrico, la Iglesia (Católica y Evangélica) tiene un papel importante, ya que cuenta con numerosas emisoras de radio, entre ellas algunas de las más populares en la región andina. En total, existen más de 90 radios católicas en Ecuador y unas 30 emisoras de radio evangélica (Checa-Godoy, 2012).

Además, el índice de penetración de las tecnologías de la información en Ecuador sigue siendo bajo: un 31,4\% de la población accede a Internet (INEC). Atendiendo a los usos que se le da, el 32,6\% lo utiliza para comunicarse, en tanto que el 31,1\% lo hace para buscar información. El Estado tiene pendiente, por tanto, garantizar el acceso de los ciudadanos a la tecnología.

6. Crisis de confianzaen los medios, lo que repercute en su credibilidad y legitimidad social. Esta falta de confianza no es

\footnotetext{
${ }^{27}$ http://www.inn.cl/pdfs/acreditacion/Evalu de la conform.pdf

(Recuperado el 21/09/14).

${ }^{28} \mathrm{http}: / /$ www.cordicom.gob.ec/certificacion -de -competencias -laborales/ (Recuperado el 21/09/14).
} 
exclusiva de los medios de comunicación ni tampoco de Ecuador o América Latina.

Tabla 3. - Confianza de los ecuatorianos en las instituciones

\begin{tabular}{|c|c|c|c|c|c|c|c|c|c|c|}
\hline & $\begin{array}{l}\text { Gobie } \\
\mathrm{r}-\mathrm{no}\end{array}$ & $\begin{array}{l}\text { Pren } \\
\text {-sa } \\
\text { (TV } \\
+)\end{array}$ & Asam & $\begin{array}{l}\text { Pode } \\
\text { r Judi } \\
\text {-cial }\end{array}$ & $\begin{array}{l}\text { Partidos } \\
\text { político } \\
\text { s }\end{array}$ & $\begin{array}{l}\text { FFA } \\
\text { A }\end{array}$ & $\begin{array}{l}\text { Admó } \\
\text { n Pca }\end{array}$ & $\begin{array}{l}\text { Municipi } \\
\text { o }\end{array}$ & $\begin{array}{l}\text { Iglesi } \\
\text { a }\end{array}$ & $\begin{array}{l}\text { Estad } \\
\text { o }\end{array}$ \\
\hline $\begin{array}{l}\text { Algo/ } \\
\text { Much } \\
\text {. }\end{array}$ & $61,9 \%$ & $45 \%$ & $\begin{array}{l}45,8 \\
\%\end{array}$ & $32,2 \%$ & $33,7 \%$ & $57,3 \%$ & $49,1 \%$ & $\begin{array}{l}50,8 \% \\
\text { (algo: } \\
43,8)\end{array}$ & $68,5 \%$ & $49 \%$ \\
\hline Poca & $26,1 \%$ & $\begin{array}{l}38,2 \\
\%\end{array}$ & $\begin{array}{l}34,5 \\
\%\end{array}$ & $41,8 \%$ & $37,2 \%$ & $30,2 \%$ & $36,7 \%$ & $34,2 \%$ & $22,8 \%$ & $34,8 \%$ \\
\hline Ning. & $11,5 \%$ & $\begin{array}{l}16,2 \\
\%\end{array}$ & $\begin{array}{l}18,2 \\
\%\end{array}$ & $24,9 \%$ & $28,5 \%$ & $11,4 \%$ & $17,2 \%$ & $14,5 \%$ & $8,1 \%$ & $15,5 \%$ \\
\hline
\end{tabular}

Fuente: elaboración propia a partir de los datos de Latinobarómetro 2011

Si atendemos sólo a la confianza social en los diferentes medios de comunicación, los datos para Ecuador son los que arroja la siguiente tabla:

Tabla 4. - Confianza de los ciudadanos ecuatorianos en los medios de comunicación (datos en porcentaje)

\begin{tabular}{|l|l|l|l|}
\hline Nivel de confianza & Prensa & Televisión & Radio \\
\hline Mucha & 6,8 & 8,5 & 6,7 \\
\hline Algo & 38,2 & 41,4 & 38,8 \\
\hline Poca & 38,2 & 35,3 & 38,5 \\
\hline Ninguna & 16,2 & 14,3 & 15,5 \\
\hline $\begin{array}{l}\text { No sabe/No } \\
\text { contesta }\end{array}$ & 0,6 & 0,4 & 0,6 \\
\hline
\end{tabular}

Fuente: Estudio Latinobarómetro -Ecuador 2011 (N=1.200)

Tal y como podemos observar en la tabla anterior, la televisión es el medio en el que más confían los ciudadanos ecuatorianos, en un contexto sin embargo dominado por la desconfianza en todos los medios convencionales: más de la mitad de los entrevistados no confía en ninguno de ellos. A pesar de todo, los datos de consumo siguen siendo elevados, en especial en el caso de la televisión y la radio. 


\section{El mapa mediático de Ecuador}

Una vez analizadas las características del sistema característico de los medios de comunicación ecuatoriano, a continuación se presenta la configuración del mapa mediático del país ${ }^{29}$.

En el panorama audiovisual, la comisión encargada de realizar la auditoría de las licencias radioeléctricas disponibles en 2009 puso de manifiesto un gran número de irregularidades, que alcanzan el campo político (concesiones realizadas a dirigentes). Sin embargo, casi ninguna de esas licencias ha sido revertida más de un año después de la aprobación de la LOC.

En el campo de la prensa escrita, Ecuador ha contado los últimos años con unos 35 diarios escritos, de los cuales una docena son de difusión nacional (Checa -Godoy, 2012). El índice de lectura en Ecuador sigue siendo bajo: un $50,3 \%$ de los ciudadanos ecuatorianos dice leer entre una y dos horas semanales (INEC, 2012). Tampoco los datos de tirada y difusión que ofrecen los medios de comunicación son totalmente fiables; no en vano, una de las obligaciones legales de la Superintendencia de la Información y la Comunicación es establecer un sistema de medición de la difusión de los medios de comunicación.

\subsection{Medios públicos}

Los medios de comunicación públicos están regulados en los artículos 78 a 83 de la Ley Orgánica de Comunicación, que establece entre sus objetivos "producir y difundir contenidos que fomenten el reconocimiento de los derechos humanos, de todos los grupos de atención prioritaria y de la naturaleza; ofrecer servicios de

\footnotetext{
${ }^{29}$ Dado que el objetivo de este trabajo no es el estudio de cada uno de los medios de comunicación, no se detallan aquí los medios de comunicación que operan en el Ecuador. Para conocer los medios de carácter nacional, el lector puede acudir al registro elaborado por el Consejo de Regulación y Desarrollo de la Información y la Comunicación:

http://issuu.com/cordicomec/docs/listado de medios de car cter naci?e $=9990954 / 9627320$
} 
información de relevancia pública, veraz, verificada, oportuna y contextualizada, con respeto a los principios de independencia profesional y pluralismo; facilitar el debate democrático y la libre expresión de opiniones; fomentar la igualdad de género y la interculturalidad; impulsar el intercambio de información y el conocimiento mutuo ente los pueblos de América Latina y del mundo; promover la producción y difusión de contenidos audiovisuales nacionales; buscar y ejecutar mecanismos de cooperación y enlace con medios públicos a nivel nacional e internacional; implementar espacios para la promoción de las actividades productivas del país y ofrecer contenidos educativos, culturales, de recreación y entretenimiento que contribuyan al buen vivir".

Según el articulado de la ley, los medios públicos nacen por decreto, ordenanza o resolución y su estructura está formada por un consejo editorial y un consejo ciudadano (salvo el caso de los oficiales). Formalmente gozan de autonomía editorial y entre sus objetivos está la difusión de contenidos que fomenten el respeto a los derechos humanos, transmitir información de relevancia pública, veraz, oportuna y contextualizada, facilitar el debate democrático, la igualdad de género, el intercambio de información y conocimiento, estimular la producción nacional y abogar por contenidos educativos, culturales y de recreación.

La financiación de los medios de comunicación públicos del Ecuador (con excepción de los medios públicos oficiales) proviene de los presupuestos propios de la institución, además de la publicidad, la comercialización de sus productos y de donaciones. 
Tabla 5. - Medios de comunicación públicos de Ecuador

\begin{tabular}{|c|c|c|}
\hline Medio & Referencia & Web \\
\hline Ecuador TV & $\begin{array}{ll}\text { - } & \text { Primer canal público } \\
\text { - } & 99 \text { estaciones } \\
\text { - } & 72 \% \text { territorio } \\
& \text { nacional } \\
\text { - } & \text { Contenido } \\
& \text { cultural/noticieros }\end{array}$ & Ecuadortv.ec \\
\hline Radio Pública Ecuador & $\begin{array}{ll}\text { - } & \text { Noticieros y } \\
& \text { entretenimiento } \\
\text { - } & \text { Cobertura nacional } \\
\text { - } & \text { Provincias } \\
\text { - } & \text { Una de las cinco más } \\
& \text { escuchadas } \\
\end{array}$ & radiopublica.ec \\
\hline ElTelégrafo & $\begin{array}{ll}\text { - } & \text { Nacional + ediciones } \\
& \text { locales } \\
\text { - } & \text { Información } \\
& \text { económica, política, } \\
& \text { cultural... } \\
\text { - } & 14.000 \text { ejemplares } \\
\text { - } & \text { Fuente para } 200 \\
& \text { radios en provincias } \\
\end{array}$ & Telégrafo.com.ec \\
\hline Radio Asamblea Nacional & - & \\
\hline Agencia Andes & $\begin{array}{ll}\text { - } & \text { Agencia informativa } \\
\text { - } & \text { Multimedia } \\
\text { - } & \text { Medios de } \\
\text { comunicación } \\
\text { nacionales, } \\
\text { internacionales y } \\
\text { público en general } \\
\text { - Español, inglés, } \\
\text { francés y portugués. } \\
\text { - } 70.000 \text { visitas } \\
\text { semanales } \\
\text { - } 205 \text { países }\end{array}$ & Andes.info.ec \\
\hline
\end{tabular}

Fuente: elaboración propia

Dentro de los medios públicos, se contempla la existencia de los medios de comunicación públicos oficiales, que son los encargados de difundir la posición oficial del Estado y de los gobiernos autónomos descentralizados. El ciudadano y PP el verdadero son los reconocidos como medios oficiales. La financiación de estos medios proviene de los presupuestos de la función del Estado o del 
gobierno autónomo descentralizado que lo crea, además de la venta de publicidad a instituciones públicas.

Lo significativo, como hemos venido viendo, es que el gobierno de Correa dota por primera vez a Ecuador de medios de comunicación públicos, inexistentes hasta entonces. La siguiente tabla muestra los medios de comunicación de naturaleza pública y oficialista del Ecuador.

\section{Medios oficiales}

En la tipología establecida por la ley, dentro de los medios de comunicación públicos, existen los medios oficiales, encargados de transmitir la labor y las acciones del Gobierno:

- El Ciudadano: periódico quincenal con una tirada de 120.000 ejemplares en 221 cantones de las 24 provincias.

- Elciudadano TV, El Ciudadano web, El ciudadano Radio, La Ciudadana: formatos audiovisuales del periódico oficialista.

- El Gobierno a sus mandantes: espacio de la Secretaría Nacional de Comunicación encargado de transmitir las actividades del Presidente de la República y otras entidades públicas.

- Enlace ciudadano. Conocido popularmente como "la sabatina", es el espacio semanal de rendición de cuentas del Presidente de la República, que toma como inspiración el antiguo Aló, presidente del expresidente venezolano Hugo Chávez. Se celebra cada sábado en una ciudad distinta de Ecuador (normalmente en espacios públicos y siempre con una audiencia presente) y es de transmisión obligada por todas las cadenas públicas de televisión y radio.

- Habla Ecuador. Espacio de rendición de cuentas de las autoridades locales.

\section{Medios de comunicación privados}

Los medios de comunicación de carácter privado están regulados por el artículo 84 de la Ley Orgánica de Comunicación, que los define como aquellas "personas naturales o jurídicas de derecho 
privado con o sin finalidad de lucro, cuyo objeto es la prestación de servicios públicos de comunicación con responsabilidad social".

En televisión, algunos de los principales canales son TC Televisión, Gama TV (incautadas por el Estado y frecuencias no redistribuidas aún), RTS, RTU y Oromar, entre otras.

En radio, las principales emisoras privadas son América, Carrusel, Sucre o Caravana, entre otras.

La prensa escrita tiene entre sus cabeceras privadas principales a $E l$ Comercio, El Universo, Hoy o Expreso, después de la desaparición en 2014 del diario Hoy (en junio la versión papel y en agosto también la versión digital).

\section{Medios de comunicación comunitarios}

Los medios de comunicación comunitarios están regulados por el artículo 85 de la LOC (85 a 87), donde quedan definidos como "aquellos cuya propiedad, administración y dirección corresponden a colectivos u organizaciones sociales sin fines de lucro, a comunas, comunidades, pueblos y nacionalidades". El objetivo de estos medios es promover la pluralidad, la diversidad, la interculturalidad y la plurinacionalidad a través de contenidos educativos y culturales.

Para conseguir este objetivo, el Estado debe promover políticas públicas para la creación y el fortalecimiento de los medios comunitarios, a través de la facilidad de acceso a créditos preferentes (para formación y compra de equipos), exenciones de impuestos, acceso a la capacitación de los trabajadores, etc. La financiación de los medios comunitarios son la venta de servicios y productos propios, la publicidad, donaciones y los fondos de cooperación.

En la actualidad, tal y como se ha señalado en apartados previos, los medios comunitarios apenas alcanzan el 3\% del espectro radioeléctrico, siendo en su mayoría medios locales, fundamentalmente cadenas de radio. Uno de los proyectos más importantes es la labor que viene realizando la Creación de Redes de 
Medios Comunitarios, Públicos y Privados Locales (Corape), que viene desarrollando su actividad desde 1990, con 45 radios y presencia en 21 de las 22 provincias del Ecuador.

Según queda establecido en la ley, ese 3\% debe convertirse en el $34 \%$ del espectro radioeléctrico, lo cual se presenta como un camino largo y tortuoso. La primera dificultad para revertir esta situación radica en el propio proceso de creación de medios comunitarios. Para iniciarlo, la solicitud de creación de un medio comunitario debe ir acompañada de una propuesta de programación y de un informe de rentabilidad económica, lo cual es incongruente con el objeto mismo de estos medios de comunicación, exentos de finalidad de lucro. Estas condiciones sitúan a los medios comunitarios en la misma situación que los medios de comunicación privados, lo cual supone de origen ubicar a los medios comunitarios en una posición de desventaja difícil de solventar si no se proponen condiciones especiales para ellos.

\section{A modo de conclusión}

A lo largo de estas páginas hemos analizado la configuración del sistema mediático ecuatoriano y el proceso de cambio -aún inacabado- por el que se ha venido generando. Si bien en la literatura académica existen modelos de estudio aceptados que se vienen trabajando en un gran número de países, las características históricas, sociales, políticas, económicas y culturales que definen una región como América Latina hacen necesaria la elaboración de un modelo propio, que atienda a las particularidades de la región y que no se limite a asumir modelos construidos para democracias consolidadas y países con larga tradición mediática.

La llegada al poder de Rafael Correa (2007) supuso la continuación de las políticas públicas latinoamericanas que apostaban por la democratización de la comunicación, y que significan la asunción del Estado de sus responsabilidades como garante de los derechos ciudadanos para un empoderamiento social en pro de la igualdad y la justicia en materia de comunicación. En este sentido, en 2009 se comienza a trabajar en una Ley de Comunicación que, sin embargo, no estará lista hasta 2013 tras un camino no exento de polémica: 
acusaciones de restricción de libertades desde los medios de comunicación privadas y demandas de mayor transparencia y participación social desde sectores profesionales y académicos. La ley que finalmente se aprueba en la Asamblea Nacional tiene entre sus puntos principales la redistribución del espectro radioeléctrico, que a partir de ahora deberá alcanzar los siguientes niveles: 33\% del espectro para medios públicos, 33\% para medios privados y $34 \%$ para medios comunitarios. Sin embargo, un año y medio después de la aprobación de la ley pocos cambios se han producido en esta materia: en torno al 90\% de los medios siguen siendo privados, los comunitarios apenas alcanzan el $3 \%$ y los medios privados incautados por el Estado siguen estando en sus manos. Esta nueva configuración intenta acabar con una concentración mediática que algunos autores han denominado "latifundios mediáticos" (De Moraes) y supone que, por primera vez, Ecuador cuente con un sistema de medios de comunicación públicos, hasta ahora inexistentes en el país, y medios oficiales, encargados de informar de la labor del Presidente y de otras entidades públicas (las cinco funciones del Estado y los gobiernos autónomos descentralizados). Otro de los puntos importantes de la ley es la creación de órganos de regulación y vigilancia con capacidad sancionatoria, que intentan poner fin a malas prácticas mediáticas pero que son recibidos por los medios de comunicación privados como mecanismos de restricción de la libertad de expresión.

Además de la Ley Orgánica de Comunicación, el gobierno de Rafael Correa tomó otras medidas en el campo de la comunicación por las que mantiene un enfrentamiento abierto con algunos sectores. La más significativa es la prohibición de que los banqueros tengan presencia en la titularidad de los medios de comunicación, medida que se toma con el objetivo de deshacer los lazos tradicionales entre el poder financiero y el poder mediático. Otras de las acciones ejecutadas es la incautación, tras la grave crisis financiera ecuatoriana, de algunos bienes, entre ellos algunos medios de comunicación.

Con todo ello, se pretende romper la tendencia generalizada al proceso de concentración de propiedad de los medios de 
comunicación y situar al Estado y al ciudadano como 'propietarios' del proceso comunicativo, en la medida en que las políticas públicas aplicadas protegen al ciudadano frente al poder mediático. Se trata, en todo caso, de un proceso que apenas acaba de comenzar en Ecuador y al que le falta un largo recorrido, para lo cual se hace necesario el apoyo estatal con mecanismos que permitan la verdadera participación ciudadana y protejan asimismo al periodista en un mercado demasiado dependiente de los devenires económicos.

En trabajos posteriores analizaremos las consecuencias de este sistema mediático en el ejercicio de la profesión periodística ecuatoriana y su relación con los órganos de poder y la toma de decisiones políticas.

\section{Referencias bibliográficas}

Abad, G. (2006). El periodismo olvidado: las instituciones mediáticas ante la rebelión de las audiencias. Quito: UASB.

Abad, G. (2010). "El club de la pelea. Poder político vs poder mediático”, en Rincón, O. (coord.) ¿Por qué nos odian tanto? Bogotá: Centro de Competencia en Comunicación para América Latina.

Abad, G. (2012). La responsabilidad social del periodismo: procesos informativos, debates políticos y ejes de políticas pública en el contexto de la Ley de Comunicación en el Ecuador. Quito: Universidad Andina Simón Bolívar.

Alaniz, M. (2013), "Medios masivos y transformaciones políticas en América Latina”. Trabajo presentado en el VI Encuentro Panamericano de Comunicación; Escuela de Ciencias de la Información, Universidad Nacional de Córdoba. 30 y 31 de agosto 2013. Córdoba (Argentina).

Alburquerque, A. (2012). "O paralelismo político em questiao". ComPolítica. 2(1).

Almeida, M. (2014). "Estado, medios y censura soft". Nueva Sociedad (249). 
Becerra, M. (2014). "Medios de comunicación: América Latina a contramano", NuevaSociedad N²49, enero -febrero 2014.

Becerra, M. (2000). "De la divergencia a la convergencia en la sociedad informacional: fortalezas y debilidades de un proceso inconcluso", en Zer. N'8 Facultad de Ciencias Sociales y de Comunicación. Universidad del País Vasco. Bilbao; pp. 93 -112.

Castells, M. (2014). "La globalización truncada de América Latina. La crisis del Estado -nación y el colapso neoliberal". Centro de Estudios Miguel Enríquez. Chile.

Chavero, P., González, J.J, Bouza, F., Castromil, A. y Rodríguez, R. (2013). "La mediatización de la agenda política: la discusión del pacto social como conflicto de agendas, 2009 -2011". Revista Latina de Comunicación Social. 68.

Checa, A. (2012). "La batalla política y legal en Ecuador ante la creación de un sector estatal de medios informativos". Anuario Americanista Europeo 9: 39 -54.

Checa Godoy, A. (2012). "La Banca y la propiedad de los medios: el caso de Ecuador", en Revista Latina de Comunicación Social, 67: 125 147. La Laguna (Tenerife). Universidad de La Laguna. DOI: 10.4185/RLCS -067 -950-125-147

De Moraes, D. (2011). "La batalla mediática en América Latina", en Políticas de Comunicación. $\mathrm{N}^{\circ} 2$.

De Moraes, D.; Ramonet, I. y Serrano, P. (2013). Medios, poder y contrapoder. De la concentración monopólica a la democratización de la información. Buenos Aires: Edit. Biblios.

Goldstein, A. (2011). "Los conflictos entre los medios y los gobiernos sudamericanos: el caso del primer gobierno de Lula Da Silva en Brasil”. Argumentos. Revista de crítica social, N 13. Disponible en http://revistasiigg.sociales.uba.ar/index.php/argumentos/article/vi ew/140/122. 
Huntington, S. (1991). The third wave: democratization in the late twentieth century. Norman and London: University of Oklahoma Press.

Hervieu, B. 2010). "El volcán mediático y su delicada regulación”. Reporteros sin Fronteras.

Ley Orgánica de Comunicación, 25 de junio 2013. Quito.

Marín, I., Yaguana, H y Barrazueta, P. (2013). "Estudio sobre uso y hábitos de consumo de medios de comunicación en la adolescencia en Loja (Ecuador)". Actas del V Congreso Internacional Latina en Comunicación Social. Disponible en http://www.revistalatinacs.org/13SLCS/2013_actas/060_Marin.pdf

Mastrini, G. y Becerra, M. (2001). “50 años de concentración de medios en América Latina: del patriarcado artesanal a la valorización en escala", en Quirós Fernández, Fernando y Francisco Sierra Caballero (eds.) Globalización, comunicación y democracia. Crítica de la economía política de la comunicación y la cultura, Comunicación Social Ediciones y Publicaciones, Sevilla, España, p. $179-208$.

Mitau, C. (2011). "El consumo de los medios de comunicación y el acelerado aumento de Internet en Ecuador". ComHumanitas. 3 (3): $101-120$.

Manifiesto Bicentenario de Caracas consolidando la Nueva Independencia, Ixe Sommet de l'ALBA, Caracas, 19 abril 2010.

Mora, A. (2010). "América Latina, el gran latifundio mediático". Ensayospedagógicos. 5 (1).

Macaroff, A. (2010). ¿Es posible democratizar la comunicación? Debates sobre los medios públicos y privados en Ecuador. Quito: Flacso Andes.

Martín Barbero, J. (2008). "Políticas de la comunicación y la cultura: claves de la investigación”. Documentos CIDOB. Dinámicas interculturales. CIDOB.

Marques de Melo, J. (2010). Comunicación Multicultural en Iberoamérica. Historia contextual y teoría comparada. São Paolo: 


\section{CONFIBERCOM / ALAIC / SOCICOM / INTERCOM/}

Cátedra UNESCO/UMESP de Comunicação.

Mellado, C. (2009). “Orígenes, evolución y desencuentros en la investigación sobre el periodista latinoamericano”. Rev. Innovar. 19(33). Consultado en:

http://www.scielo.org.co/pdf/inno/v19n33/v19n33a01.pdf

Oller, M. y Chavero, P. (2014). "La profesionalización del periodismo y el profesionalismo de los periodistas en Ecuador". Prisma. Disponible en http://revistas.ua.pt/index.php/prismacom/

Organización de Naciones Unidas para la Educación, la Ciencia y la Cultura (2011). Análisis del Desarrollo Mediático en Ecuador -2011. Quito.

Ortega, F. y Humanes, M.L. (2000). Algo más que periodistas. Sociología de una profesión. Barcelona: Ariel.

Pfetsch, B. (2013). "Comparing Media Systems Beyond the Western World”. Political Communication. 30(1): 162 -165.

Ramírez Gallegos, F. (2006). "Mucho más que dos izquierdas". Nueva Sociedad 205: 30 -44.

Sánchez Ruiz, E. (2009). "Poderes fácticos y gobernabilidad autoritaria. La Ley Televisa como estudio de caso" en Esteinou, J. y Alva, A.R. (eds.) La Ley Televisa y su lucha por el poder en México. México DF: Universidad Autónoma Metropolitana.

The Economist Intelligence Unit (2013). Democracy index. Democracy at a standstill.

Trejo Delarbre, R. (2010). "Muchos medios en pocas manos: concentración televisiva y democracia en América Latina". Intercom -Revista Brasileira de Ciencias da Comunicacao. Sao Paulo, 33 (1): $17-51$.

Unesco (2011). Análisis del Desarrollo Mediático en Ecuador -2011. Quito: Unesco.

Virtue, J. (1994). Journalists in the Andes. Miami: Florida International University. 



\title{
IIII
}

\section{Ley Orgánica de Comunicación y comunicación responsable}

\author{
José Maria Pérez Zúniga. Universidad de Granada, España \\ y Daniel Barredo Ibánez. Universidad de las Américas, Ecuador
}

\section{Introducción}

T A LEY Orgánica de Comunicación ha recibido en los últimos 1 meses, desde su puesta en marcha en 2013, numerosas críticas en ámbitos nacionales e internacionales. En este capítulo, desde el ámbito del Derecho, reflexionamos sobre la pertinencia de este instrumento legal. Asimismo, comparamos el clima regulador establecido en Ecuador con un equivalente internacional: la jurisprudencia española, la cual introduce pautas que sirven para aclarar aspectos como el régimen jurídico del derecho a la información o el linchamiento mediático. Desde nuestro punto de vista, la intervención de la Administración ecuatoriana resulta necesaria, tanto porque la actividad informativa es un servicio público, como por el hecho de que los profesionales -y fundamentalmente los medios - no han sabido ejercer su actividad.

\section{La comunicación como servicio público en la LOC}

Lo primero que llama la atención de la Ley Orgánica de Comunicación (en adelante, LOC) es el objeto de regulación y su ámbito de aplicación, pues, en sintonía con el artículo 16 de la Constitución de la República de Ecuador de 2008 (CEc, en 
adelante), al que se remite, regula el derecho a la comunicación, un término más omnicompresivo que el tradicional derecho a la información, entendido como un derecho complejo que engloba el derecho a comunicar y recibir información veraz y a la libertad de expresión (transmisión de ideas, pensamientos y opiniones), fundamentalmente, como establecen el artículo 13 de la Convención Interamericana de Derechos Humanos y el artículo 19 de la Declaración Universal de Derechos Humanos, y que han tomado como modelo Constituciones como la española, a la que nos referiremos por afinidad cultural y jurídica y porque la doctrina del Tribunal Constitucional (TC) español (verdadero artífice del régimen jurídico del derecho a la información en España) nos parece ejemplar en este ámbito, no habiendo jurisprudencia relevante al respecto de la Corte Constitucional del Ecuador. Este planteamiento revela la preocupación del legislador por transformar el mercado de la información (no el derecho a la información, que por ser uno de los derechos fundamentales y universales no puede transformarse por voluntad del legislador nacional, reconocido expresamente a lo largo del texto constitucional: artículos 16, 17, 18, 19, 20, 66.6 y 384 CEc) y convertirlo en un servicio público, como lo define el artículo 71 de la LOC: "la comunicación social que se realiza a través de los medios de comunicación es un servicio público que deberá ser prestado con responsabilidad y calidad, respetando los derechos de la comunicación establecidos en la Constitución, los instrumentos internacionales y contribuyendo al buen vivir de las personas". Así, se trata de un servicio público prestado bajo la tutela de la Administración pero también, por la especial configuración del derecho a la información, de un derecho fundamental de los ciudadanos, verdaderos titulares del mismo, pues constituye la base de una opinión pública libre $\mathrm{y}$, por tanto, del propio Estado democrático, como han reiterado el Tribunal Constitucional español y la Corte Interamericana de Derechos Humanos. En este sentido, resulta esencial la "publicatio", que es la declaración que hace esta ley de la comunicación social como servicio público. Pues, cuando una actividad es declarada como servicio público, se convierte también en una actividad administrativa, lo que no significa que el Estado preste el servicio de manera monopolística, algo expresamente prohibido por la CEc (ar. 17.3) y por la propia LOC, 
que permite prestar este servicio en régimen de concurrencia de empresas públicas, privadas y comunitarias, como veremos a continuación. Podemos considerar servicios públicos estatales aquellas actividades prestacionales de titularidad del Estado.Garrido Falla (1981: 225 y ss) señala que el concepto de servicio público en el Derecho Administrativo tradicional es el de "una actividad de prestación y satisfacción de necesidades colectivas cuya titularidad, precisamente por esto, asume el Estado", advirtiendo expresamente: "obsérvese que hablamos de titularidad, no de gestión". Para Ariño Ortiz (1981: 13 y ss), "la declaración de una actividad como servicio público ha de ser hecha por ley formal y supone el reconocimiento de la titularidad estatal sobre aquélla: la actividad queda desde ese momento incorporada al quehacer del Estado en régimen de reserva, y se le reconoce a ésta, al menos potencialmente, el derecho excluyente a su prestación". Como explica Fernández González (1995: 148), "esta concepción del servicio público como actividad prestacional cuya titularidad corresponde al Estado tiene una consecuencia trascendental desde el punto de vista de los títulos que legitiman la actuación de las Administraciones Públicas, pues supone que el Estado, titular del servicio, se convierte el dominus del mismo, lo cual produce el efecto de legitimar al Estado para llevar a cabo una gestión monopolística del servicio en cuestión", si así lo quisiera. De este modo, continúa el autor, en las actividades declaradas de servicio público del Estado, éste podrá, en cuanto titular de las mismas, excluir de su prestación a la iniciativa particular -también la iniciativa pública de otras Administraciones distintas- y prestar el servicio en régimen de monopolio; produciéndose, así, una identificación entre los servicios públicos estatales y los servicios esenciales reservados a favor del Estado, por lo que en la esfera estatal puede mantenerse un concepto de servicio público comprensivo de aquellas actividades prestacionales de titularidad del Estado y, por tanto, reservadas a su favor (Fernández González, 1995: 149). Sin bien, como añade Sala Arquer (1992: 412 -413), "cada vez son más numerosas las actividades tradicionalmente consideradas de "servicio público" que se transforman en actividades de mercado"; por lo que López Pellicer (1973:266) define servicio público como "la actividad de prestación cuya titularidad corresponde legalmente a la Administración Pública, de 
modo exclusivo o en concurrencia de los particulares, y que tiene por objeto la satisfacción de una necesidad general o colectiva". Por tanto, podemos afirmar que serán servicios públicos los que así califique la legislación del Estado. De ahí el objeto y ámbito de la ley descritos en el artículo 1 LOC: "desarrollar, proteger y regular, en el ámbito administrativo, el ejercicio de los derechos a la comunicación establecidos constitucionalmente"; lo que significa no someter a tutela administrativa el derecho a la información considerado de un modo abstracto, sino, como concreta el artículo 3 LOC (contenido comunicacional), "todo tipo de información u opinión que se produzca, reciba, difunda e intercambie a través de los medios de comunicación social", definidos en el artículo 5, como: "las empresas, organizaciones públicas, privadas y comunitarias, así como las personas concesionarias de frecuencias de radio y televisión, que prestan el servicio público de comunicación masiva que usan como herramienta medios impresos o servicios de radio, televisión y audio y vídeo por suscripción, cuyos contenidos pueden ser generados o replicados por el medio de comunicación a través de internet"; en lo que incide el artículo 4 del Reglamento que desarrolla la LOC (Decreto Ejecutivo 214. Registro Oficial Suplemento 170 de 27 -ene -2014): "Para efectos regulatorios, se entenderá por actividad comunicacional exclusivamente a aquellas actividades que realizan los medios de comunicación social definidos como tales en el artículo 5 de la Ley Orgánica de Comunicación”. Quedando así expresamente fuera de esta regulación la información u opinión que, de un modo personal se emita a través de internet (por medio de un blog, por ejemplo, o utilizando las redes sociales), según el artículo 4 LOC y el artículo 2 del Reglamento: "Están excluidos del ámbito de regulación y control administrativos los contenidos que formulen los ciudadanos y las personas jurídicas en sus blogs, redes sociales y páginas web personales, corporativas o institucionales". Incluso los medios de comunicación privados (artículo 84 LOC) son definidos como "personas naturales o jurídicas de derecho privado con o sin finalidad de lucro, cuyo objeto es la prestación de servicios públicos de responsabilidad social". No obstante, el artículo 3 del Reglamento parece referirse únicamente como medios de comunicación a las personas jurídicas (entidades mercantiles) y no a las personas físicas, al establecer: "Son 
también medios de comunicación aquellos que operen sobre la plataforma de internet, cuya personería jurídica haya sido obtenida en Ecuador y que distribuyan contenidos informativos y de opinión, los cuales tienen los mismos derechos y obligaciones que la Ley Orgánica de Comunicación establece para los medios de comunicación social definidos en el Art. 5 de dicha Ley"; creando además el artículo 37 de este mismo cuerpo normativo un Registro Público de Medios, dependiente del Consejo de Regulación y Desarrollo de la Información y Comunicación. Es decir, esta ley se circunscribe al ejercicio del derecho a la información por aquellas empresas o entidades que tengan a la comunicación como base de su actividad social (de societaria), mercantil o económica, y por los profesionales que trabajen o colaboren en ellas. Pero expliquemos primero el régimen jurídico del derecho a la información y la libertad de expresión.

\section{Derecho a la información y libertad de expresión: diferencias y límites}

Sin duda, “es más fácil dejarse llevar por una intuición presentida de la libertad, que implica aparentemente una ausencia de ataduras, que comprender la dialéctica del derecho cuya complejidad técnica solamente dominan los iniciados y, por tanto, escapa al arbitrio espontáneo individual" (Desantes-Guanter, 2004: 85). Esto explicaría muchas de las manifestaciones que hemos podido leer en los medios últimamente a propósito de la libertad de expresión a raíz de la aprobación de la LOC, pues cuando hablamos de derechos y libertades, casi en cualquier ámbito, a menudo se imponen nociones intuidas más que un debate serio que lógicamente debe partir de su regulación legal. En este sentido, no podemos sino constatar que el origen del derecho a la información es el mismo que el del resto de los derechos fundamentales. Desde una somera perspectiva histórica, ya en las primeras Declaraciones universales se recoge la libertad de expresión y el derecho a la información, si bien se pone el énfasis en la difusión de las ideas políticas. Así ocurre en la Declaración de Derechos del Buen Pueblo de Virginia (1770) y en la Declaración de los Derechos del Hombre y del Ciudadano (1789) y, en España, en la Constitución de Cádiz de 1812. Más 
modernamente, y en lo que a nosotros nos interesa, el derecho humano a la información es reconocido por primera vez en el artículo 19 de la Declaración Universal de Derechos Humanos de 1948, y, aunque "esto no era suficiente para garantizar su efectividad en los ordenamientos jurídicos de las naciones" (Azurmendi, 2001: 54), fue después recogido en el Convenio Europeo de Derechos Humanos de 1950 y en la Convención Americana de Derechos Humanos de 1969, si bien en este último texto utiliza el epígrafe Libertad de Pensamiento y de Expresión para referirse al conjunto de libertades protegidas por el derecho a la información. Un concepto, el del derecho a la información ${ }^{30}$, que es sin duda complejo, y para cuya interpretación debemos acudir a la misma Declaración de 1948, porque nos ofrece una visión completa y abierta de la comunicación considerada como derecho fundamental y por la importancia del instrumento jurídico donde se recoge, que constituye una "conciencia jurídica de la humanidad" (Truyol, 1968: 25). Así, el art. 19 proclama: "Todo individuo tiene derecho a la libertad de opinión y de expresión; este derecho incluye el de no ser molestado a causa de sus opiniones, el de investigar y recibir informaciones y opiniones y el de difundirlas, sin limitación de fronteras, por cualquier medio de expresión". Una redacción paralela a la del artículo 13 de la Convención Americana de Derechos Humanos, que pone su énfasis en la libertad de pensamiento y opinión y la prohibición de censura previa y de restricciones en la actividad informativa; y que incluye dentro de las libertad de pensamiento y de expresión "la libertad de buscar, recibir y difundir informaciones e ideas de toda índole". Como ha explicado Desantes-Güanter (1974: 35), este derecho recoge en realidad "un haz de derechos que, apreciados en su conjunto,

\footnotetext{
${ }^{30}$ No está de más que hagamos en este momento una pequeña precisión terminológica. Los términos derecho a la información y Derecho de la Información irrumpen con el estudio encargado por la UNESCO al francés Fernand Terrrou en un libro clásico (Terrou, Fernand y Solal, Lucien (1952). El Derecho de la Información. París: UNESCO), en el que por primera vez se denomina derecho a la información al conjunto de libertades proclamadas en el artículo 19 de la Declaración Universal de los Derechos Humanos, y derecho de la información a las legislaciones que se sintetizan en el estudio, por lo que no es correcto utilizar el término "derecho de la información" para referirse al derecho fundamental.
} 
pueden considerarse como integrantes de un derecho homogéneo y complejo, que es el que merece llamarse derecho a la información"; y que el mismo artículo 19 DUDH denomina derecho a la libertad de opinión y de información. Como señala también Díaz Arias (2000: 53), "se enlaza así con el término venerable de libertad de expresión, pero el contenido que de este modo se rotula supera, con mucho, lo que tradicionalmente se había entendido por libertad de expresión y opinión, pues su objeto son todas las formas posibles de mensajes (y ya no sólo los ideológicos) y se atiende tanto a las etapas activas del proceso (difundir), como a las previas y finales (investigar y recibir)". La Constitución de la República deEcuador de 2008 también recoge un haz de derechos en los artículos 16, 17, 18, 19, 20, 66.6 y 384, bajo los rótulos "comunicación e información", "derechos de libertad" y "comunicación social":

- Una comunicación libre, intercultural, incluyente, diversa y participativa (artículo $16 \mathrm{CEc}$ ).

- El acceso universal a las tecnologías de información y comunicación (artículo 16 CEc).

- La creación de medios de comunicación social, y al acceso en igualdad de condiciones al uso de las frecuencias del espectro radioeléctrico para la gestión de estaciones de radio y televisión públicas, privadas y comunitarias, y a bandas libres para la explotación de redes inalámbricas (artículo $16 \mathrm{CEc}$ ).

- El acceso y uso de todas las formas de comunicación visual, auditiva, sensorial y a otras que permitan la inclusión de personas con discapacidad (artículo 16 CEc).

- La asignación de las frecuencias del espacio radioeléctrico (artículo $17 \mathrm{CEc}$ ).

- La creación y el fortalecimiento de medios de comunicación públicos, privados y comunitarios (artículo $17 \mathrm{CEc}$ ).

- Buscar, recibir, intercambiar, producir y difundir información veraz, verificada, oportuna, contextualizada, plural, sin censura previa acerca de los hechos, acontecimientos y procesos de interés general, y con responsabilidad ulterior (artículo 18 CEc). 
- El Estado garantizará la cláusula de conciencia a toda persona, y el secreto profesional y la reserva de la fuente a quienes informen, emitan sus opiniones a través de los medios u otras formas de comunicación, o laboren en cualquier actividad de comunicación (artículo $20 \mathrm{CEc}$ ).

- El derecho a opinar y expresar su pensamiento libremente y en todas sus formas y manifestaciones (artículo 66.6 CEc).

$\mathrm{Y}$, por último, establece un mandato en el ámbito de la Comunicación Social:

- El sistema de comunicación social asegurará el ejercicio de los derechos de la comunicación, la información y la libertad de expresión, y fortalecerá la participación ciudadana (artículo 384 $\mathrm{CEc})$.

- Además, la CEc prohíbe expresamente la existencia de monopolios y oligopolios en el mercado de la información (artículo $17 \mathrm{CEc}$ ), y señala ese papel vigilante y regulador del Estado al establecer: "La ley regulará la prevalencia de contenidos con fines informativos, educativos y culturales en la programación de los medios de comunicación, y fomentará la creación de espacios para la difusión de la producción nacional independiente; prohibiendo la emisión de publicidad que induzca a la violencia, la discriminación, el racismo, la toxicomanía, el sexismo, la intolerancia religiosa o política y toda aquella que atente contra los derechos" (artículo 19 CEc). Por lo que debemos destacar que la tutela administrativa y el control de la actividad informativa por parte del Estado es un mandato constitucional, del que la actual LOC no es más que una consecuencia. Si bien creemos que dentro del ámbito del derecho a la información debemos entender comprendidos el derecho a recibir y comunicar información veraz y la libertad de expresar ideas, pensamientos y opiniones, siendo el resto de libertades meras garantías para hacerlo posible dentro del mercado de la información.

La Constitución española de 1978 también reconoce un haz de derechos (artículo 20, dentro del Título I, "De los derechos y deberes fundamentales"): 
a) A expresar y difundir libremente los pensamientos, ideas y opiniones mediante la palabra, el escrito o cualquier medio de reproducción.

b) A la producción y creación literaria, artística, científica y técnica.

c) A la libertad de cátedra.

d) A comunicar y recibir libremente información veraz por cualquier medio de difusión.

Reconociendo también la cláusula de conciencia y al secreto profesional en el ejercicio de estas libertades, y prohibiendo la censura previa. De la simple lectura de los artículos citados podemos inferir que las facultades reconocidas dentro de este derecho complejo son: difundir ideas, difundir opiniones, creación intelectual (literaria, científica, técnica), creación artística, difundir informaciones y recibir informaciones. Libertades que podrán ejercerse mediante los medios naturales o de reproducción (libertad de expresión) y difusión (libertad de información) y que podemos considerar -recurriendo al criterio interpretativo de las Declaraciones internacionales- como universales. En torno a estas dos libertades se estructuran el resto de los elementos para hacerlos posibles. Podemos clasificarlos en garantías institucionales y límites. La garantía básica es la prohibición de la censura, en la tradición de que la comunicación no puede ser sometida a control previo e, íntimamente ligada con ésta, la garantía de limitar el secuestro de los soportes informativos al decretado por resolución judicial; cláusula de conciencia y secreto profesional son garantías institucionales para el ejercicio de estas libertades mediante la práctica profesional. Además, para comprender la amplitud de este derecho, hay que destacar la interpretación del TC (recordemos que en España no existe una ley que desarrolle el contendido del derecho a la información, sí una Ley 7/2010, de 31 de marzo, General de la Comunicación Audiovisual, por lo que la jurisprudencia del TC es esencial), cuando señala (STC107/1988) que "las libertades del artículo 20 de la Constitución no sólo son derechos fundamentales de cada persona, sino que también significan el reconocimiento y garantía de la opinión pública libre, que es una institución ligada de 
manera imprescindible al pluralismo político, valor esencial del Estado democrático, estando dotadas por ello esas libertades de una eficacia que trasciende a la que es común y propia de demás derechos fundamentales" (F.J $\left.\mathrm{J}^{\mathrm{o}} 2^{\mathrm{o}}\right)$. Un argumento análogo al utilizado por la Corte Interamericana de Derechos Humanos (Caso Claude Reyes y otros Vs. Chile. Fondo, Reparaciones y Costas. Sentencia de 19 de septiembre de 2006. Serie C No. 151, Párrafo 87): "El control democrático, por parte de la sociedad a través de la opinión pública, fomenta la transparencia de las actividades estatales y promueve la responsabilidad de los funcionarios sobre su gestión pública"; considerando a la libertad de expresión: "como piedra angular de una sociedad democrática, es una condición esencial para que ésta esté suficientemente informada" (Corte IDH. Caso "La Úlima Tentación de Cristo" (Olmedo Bustos y otros) Vs. Chile. Fondo, Reparaciones y Costas. Sentencia de 5 de febrero de 2001. Serie C No. 73, Párrafo 66). Y: "La Corte Europea de Derechos Humanos ha señalado que [la] función supervisora [de la Corte le] impone [...] prestar una atención extrema a los principios propios de una 'sociedad democrática'. La libertad de expresión constituye uno de los fundamentos esenciales de tal sociedad, una de las condiciones primordiales para su progreso y para el desarrollo de los hombres. El artículo 10.2 [de la Convención Europea de Derechos Humanos] es válido no sólo para las informaciones o ideas que son favorablemente recibidas o consideradas como inofensivas $\mathrm{O}$ indiferentes, sino también para aquellas que chocan, inquietan u ofenden al Estado o a una fracción cualquiera de la población. Tales son las demandas del pluralismo, la tolerancia y el espíritu de apertura, sin las cuales no existe una 'sociedad democrática'. Esto significa que toda formalidad, condición, restricción o sanción impuesta en la materia debe ser proporcionada al fin legítimo que se persigue" (Párrafo 69).

\section{La jurisprudencia del Tribunal Constitucional español}

El Tribunal Constitucional analiza las diferencia de las distintas libertadas contenidas en el derecho a la información, tal y como lo vemos configurado en las declaraciones internacionales de derechos y en las constituciones ecuatoriana y española. Fundamentalmente, 
la distinción entre las libertades de expresión e información se basa en el distinto alcance y protección dada a una y a otra por el Tribunal Constitucional a la hora de resolver el conflicto entre el derecho a la información y los derechos de la personalidad, por encima de todos, el derecho al honor. Así, desde sus primeras sentencias, el Tribunal afirma el carácter institucional del derecho reconocido en el artículo 20, su función pública, que no es otra que el mantenimiento de una comunicación pública libre: "El artículo 20 de la Constitución, en sus distintos apartados, garantiza el mantenimiento de una comunicación pública libre, sin la cual quedarían vaciados de contenido real otros derechos que la Constitución consagra, reducidas a formas hueras las instituciones representativas y absolutamente falseado el principio de legitimidad democrática que enuncia el art. $1^{\circ}$, apartado 2 de la Constitución, y que es la base de toda nuestra ordenación jurídico -política" (STC 6/1981, F. J. $4^{\circ}$ ). En cuanto a los medios, incluidos la radio, el cine y la televisión, la STC 76/1995 concreta esa función pública como función constitucional, pues su actividad forma parte del sistema de frenos y contrapesos en que consiste la democracia. A decir de Díaz Arias (2000: 117), pronto esta dimensión institucional se interpreta como "garantía de una institución política fundamental, que es la opinión pública libre" (STC 12/1982, F. J. $3^{\circ}$ ). El Tribunal (STC 6/1988) delimita ambas libertades en estos términos: "En el art. 20 de la Constitución la libertad de expresión tiene por objeto pensamientos, ideas y opiniones, concepto amplio dentro del que deben incluirse también las creencias y los juicios de valor. El derecho a comunicar libremente información versa, en cambio, sobre hechos o, tal vez más restringidamente, sobre aquellos hechos que pueden considerarse noticiables. Es cierto que, en los casos reales que la vida ofrece, no siempre es fácil separar la expresión de pensamientos, ideas y opiniones de la estricta comunicación informativa, pues la expresión de pensamientos necesita a menudo apoyarse en la narración de hechos y, a la inversa, la comunicación de hechos o de noticias no se da nunca en un estado químicamente puro y comprende, casi siempre, algún elemento valorativo o, dicho de otro modo, una vocación a la formación de una opinión. Ello aconseja, en los supuestos en que pueden aparecer entremezclados elementos de una y otra significación, atender (...) al elemento que 
en ellos aparece como preponderantes" (F. J. 50). Esta sentencia interpreta la veracidad, exigida por el propio texto constitucional, como deber de diligencia profesional: "Cuando la Constitución requiere que la información sea "veraz" no está tanto privando de protección a las informaciones que pueden resultar erróneas -O sencillamente no probadas en juicio- cuanto estableciendo un específico deber de diligencia sobre el informador, a quien se le puede y debe exigir que lo que transmita como "hechos" haya sido objeto de previo contraste con datos objetivos, privándose, así, de la garantía constitucional a quien, defraudando el derecho de todos a la información actúe con menosprecio de la veracidad o falsedad de lo comunicado..." (F. J. 5\%). Además, para que el ámbito de los derechos de la personalidad de los otros pueda ser invadido, la información debe versar sobre asuntos de interés general y relevancia pública (STC 171/1990). Por resumir esta doctrina en los términos de la STC 190/1996: "Forma parte del acervo jurisprudencial de este Tribunal el criterio de que la comunicación que la Constitución protege es la que transmite información veraz relativa a asuntos de interés general o relevancia pública (entre otras muchas, SSTC 6/1988, 171/1990). Información veraz es, al respecto, ante todo, información verdadera. No obstante la trascendencia constitucional en una sociedad democrática de un flujo informativo libre y sin cortapisas (SSTC 6/1981, 159/1986, 240/1992, 78/1995, 132/1995, 19/1996) impone bajo la égida de la libertad analizada aquellas informaciones de relieve público que, aunque puedan resultar falsas a posteriori hayan sido debidamente contrastadas ex ante por su agente (SSTC 6/1988, 105/1990, 223/1992, 132/1995, 61/1996). La identificación de la veracidad con la objetividad (STC 143/1991) o la "realidad incontrovertible" (STC 41/1994) constreñiría inevitablemente el cauce comunicativo al acogimiento de aquellos hechos que hayan sido plena $y$ exactamente demostrados (STC 143/1991)" (F. J. 3). No debe confundirse la relevancia pública con el carácter noticioso del hecho de que se informa, ni la determinación de esa relevancia pública puede quedar al arbitrio del medio de comunicación, pues, según declara la STC 134/1999: "Ni son los medios de comunicación los llamados por la CE para determinar qué sea o no de relevancia pública, ni esto puede confundirse con el difuso objeto de un 
inexistente derecho a satisfacer la curiosidad ajena (STC 20/1992, F. J. $3^{\circ}$ ). El artículo 20.1 d) CE, al garantizar los derechos a comunicar y a recibir libremente información, no protege la satisfacción de la mera curiosidad de los que componen el público en general, sino el interés colectivo de la información, lo que no debe identificarse sin más con lo que para el medio de comunicación puede resultar noticioso (SSTC 105/1983, 159/1986 y 168/1986)" (F. J. 8º). Por lo demás, la libertad de expresión -más amplia que la libertad de información, porque no opera para ella el requisito interno de la veracidad (STC 107/1988) - se evalúa sobre todo como libertad de crítica, muy amplia cuando se proyecta sobre personajes públicos, hasta el punto de que sólo quedan excluidas las expresiones injuriosas (STC 3/1997): “Cuando se ejercita la libertad de expresión (...) los límites permisibles de la crítica son más amplios si ésta se refiere a personas que, por dedicarse a actividades públicas están expuestas a un riguroso control de sus actividades y manifestaciones que si se trata de simples particulares sin proyección pública alguna, pues en un sistema inspirado en los valores democráticos, la sujeción a esta crítica es inseparable de todo cargo de relevancia pública (...). La crítica legítima en asuntos de interés público ampara incluso aquellas que puedan molestar, inquietar, disgustar (...) (aunque) no puede estar amparado por la libertad de expresión quien, al criticar una determinada conducta, emplea expresiones que resultan lesivas para el honor de la persona que es objeto de la crítica, aun cuando ésta tenga carácter público (...) (pues) una cosa es efectuar una evaluación personal, por desfavorable que sea... y otra cosa distinta el empleo de expresiones o calificativos que, apreciados en su significado usual y en su contexto, no guardan relación con la formación de la opinión pública libre" (F. J. $6^{\circ}$ ). En el mismo sentido: SSTC 6/2000, 49/2001, 204/2001). Y añade el Tribunal Constitucional en su ST 20/2002: “...pues así lo requieren el pluralismo, la tolerancia y el espíritu de apertura, sin los cuales no existe "sociedad democrática"; remitiéndose a la doctrina del Tribunal Europeo de Derechos Humanos (SSTEDH de 23 de abril de 1992, Castells c. España, 42, y de 29 de febrero de 2000, Fuentes Bobo c. España, 43). Y especifica a continuación: “...el artículo 20.1 a) de la $\mathrm{CE}$ no reconoce un pretendido derecho al insulto, que sería, por lo demás, incompatible con la norma fundamental (SSTC 
204/1997, 134/1999, 6/2000, 11/2000, 110/2000, 297/2000, 49/2001 y 148/2001)" (F. J. 4 ${ }^{\circ}$ ). Como vemos, para el Tribunal Constitucional, lo relevante es si se trata de informaciones de hechos o bien entramos en el terreno de la opinión, distinguiendo por tanto entre la libertad de información -en la que opera siempre el requisito interno de la veracidad-, y la libertad de expresión, que es más amplia. En el primer caso, el Tribunal exige siempre un deber de diligencia profesional; así, la información veraz sería la información verdadera, entendiendo por tal la debidamente contrastada, pudiendo incluso resultar falsa a posteriori, lo cual no invalidaría su consideración de información veraz, siempre que se hubiera cumplido el correspondiente deber de diligencia. En el segundo, los límites se encontrarían en la relevancia pública de la información y en el honor de la persona que pueda resultar afectada, si bien el Tribunal considera más importante el derecho a la información como garantía de una "opinión pública libre"; no pudiendo confundirse la relevancia pública con el carácter noticioso del hecho de que se informa, cuestión que tampoco puede quedar al arbitrio del medio de comunicación: "el art. 20.1 no protege la satisfacción de la mera curiosidad de los que componen el público en general, sino el interés colectivo de la información”. Por tanto, la libertad de expresión -más amplia que la libertad de información, porque no opera para ella el requisito interno de la veracidad- se evalúa sobre todo como libertad de crítica, tolerada cuando se proyecta sobre personajes públicos hasta el punto de que sólo quedan excluidas las expresiones injuriosas; pues, según el Tribunal Constitucional, así lo requieren el pluralismo, la tolerancia y el espíritu de apertura, sin los cuales no existe "sociedad democrática". Aunque aclara que el artículo 20.1 a) de la CE no reconoce un pretendido derecho al insulto, que sería incompatible con la norma fundamental.

Un criterio al que parece acogerse el artículo 7 del Reglamento cuando desarrolla el concepto de "Información de relevancia pública o de interés general" contenido en el artículo 7 de la LOC: "Es información de relevancia pública la que puede afectar positiva o negativamente los derechos de los ciudadanos, el orden constituido o las relaciones internacionales, que se difunde a través de los 
medios de comunicación social. Las opiniones sobre asuntos de relevancia o interés público no están sujetas a las condiciones establecidas en el Art. 22 de la Ley Orgánica de Comunicación. La difusión de información de relevancia o interés público está sujeta a lo establecido en el Art. 19 de la Ley Orgánica de Comunicación”. Como podemos observar, este artículo distingue entre información y opinión, excluyendo en el caso de las opiniones la exigencia de que la información sea verificada, contrastada, precisa y contextualizada (artículo 22 LOC), si bien se remite expresamente a la responsabilidad ulterior (artículo 19 LOC) como límite de la libertad de expresión, así como al linchamiento mediático (artículo 16 LOC), al que nos referimos a continuación.

\section{E1 linchamiento mediático}

Visto el régimen jurídico del derecho la información y la libertad de expresión, así como sus límites, analicemos ahora una de las figuras contenidas en esta ley y que han generado mayor controversia: el linchamiento mediático. Si acudimos a la regulación de la LOC, el artículo 26 dispone: "Queda prohibida la difusión de Información que, de manera directa o a través de terceros, sea producida de forma concertada y publicada reiterativamente a través de uno o más medios de comunicación con el propósito de desprestigiar a una persona natural o jurídica o reducir su credibilidad pública”.

De esta redacción podemos destacar dos elementos:

1. La difusión de una información de manera reiterada, ya sea directamente o a través de terceros, de manera concertada.

2. Que esa información tenga por objeto desprestigiar a una persona natural o jurídica o reducir su credibilidad pública.

Dejando de lado por circunstancial el elemento de la reiteración, el segundo nos recuerda a la concepción del TC sobre los límites de la libertad de expresión. Pues el límite se encuentra precisamente en la lesión del honor de la persona, es decir, en la injuria ("no existe un derecho al insulto", dice el TC). Y creemos que la regulación de la figura del linchamiento mediático encuentra su lógica interna en la 
protección del derecho al honor y el derecho a la intimidad personal y familiar, protegidos expresamente por el artículo 66, numerales 18 y $20 \mathrm{CEc}$, que además recoge (numeral 7) "el derecho de toda persona agraviada por informaciones sin pruebas o inexactas, emitidas por medio de comunicación social, a la correspondiente rectificación, réplica o respuesta, en forma inmediata, obligatoria y gratuita, en el mismo espacio u horario"; precisamente las consecuencias que el artículo 29 de la LOC prevé para el linchamiento mediático, "sin perjuicio de que los autores de la infracción respondan por la comisión de delitos y/o por los daños causados y por su reparación integral". Es decir, como en el caso español, si se ha cometido un delito de injuria, definido por el artículo 489 del Código Penal de Ecuador como: "La injuria es: calumniosa, cuando consiste en la falsa imputación de un delito; y, no calumniosa, cuando consiste en toda otra expresión proferida en descrédito, deshonra o menosprecio de otra persona, o en cualquier acción ejecutada con el mismo objeto". A nuestro juicio, éste debe ser entonces el criterio para entender si ha habido linchamiento mediático o no: si se ha lesionado el honor de la persona o, como diría el TC español, si se ha producido un insulto o una calumnia. Una acción que puede castigar en virtud de la LOC en el ámbito administrativo, o por la jurisdicción penal, si alcanza la categoría de delito. Se trata, por tanto, de criterios jurídicos que pueden servirnos de guía a la hora de interpretar el alcance de la ley y, sobre todo, para su aplicación al caso concreto.

\section{Derecho a la información y mercado de la información: la comunicación responsable}

En este sentido, hay que resaltar que, más que el régimen jurídico del derecho a la información y a la libertad de expresión y sus límites jurídicos y éticos, la verdadera piedra de toque de la actividad informativa hoy día en todos los países es la regulación o no del mercado de la información, cuya actividad ha venido determinada por intereses económicos y comerciales que nada tienen que ver con los bienes internos de la comunicación como expresión de un derecho fundamental del ser humano. Como escribió Kapucinski (2002: 36), "en la segunda mitad del siglo XX, especialmente en 
estos últimos años, tras el fin de la guerra fría, con la revolución de la electrónica y de la comunicación, el mundo de los negocios descubre de repente que la verdad no es importante, y que ni siquiera la lucha política es importante: que lo que cuenta, en la información, es el espectáculo. Y una vez que hemos creado la información -espectáculo, podemos vender esa información en cualquiera parte. Cuanto más espectacular es la información, más dinero podemos ganar con ella. De esta manera la información se ha separado de la cultura: ha comenzado fluctuar en el aire; quien tenga dinero pude cogerla, difundirla, y ganar más dinero todavía". Y es que en los medios de comunicación confluyen tanto las exigencias de su configuración empresarial dentro de un mercado muy competitivo, como las exigencias de operar con un bien fundamental para las sociedades y las personas: la difusión de información y otros contenidos. Unas exigencias que a menudo colisionan entre sí, como la historia reciente del Ecuador ha venido demostrando, con prácticas abusivas de algunos grupos económicos, con las que ha querido acabar este Gobierno. Sin embargo, siempre que se regula el mercado de la información, el regulador es objeto de críticas, siendo la acusación de censura la más habitual, cuando lo cierto es que lo que se regula en la mayoría de los casos no es el ejercicio del derecho a la información, sino la actividad empresarial y económica que opera un con servicio y un producto especial: el derecho fundamental a la información, que no es un derecho de las empresas ni de los profesionales de la comunicación, sino un derecho de la sociedad en su conjunto y delegado tácitamente por la sociedad en estos actores del mercado de la información, como señalaba el Tribunal Constitucional español. Así, para asegurar que esa actividad se realice de acuerdo a los bienes internos de la comunicación o, lo que es lo mismo, según los valores constitucionales y universales, se han seguido tradicionalmente dos caminos: el de la regulación (elaboración de normas jurídicas) y el de la autorregulación (elaboración de normas éticas y de deontología profesional por los propios actores de la comunicación: empresas, medios, profesionales y el propio público), al que últimamente se ha unido una tercera práctica: la corregulación, donde se funden normas éticas y jurídicas por la iniciativa gubernamental y de los actores de la comunicación y donde, a nuestro juicio, habría que 
incluir esta Ley Orgánica de Comunicación, pues responde a un clamor popular refrendado por la consulta de 7 de mayo de 2011, en la que los ciudadanos apoyaron masivamente la iniciativa política para eliminar la influencia del poder económico y político sobre los medios de comunicación del Ecuador y mejorar los contenidos de su oferta informativa. Además, la LOC establece la obligación para los medios de expedir códigos deontológicos (artículo 9 LOC), el mecanismo de autorregulación por excelencia de la actividad informativa, señalando las normas deontológicas que deben contener (artículo 10 LOC). Hay que decir, sin embargo, que desde el momento en que se recogen en la ley, estas normas deontológicas se convierten en normas jurídicas $y$, por tanto, de obligado cumplimiento. De hecho, señala la ley que "el incumplimiento de las normas deontológicas establecidas en este artículo podrá ser denunciado por cualquier ciudadano u organización ante la Superintendencia de la Información y Comunicación, la que, luego de comprobar la veracidad de lo denunciado, emitirá una amonestación escrita, siempre que no constituya una infracción que amerite otra sanción o medida administrativa contenida en la ley". Un párrafo que contiene formas de actuar propias de mecanismos de autorregulación (denuncia pública y amonestación), pero que también incluye otras formas propias del procedimiento administrativo (regulación) que, sin embargo, también practican los Consejos Audiovisuales en España, como explicaremos a continuación, un organismo creado por una ley que señala sus competencias, entre ellas también la potestad sancionadora (hay consejos audiovisuales en las Comunidades Autónomas de Andalucía y Cataluña, no a nivel estatal, aunque España es actualmente el único país de la Unión Europea que no cuenta con un Consejo Audiovisual de competencia estatal ${ }^{31}$ ). Porque lo que diferencia a las normas jurídicas de las normas éticas (y las normas de deontología profesional son normas éticas aplicadas a un determinado ámbito profesional), es que las primeras son coactivas,

\footnotetext{
${ }^{31}$ La Ley 7/2010, de 31 de marzo, General de la Comunicación Audiovisual, creó en su Título V el Consejo de Medios Audiovisuales, pero este título fue derogado por la letra g) de la disposición derogatoria de la Ley 3/2013, de 4 de junio, de creación de la Comisión Nacional de los Mercados y la Competencia («B.O.E.» 5 junio).Vigencia: 6 junio 2013.
} 
llegando a aplicarse por la fuerza en caso de incumplimiento. No obstante, normas éticas y jurídicas persiguen los mismos fines: proteger los bienes internos de la comunicación, como derecho protegido constitucionalmente. El Derecho establece un mínimo común denominador que todos los medios y los profesionales deben respetar y cumplir, pero entre ese mínimo garantizado por el Derecho y una comunicación guiada por criterios y principios éticos resta un espacio muy amplio. Y ésta es la tarea de la autorregulación: tratar de cubrir la distancia entre el mínimo regulador del Derecho y el ideal ético exigible en una esfera de la actividad social, propiciando que cada uno asuma su parte correspondiente de responsabilidad (Aznar, 2005: 30). Así, la diferencia principal que hay entre ellas es que en la regulación hay una acción coercitiva y correctora por parte del Estado, y en la autorregulación es la misma sociedad la que pone en marcha mecanismos para orquestar esta actividad; en especial, las sociedades que las ejercen y los ciudadanos afectados por ellos.

Tradicionalmente, los mecanismos de autorregulación más habituales son los códigos deontológicos, los principios editoriales, los libros de estilos, los consejos de medios, el ombudsman, estatutos de redacción, cláusula de conciencia, etc., pero lo característico de la LOC es que los convierte en mecanismos de regulación, pues los establece de forma obligatoria, caso de los códigos deontológicos citados (artículo 9 LOC), de los principios editoriales (artículo 6 LOC), de la cláusula de conciencia -que suele ser recogida en las constituciones y las leyes por sus consecuencias jurídicas, como la indemnización por despido improcedente- (artículo 39 LOC), del defensor de las audiencias (artículo 73 LOC) y de la Superintendencia de Comunicación e Información (artículo 55 LOC) que, aunque es una figura constitucional y que opera también en otros ámbitos, tiene muchas cosas en común con los Consejos Audiovisuales españoles. Se trata del mecanismo creado por esta ley que ha generado mayor polémica, y al que nos referiremos a continuación. 


\section{La Superintendencia de la Información y Comunicación}

La Superintendencia de la Información y Comunicación -y las Superintendencias en general - es un organismo técnico de vigilancia previsto, sin embargo, por el artículo 213 CEc para la intervención y control de todas las actividades económicas, sociales y ambientales prestadas por entidades públicas y privadas, no sólo en el ámbito de la comunicación; cuyos superintendentes son nombrados por el Consejo de Participación Ciudadana y Control Social de una terna enviada por la Presidencia de la República; algo completamente normal dentro de un régimen presidencialista como es el Ecuador, y que además recuerda a la forma de elección de los miembros de los Consejos de Medios Audiovisuales en España, según la mayoría parlamentaria de los partidos en los parlamentos autonómicos $^{32}$, órganos que también ejercen una potestad administrativa que se torna en sancionadora llegado el caso. La Superintendencia de la Información y Comunicación hay que diferenciarla del Consejo de Regulación y Desarrollo de la Información y Comunicación (artículo 47 LOC) que, fundamentalmente, es un órgano de regulación (artículo 49 LOC), integrado por un representante de la Función Ejecutiva, un representante de los Consejos Nacionales de Igualdad, un representante del Consejo de Participación Ciudadana y Control Social, un representante de los Gobiernos Autónomos Descentralizados y un representante del Defensor del Pueblo (artículo 48 LOC); la Superintendencia, por su parte, es un órgano de fiscalización, supervisión y control (artículo 56 LOC), pero que también actúa como nexo con el público y los ciudadanos en general al atender y resolver reclamaciones y denuncias, lo que la asemeja a mecanismos de autorregulación como el

\footnotetext{
${ }^{32} \mathrm{El}$ artículo 5 de la Ley 1/2004, de 17 de diciembre, de Creación del Consejo Audiovisual de Andalucía, señala: "El Consejo Audiovisual de Andalucía estará integrado por once miembros, elegidos por el Parlamento de Andalucía por mayoría de tres quintos de sus miembros, y nombrados por el Consejo de Gobierno". (...) "Los miembros del Consejo Audiovisual de Andalucía serán elegidos entre personas de reconocido prestigio profesional en el ámbito de la comunicación audiovisual, científico, educativo, cultural o social." Una fórmula que, en España, que fomenta la iniciativa parlamentaria en vez de la presidencial, se utiliza para la elección de los órganos de mayor relevancia pública.
} 
ombudsman (defensor del lector o espectador) y, sobre todo, a los Consejos Audiovisuales europeos; ambos forman parte del Sistema de Comunicación Social (artículos 45 y 46 LOC), cuyo objetivo es "lograr el pleno ejercicio de los derechos de la comunicación reconocidos en la Constitución, en esta Ley y en otras normas del ordenamiento jurídico ecuatoriano" (artículo 46 LOC). Pero, como decíamos, la Superintendencia se parece más a los Consejos Audiovisuales europeos. Así, tomaremos como referencia la Ley 1/2004, de 17 de diciembre (artículo 1), que crea el Consejo Audiovisual de Andalucía (España) como "autoridad audiovisual independiente encargada de velar por el respeto de los derechos, libertades y valores constitucionales y estatutarios en el ámbito de los medios audiovisuales en Andalucía y por el cumplimiento de la normativa vigente en materia audiovisual y de publicidad, de acuerdo con los principios de actuación y funciones que establece la presente Ley". Y comparémosla con el artículo 55 LOC: "La Superintendencia de la Información y Comunicación es el organismo técnico de vigilancia, auditoría, intervención y control, con capacidad sancionatoria, de administración desconcentrada, con personalidad jurídica, patrimonio propio y autonomía administrativa, presupuestaria y organizativa; que cuenta con amplias atribuciones para hacer cumplir la normativa de regulación de la Información y Comunicación". En los dos casos, se trata de organismos de derecho público de carácter autónomo, creados por una ley y que actúan con facultades delegadas de la Administración que tiene atribuidas las competencias para regular el mercado de la información dentro de su circunscripción territorial: la Junta de Andalucía, en el ámbito regional de la Comunidad Autónoma Andaluza (España), y el Estado ecuatoriano en el ámbito territorial del Ecuador. Así, el artículo 57 de la LOC, establece expresamente que el procedimiento de actuación de la Superintendencia de la Información y Comunicación será un procedimiento administrativo; y el artículo 12 Ley 1/2004, de 17 de diciembre, otorga al Consejo Audiovisual de Andalucía potestad sancionadora: "El Consejo Audiovisual de Andalucía ejercerá la potestad sancionadora que las leyes reguladoras de la comunicación audiovisual y de la publicidad otorguen a la Administración de la Junta de Andalucía, en lo referente al ámbito de actuación y las funciones del Consejo 
Audiovisual de Andalucía establecidas en la presente Ley, elaborando también las correspondientes propuestas de sanción". Como vemos, se trata, en los dos casos, de una potestad delegada por la Administración competente. Así, en los dos casos nos encontramos en un ámbito de regulación del mercado de la información, lo que se ha convertido en un algo común en muchos países. Y lo que debemos preguntarnos es por qué se convierte en algo necesario regular, en el ámbito administrativo, el ejercicio del derecho a la información, creando, para ello, organismos de control.

\section{E1 ámbito administrativo de la actividad informativa}

¿Por qué es necesario que intervenga la Administración? Pues primero porque la actividad informativa es un servicio público, desde el momento que, por aplicación de un principio básico del Derecho Administrativo como es el principio de territorialidad, el uso del espacio radioeléctrico está sometido a concesión administrativa ("el espacio radioléctrico es un bien de dominio público, cuya administración y aprovechamiento es competencia del Estado central", señala el artículo 105 de la LOC); y segundo, porque los profesionales de la comunicación y, fundamentalmente, los medios, no han sabido ejercer su actividad de acuerdo a los valores jurídicos y éticos que protegen el ejercicio de este derecho fundamental. La primera cuestión nos conecta con la definición que hace la LOC de los medios de carácter nacional, la regulación de la publicidad y la asignación de frecuencias y la protección y estímulo de las producciones audiovisuales ecuatorianas, materias reguladas en los artículos 70 y ss. de la LOC. Así, la regulación de la publicidad en esta ley encuentra su razón de ser en que la publicidad es una forma de comunicación caracterizada por su finalidad comercial, por lo que debe aplicársele el régimen jurídico del derecho a la información, lo que se evidencia en la prohibición de la publicidad engañosa (artículo 94 LOC), que es aquella que por cualquier medio, incluida su forma de presentación, induce o puede inducir a error a su destinatario, modificando su comportamiento económico, y que está conectada con el criterio principal que rige el derecho a comunicar y recibir información, como es la veracidad. Por su parte, los criterios para la asignación (durante un plazo de 15 años, artículo 
116 LOC el mismo que establece el artículo 28 de la Ley 7/2010, de 31 de marzo, General de la Comunicación Audiovisual española) y distribución de frecuencias (33\% para los medios públicos, 33\% para la operación de los medios privados y 34\% para la operación de medios comunitarios) responden a la influencia, también en este ámbito, de uno de los principios fundamentales que vertebran la CEc, como es la participación ciudadana en todas las actividades del Estado (artículos 56, 57, 61, 95, 96, 102, 103, 104, 105, 204, 207, 208 CEc). Y el fomento progresivo de la producción nacional y producción nacional independiente (que deberá ser del $20 \%$ en el primer año, el $40 \%$ el segundo y el $60 \%$ el tercero, para las producciones audiovisuales; 25\%, 35\% y 50\%, respectivamente para los contenidos musicales, según la Disposición Transitoria Sexta; siempre para medios de comunicación audiovisual cuya señal es de origen nacional, según el artículo 97 LOC), y estaciones de radiodifusión sonora que no tengan carácter telemático o especializado (artículo 103 LOC) es algo lógico desde la perspectiva nacional, y común en la normativa de la mayoría de los países, que la protegen en mayor o menor medida (en España tienen competencias en esta materia tanto el Estado, como las Comunidades Autónomas y las Entidades Locales).

La segunda cuestión -nuestra incapacidad, al parecer, para ejercer el derecho a la información de acuerdo a los valores internos de la comunicación- nos lleva a hablar, para concluir, de la lamentable desvirtuación de la actividad informativa en la mayoría de los países, ejercida por empresas que buscan la obtención del máximo beneficio y no los objetivos sociales y culturales que se le presuponen a la misma. Estos factores, a los que Aznar (2005) se refiere como "problemas éticos derivados de la estructura empresarial de los medios", son la competencia, la publicidad, la propiedad y la concentración empresarial, que se convierten en un problema cuando la competencia de entre las empresas no promueve los valores propios de la comunicación.

Muy al contrario, las empresas trasladan sus exigencias competitivas a los medios, condicionando los contenidos y mensajes que difunden, y el lugar que deberían ocupar los criterios y valores éticos 
de la comunicación lo ocupan los criterios y requisitos del marketing, como han destacado Day (1991), Kovach y Rosenstiel (2003), Riviére (2003) o Lipovetsky (1994), quien alertaba de los shocks informativos y la puesta en escena emocional.

No vamos a ahondar aquí más en estas cuestiones de sobra conocidas, pero nos gustaría concluir este artículo con una reflexión de Desantes -Guanter (2004: 85), que debería inspirar cualquier regulación de la actividad informativa: "La propiedad es una institución que confiere unos derechos o unas facultades erga omnes, excluyentes, frente a todos. La información, como fenómeno natural y como institución jurídica, es algo que tan sólo tiene sentido si se produce propter omnes, para todos, a disposición de todos, en favor de todos y a la vista de todos".

\section{Conclusiones}

Lo primero que llama la atención de la LOC es su ámbito: la comunicación social, definida como un servicio público, realizado por medios de comunicación social. En este sentido, resulta esencial la "publicatio", que es la declaración que hace la LOC de la comunicación social como servicio público. Cuando una actividad es declarada como servicio público, se convierte también en una actividad administrativa, lo que no significa que el Estado preste el servicio de manera monopolística, algo expresamente prohibido por la CEc y por la propia LOC, que permite prestar este servicio en régimen de concurrencia de empresas públicas, privadas y comunitarias. Un debate serio sobre los límites de la libertad de expresión debe partir de su configuración legal. El origen del derecho a la información es el del resto de los derechos fundamentales, lo que determina su configuración legal.

La CEc recoge un haz de derechos agrupados en un concepto complejo: el derecho a la información. Para comprender la amplitud de este derecho, acudimos a la jurisprudencia del Tribunal Constitucional, para quien las libertades agrupadas por el derecho a la información y la libertad de expresión no sólo son derechos fundamentales de cada persona, sino que también significan el reconocimiento y garantía de la opinión pública libre, que es una 
institución ligada de manera imprescindible al pluralismo político, valor esencial del Estado democrático.

La distinción entre las libertades de expresión e información se basa en el distinto alcance y protección dada a una y a otra a la hora de resolver el conflicto entre el derecho a la información y los derechos de la personalidad, por encima de todos, el derecho al honor. Desde sus primeras sentencias, el TC afirma el carácter institucional del derecho a la información, su función pública, que no es otra que el mantenimiento de una comunicación pública libre, distinguiendo entre la libertad de información -en la que opera siempre el requisito interno de la veracidad- y la libertad de expresión, que es más amplia. En el primer caso, se exige siempre un deber de diligencia profesional; la información veraz sería la información verdadera, entendiendo por tal la debidamente contrastada. En el segundo, los límites se encontrarían en la relevancia pública de la información y en el honor de la persona que pueda resultar afectada; no pudiendo confundirse la relevancia pública con el carácter noticioso del hecho de que se informa, cuestión que tampoco puede quedar al arbitrio del medio de comunicación.

Por lo demás, la libertad de expresión se evalúa sobre todo como libertad de crítica, tolerada cuando se proyecta sobre personajes públicos hasta el punto de que sólo quedan excluidas las expresiones injuriosas, ya que no se reconoce un pretendido derecho al insulto. Pensamos que estos criterios jurídicos deben servirnos de guía para interpretar figuras como el linchamiento mediático y la aplicación de la LOC. Uno de los mecanismos creados por esta ley y que han generado mayor polémica, ha sido la Superintendencia de la Información y Comunicación, un organismo técnico de vigilancia previsto, sin embargo, por el artículo 213 CEc para la intervención y control de todas las actividades económicas, sociales y ambientales prestadas por entidades públicas y privadas, no sólo en el ámbito de la comunicación.

La Superintendencia de la Información y Comunicación, es un órgano de fiscalización, supervisión y control, pero que también actúa como nexo con el público y los ciudadanos en general al 
atender y resolver reclamaciones y denuncias, lo que la asemeja a mecanismos de autorregulación como el ombudsman (defensor del lector o espectador) y, sobre todo, a los Consejos Audiovisuales europeos. En los dos casos, se trata de organismos de derecho público de carácter autónomo, creados por una ley y que actúan con facultades delegadas de la Administración que tiene atribuidas las competencias para regular el mercado de la información dentro de su circunscripción territorial.

La intervención de la Administración resulta necesaria, primero, porque la actividad informativa es un servicio público, desde el momento que, por aplicación del principio de territorialidad, el uso del espacio radioeléctrico está sometido a concesión administrativa; y, segundo, porque los profesionales de la comunicación y, fundamentalmente, los medios, no han sabido ejercer su actividad de acuerdo a los valores jurídicos y éticos que protegen el ejercicio de este derecho fundamental. Pero la información, como fenómeno natural y como institución jurídica, es algo que tan sólo tiene sentido si se produce propter omnes, para todos, a disposición de todos, en favor de todos y a la vista de todos.

\section{Referencias bibliográficas}

Ariño Ortiz, Gaspar (1981). “La empresa pública”. En Garrido Falla, Fernando (Ed.). El modelo económico en la Constitución Española, vol. II. Madrid: Instituto de Estudios Económicos.

Aznar, Hugo (2005). Comunicación responsable. Barcelona: Arial.

Azurmendi, Ana (2001). Derecho de la información: guia jurídica para profesionales de la comunicación <segunda edición>. Barañáin: EUNSA.

Desantes -Guanter, José María (1974). La información como derecho. Madrid: Editora Nacional.

- (2004). Derecho a la información. Valencia: Fundación Coso.

Díaz Arias, Rafael (2000). La libertad de programación en radiodifusión.

Un desarrollo del art. 20 de la Constitución Española. Madrid: Universidad Complutense. 
Fernández González, José Francisco (1995). La intervención del municipio en la actividad económica. Los titulos que la legitiman. Gijón: Cívitas.

Garrido Falla, Fernando (1981). El modelo económico en la Constitución y la revisión del concepto de servicio público. Revista Española de Derecho Administrativo, 29, 225 - 238.

Kapuscinski, Ryszard (2002). Los cínicos no sirven para este oficio. Barcelona: Anagrama.

Kovach, Bill y Rosenstiel, Tom (2003). Los elementos del periodismo. Madrid: Aguilar.

Llamas Pombo, Eugenio (1997). Libertad de expresión. Estudio jurisprudencial. Madrid: Trivium.

López Pellicer, José Antonio (1973). Servicio público municipal y actividades particulares de interés público. Revista de Estudios de la Vida Local, 178, 259 - 306.

Rodríguez Bereijo, Álvaro (1997). La libertad de información en la jurisprudencia constitucional. Del periódico a la Sociedad de la Información, 2, $71-84$.

Riviere, Margarita (2003). El malentendido: cómo nos educan los medios de comunicación. Barcelona: Icaria.

Sala Arquer, José Manuel (1992). Huida al Derecho Privado y huida del Derecho. Revista Española de Derecho Administrativo, 75, 399 - 416.

Soriano García, José Eugenio (1993). Desregulación, privatización y Derecho administrativo. Bolonia: Real Colegio de España.

Terrou, Fernand y Solal, Lucien (1952). El Derecho de la Información. París: UNESCO.

Truyol y Serra, Antonio (1968). Los derechos bumanos. Tecnos: Madrid. 



\title{
El periodismo ecuatoriano en entredicho. Descenso de credibilidad y nuevas perspectivas comunicacionales
}

\author{
Daniel Barredo Ibáñez. Universidad de las Américas, Ecuador \\ José María Pérez Zúniga. Universidad de Granada, España \\ Rocio Vivas. Universidad Central del Ecuador, Ecuador \\ Montserrat Fernández: Universidad Central del Ecuador, Ecuador
}

\section{Introducción}

L

A CRISIS del periodismo parece un hecho sintomático de las sociedades contemporáneas, como ya describimos en algunos trabajos anteriores (Barredo, 2013a; 2013b). Son muchos los factores que apuntalan un descreimiento cada vez más generalizado de los contenidos que producen los medios; el Grupo Infotendencias (2012: 22) señala, por ejemplo, el impacto de la crisis económica y las "dificultades estructurales" como causas que socavan la reputación de quienes, hasta hace unos años, monopolizaban la gestión de la información. En ese sentido, el uso cada vez más generalizado de las TICs ofrece a los ciudadanos la posibilidad de interactuar con las instituciones, sin una necesidad aguda de acudir a la mediación de los medios; han aparecido, bajo la premisa de la autoproducción comunicativa, el periodismo 
participante (Bowman y Willis, 2003) ${ }^{33}$, y el periodismo ciudadano (García de Torres, Yerzers'ka, Rojano et al., 2009) ${ }^{34}$. La eclosión de plataformas informativas ciudadanas, de contenidos originados lejos de las redacciones profesionales, y la influencia de Internet sobre las rutinas interpersonales, son algunos de los factores que están reconfigurando el espacio simbólico:

"The new, symbolic space includes a dramatic increase of hidden marketing tactics, but it is also the emergence of a form of collective intelligence $<\ldots>$ leading to a deeper fragmentation, paradoxically, to a deeper connection between the users or devisers $<\ldots>$ ". 35

(Barredo, Oller y Buenaventura, 2013: 85).

En el caso ecuatoriano, estos cambios se producen a una velocidad más reducida que en los países occidentales, debido a las bajas tasas de conexión que registra el país andino: unos tres de cada diez habitantes, según explica Villacís (s.f.) tenían conexión a Internet en 2010. El crecimiento, sin embargo, parece constante: en 2013, tres años después, cuatro de cada diez ecuatorianos navegaban en el ciberespacio (Ministerio de Telecomunicaciones, 2014, 19 de mayo). Sin embargo, hay otros factores que intervienen al margen de la falta de infraestructuras en algunas zonas del país, o la carestía de los equipos de conexión. Dentro de esas problemáticas, por ejemplo, destaca el hecho de que según cifras oficiales alrededor del 20,8\% de la población del Ecuador, en 2013, fuera clasificada como analfabeta digital (INEC, s.f.: 26). En líneas generales, según hemos percibido en algunas investigaciones complementarias (Barredo, 2014; Barredo y Silva, 2014), en 2014 predominan en el contexto mediático

\footnotetext{
${ }^{33}$ Se describe como "el acto de un ciudadano, o grupo de ciudadanos, jugando un rol activo en el proceso de recoger, cubrir, analizar y diseminar noticias e información" (Bowman y Willis, 2003: 9) [traducción propia].

${ }^{34} \mathrm{El}$ periodismo ciudadano ha sido definido como "<...> práctica no profesional que se sitúa en la periferia de los medios" (Barredo, 2013a: 104). 35 "El nuevo espacio simbólico incluye un notable incremento de las tácticas del marketing encubierto, pero también representa la emergencia de una forma de inteligencia colectiva $<\ldots>$ la cual conlleva una mayor fragmentación que, paradójicamente, promueve una mayor interconexión entre los usuarios o ideantes $<\ldots>$ " [traducción propia].
} 
ecuatoriano sobre todo dos grupos de usuarios de los medios de comunicación:

a) Quienes carecen de cultura digital o dispositivos y, por tanto, centran su interés en los canales mediáticos convencionales, sea televisión, prensa o radio.

b) Quienes utilizan dispositivos de conexión a Internet -tanto computadores como teléfonos inteligentes- y optimizan sus posibilidades de interacción.

Ambos tipos (el primero: mayoritario; el segundo: minoritario, pero creciente), asisten a la reinterpretación paulatina del concepto de comunicación que se está dando desde instancias gubernamentales. A modo de breve síntesis, estos son los hechos que deben tenerse en cuenta para tener una mayor perspectiva de los cambios registrados en el paradigma comunicativo del Ecuador:

1) La poderosa influencia del Estado ecuatoriano sobre los medios, habida tanto por el fuerte impacto estatal en la publicidad (Checa Godoy, 2012), como por la incautación pública de canales privados o la inauguración de medios estatales a partir de la llegada al poder de Rafael Correa (Punín, 2010).

2) La presencia de una sociedad con escasa participación en los medios de comunicación (Ayala y Calvache, 2009) y en la arena política (Coronel y Mier, 2011).

3) La escasa credibilidad de los medios de comunicación, vinculados a su anterior pertenencia a corporaciones (Checa Godoy, 2012), o por el sometimiento profesional a los intereses de las organizaciones informativas (Abad, 2010).

Dentro de este último rasgo -el de la escasa credibilidad- estudios previos como el de Vásconez (2011) o Rodrigo (2012) apuntalan la caída progresiva que señala el distanciamiento entre la valoración social y los medios de comunicación ecuatorianos. Pero la principal innovación sucedió en 2013, cuando se aprobó la Ley Orgánica de Comunicación [LOC], un instrumento legal que comenzó a gestarse en 2009, coincidiendo con la oleada reguladora de la comunicación 
surgida en la región latinoamericana (Ávila, 2013). En 2013, para algunos autores, se produjo "el afianzamiento del modelo autoritario - competitivo del gobierno de Rafael Correa" (Basabe -Serrano y Martínez, 2014: 146). Otros autores, sin embargo, opinan que la LOC fue una respuesta del Estado ecuatoriano para devolver a lo público lo que estaba en manos privadas:

"Hasta este gobierno, la histórica privatización del espacio mediático se encontraba completamente naturalizada pues los ecuatorianos nunca nos habíamos preguntado si era legítimo o si era democrático- que los propietarios de medios utilicen el tiempo de aire y las páginas de diarios y revistas según sus conveniencias e intereses particulares. Tampoco se nos ocurrió impugnar las relaciones, con frecuencia incestuosas y promiscuas, entre las empresas de comunicación y el capital financiero"

(Ramos, 2012: 69).

Recordemos que, hasta la llegada al poder de Rafael Correa en 2007, Ecuador no solo no tenía una televisión del Estado, sino que la inmensa de los medios pertenecían a corporaciones financieras, como explica Checa - Godoy (2012). Lo cierto es que como resalta el Latinobarómetro (2013: 6), entre 1995 y 2013, se ha producido un aumento de "más de 10 puntos" de apoyo a la democracia en la República andina, e incluso la misma fuente, en su página 9, subraya el "impacto positivo" del triunfo electoral de Rafael Correa. Y en esos dieciocho años resumidos, hasta un 59\% de la población ecuatoriana se encuentra satisfecha con la democracia, siendo Ecuador el segundo país latinoamericano en nivel de satisfacción, solo por detrás de Uruguay (Latinobarómetro, 2013: 36). En términos generales, este clima de confianza en las acciones gubernamentales ha sido posible, en parte, gracias a un incentivo progresivo de una comunicación más responsable, en que se promueve una mayor integración de las distintas naciones que componen al Ecuador ${ }^{36}$. El estímulo de esos vectores aparece entre los objetivos esenciales organizados por el gobierno ecuatoriano en el llamado Plan Nacional del Buen Vivir (Senplades, 2013). En su

${ }^{36}$ Por ejemplo, en los artículos 35 y 36 de la citada LOC. 
objetivo 1, por ejemplo, se establece consolidar el Estado democrático y la construcción del poder popular, mientras que el objetivo 4 apuesta por fortalecer las capacidades y potencialidades de la ciudadania; ambos objetivos -aunque podríamos haber citado alguno más- están íntimamente relacionados con el desarrollo de una comunicación plural y crítica. Quizá por la importancia que tiene la comunicación en el proceso revolucionario ecuatoriano, el presidente Correa suele reivindicar constantemente una mayor regulación de ese ámbito fundamental de la democracia:

“< $<>$ se denunció el ataque brutal que tiene Ecuador de la prensa corrupta, un poder tan grande, tan ilegítimo que está atentando contra la democracia. Privatizaron la libertad de expresión, resulta que la libertad de expresión es solo de los medios de comunicación, éste es un derecho de todos los ciudadanos. $<\ldots>$ Mi deber principal más que dejar carreteras, escuelas, hospitales, es dejar un país que viva permanentemente en la verdad, combatiendo a esta prensa corrupta"

(ElComercio.com, 2011, 10 de diciembre).

Este tipo de declaraciones suele ser habitual dentro de los Enlaces Ciudadanos, unos espacios comunicacionales de la Presidencia de la República, de unas tres horas de duración, que se emiten los sábados en las radios y en las cadenas de televisión del Estado; LaRepublica.pe (2011, 31 de julio) asegura que son "monólogos", e incluso autores como Basabe-Serrano y Martínez (2014) los han catalogado dentro de las herramientas de persecución utilizadas por el Estado. Pero este formato, que tiene un promedio de ochocientos mil espectadores por emisión (Andes, 2014, 28 de noviembre), también sirve para rendir cuentas y activar medidas de transparencia activa, con las cuales semana a semana la Presidencia de la República contacta a la ciudadanía sin necesidad de filtrar sus mensajes a través de los profesionales de la información. Esta posibilidad de dirigirse abiertamente a la nación, ayuda a comunicar los avances que se van generando en los diversos ámbitos representativos; no olvidemos que Ecuador tiene un grave problema al describir los hallazgos que se dan en ámbitos como el científico, según demostró Barredo 
(2014) al comparar la gestión comunicacional de dos instituciones representativas del país. Por otro lado, Ramos (2012: 66) ha advertido la presencia de una "cruzada mediática de corte corporativo" en muchos de los países latinoamericanos -entre ellos, obviamente, Ecuador- que emprenden reformas estructurales de corte progresista; desde los Enlaces ciudadanos, según esa perspectiva, Rafael Correa replicaría a todos aquellos medios que intentan desestabilizar a la Revolución Ciudadana mediante campañas financiadas por los rivales políticos. El propio presidente recalca este propósito a menudo; veamos las siguientes declaraciones (el subrayado es nuestro):

"En diario La Hora redactan: "Cada candidato se refuerza a su modo" donde dicen que hay una concentración de apoyo para el uno y ayuda para otro. Ponen que es ayuda de otras provincias para el candidato de la revolución ciudadana, aquí no hará nada el CNE. Es una prensa deshonesta y corrupta. Mientras haya esta clase de prensa cada semana habrá enlace ciudadano"

(ElComercio.com, s. f.). Esta agitación que promueve el presidente configura, para Ramos (2013: 76), un “activismo estatal", gracias al cual el Estado ecuatoriano recupera el protagonismo perdido en las décadas anteriores. Quizá uno de los mayores problemas del novedoso ámbito regulatorio comunicacional ecuatoriano es la presencia de lagunas y deficiencias, motivadas - desde nuestro punto de vistapor la complejidad y la ambición de las propuestas. Hay muchos aspectos "de carácter superficial", en opinión de Ramos y Gómez (2014: 309), que esquivan una democratización real del paradigma comunicacional del Ecuador. Pero resultan indudables los esfuerzos del gobierno de este país por promover una comunicación no necesariamente ligada a las organizaciones mediáticas convencionales; se busca, sobre todo, la organización social alrededor de la comunicación comunitaria, como también la normalización de aspectos -como la "prohibición de censura previa" (art. 18) o el "derecho a la réplica" (art. 24) propuestos por la LOC- que entran en conflicto con el todo vale habitual del neoliberalismo informativo. $\mathrm{Y}$ para viabilizar estos impulsos transformadores, se crearon tanto el 
Consejo de Regulación y Desarrollo de la Información y Comunicación [CORDICOM], como la Superintendencia de la Información y Comunicación [SUPERCOM], organismos encargados de vigilar y asegurar el cumplimiento de la LOC. Una de las mayores críticas que se le plantea al sistema de medios reconfigurado por los gobiernos de Correa, es la presencia abrumadora de "actores gubernamentales" (Ramos y Gómez, 2014: 307) encargados de abordar unos ámbitos tan sensibles, en detrimento de actores procedentes de esferas como la académica, la profesional o la civil. En cualquier caso, consideramos que el debate descrito sucintamente en las páginas anteriores está todavía en proceso de conclusión, por lo que resulta complicado definir un semblante exacto. Sin embargo, al calor de unas reformas históricas que cristalizaron con la entrada en vigor de la LOC en 2013, creemos que resulta pertinente evaluar las percepciones de dos grupos de ciudadanos ecuatorianos sobre la credibilidad de los medios de comunicación, así como anotar los posibles factores (educativos o etarios) que pueden influir en el desarrollo de esos imaginarios. Son los anteriores los objetivos principales alrededor de los cuales hemos trazado este proyecto. Los resultados, en nuestra opinión, permitirán observar de manera exploratoria hasta qué punto se están incentivando las capacidades de la ciudadanía, es decir, algunas de las pautas esenciales contenidas en el Plan Nacional del Buen Vivir.

\section{Metodología}

Se ha propuesto un método exploratorio, con un enfoque basado en una técnica cuantitativa tan empleada en las Ciencias Sociales, como explica Ander-Egg (1993), como es la encuesta. Las 20 preguntas que integraban el cuestionario estaban divididas en tres bloques:

\section{Fig. 1 Bloques temáticos del cuestionario y sus objetivos fundamentales}

Contextualización

- Variables vinculadas a la caracterización del encuestado
Perfiles de uso

-Variables que catalogaban los perfiles de uso de Internet o de las redes sociales
Proyecto experimental

- Variables que examinaban las percepciones íntimas de los encuestados 
A través de estos bloques, buscábamos tanto clasificar aspectos socioculturales de los encuestados, como sus perfiles de uso de las redes sociales o de Internet; en las páginas siguientes se ofrecerá únicamente un extracto de dicha catalogación. Pero quizá la particularidad más interesante de la encuesta fue un experimento trazado a partir de las experiencias demoscópicas de Noelle Neumann (1995) y replicadas en algunos trabajos posteriores (Barredo, 2011; 2013c). Este experimento consistió en confrontar a los encuestados con un diálogo entre dos contertulios; al terminar dicho debate, las personas que integraron la muestra tenían que decantarse por una u otra opción. Por último, se escogió un muestreo no probabilístico, aleatorio y por cuotas. En concreto, nos centramos en dos entornos urbanos muy representativos del Ecuador: Quito, capital del país, radicada en Pichincha, donde se encuentra el mayor número de personas que empleaban computador y teléfonos celulares en 2013 (INEC, s.f.). Y Riobamba, capital de Chimborazo, la décima provincia del Ecuador en el uso de computadores y la última en el número de teléfonos celulares activados, según la misma fuente. La información correspondiente a Riobamba fue levantada durante el mes de noviembre de 2013 con la colaboración del Grupo de Alto Rendimiento de la Escuela Superior Politécnica de Chimborazo; la de Quito, en cambio, fue tomada entre los meses de marzo y junio de 2014 con la ayuda de varios cursos de estudiantes de la Facultad de Comunicación de la Universidad Central del Ecuador. El principal problema de los proyectos no financiados - como el presente, el cual únicamente incluyó los recursos económicos de los propios investigadores- es tener que enfrentar determinados desafíos, como la falta de entrenamiento de los encuestadores, la falta de expectativa o interés por el proyecto, etcétera. En ese sentido, tras tomar las muestras solicitadas, percibimos algunos problemas vinculados a la inexperiencia de los encuestadores, y puesto que el muestreo por cuotas "no contempla la revisita para solucionar el problema de las ausencias" (Núñez, 2005: 228), observamos una descompensación parcial de las muestras, lo que menoscaba la equivalencia exigida de antemano. En cualquier caso, advertimos que los resultados que se ofrecerán en las páginas siguientes no pueden generalizarse, algo 
habitual en los muestreos no probabilísticos (Casal y Mateu, 2003), aunque sin embargo pueden ofrecer algunas sugerencias sobre el estado en que se encuentra el objeto de estudio analizado.

\subsection{Descripción de la muestra}

En Riobamba se consiguieron 547 opiniones; en Quito, por el contrario, se consolidaron 526 opiniones de calidad, es decir, sin errores de escritura o datos repetidos o faltantes:

\begin{tabular}{|c|c|c|c|c|}
\hline Variable & Riobamba & $\%$ & Quito & $\%$ \\
\hline Sexo & 547 & 100 & 526 & 100 \\
\hline Hombres & 277 & 50,6 & 237 & 45,1 \\
\hline Mujeres & 270 & 49,4 & 289 & 54,9 \\
\hline Educación & 547 & 100 & 526 & 100 \\
\hline Escuela & 113 & 20,7 & 110 & 20,9 \\
\hline Secundaria & 251 & 45,9 & 196 & 37,3 \\
\hline $\begin{array}{l}\text { Licenciatura / } \\
\text { Ingeniería }\end{array}$ & 130 & 23,9 & 153 & 29,1 \\
\hline Maestría & 27 & 4,9 & 18 & 3,4 \\
\hline $\mathrm{PhD}$ & 2 & 0,4 & 0 & 0 \\
\hline Ninguno & 7 & 1,3 & 38 & 7,2 \\
\hline Otros & 17 & 3,1 & 11 & 2,1 \\
\hline No registrados & 0 & 0 & 0 & 0 \\
\hline Residencia & 547 & 100 & 526 & 100 \\
\hline $\begin{array}{c}\text { En la capital o en la } \\
\text { provincia }\end{array}$ & 515 & 94,1 & 515 & 97,9 \\
\hline $\begin{array}{c}\text { Fuera de la } \\
\text { provincia, pero en } \\
\text { Ecuador }\end{array}$ & 27 & 4,9 & 11 & 2,1 \\
\hline Fuera del Ecuador & 5 & 0,9 & 0 & 0 \\
\hline No registrado & 0 & 0 & 0 & 0 \\
\hline Edad & 547 & 100 & 526 & 100 \\
\hline $5-20$ años & 108 & 19,7 & 104 & 19,8 \\
\hline $21-35$ años & 107 & 19,6 & 135 & 25,7 \\
\hline $36-50$ años & 114 & 20,8 & 93 & 17,7 \\
\hline $51-65$ años & 108 & 19,7 & 103 & 19,6 \\
\hline $66-80$ años & 110 & 20,1 & 91 & 17,3 \\
\hline No registrados & 0 & 0 & 0 & 0 \\
\hline
\end{tabular}

Según puede contemplarse en las columnas de la figura anterior, se ha demandado una gran equivalencia entre las dos muestras 
recabadas en una ciudad y otra, aunque los errores y la precisión y estabilidad exigida a los datos, conllevan una varianza de hasta nueves puntos porcentuales entre algunos ítems.

\section{Resultados}

En las zonas urbanas del Ecuador, en 2013, el 47,6\% de las personas se conectaron a Internet, de los cuales el 64\% lo hacían a diario (INEC, s.f.: 14 - 18). En Riobamba, el 69,1\% (n=378) de los encuestados reconocía que se había conectado alguna vez a Internet, de los cuales el 65,6\% $(n=248)$ lo hacía prácticamente a diario; $y$, en ese sentido, el 90,5\% $(n=342)$ de las personas que se conectaban a Internet afirmaban que la red era importante o más o menos importante en relación con sus vidas. En Quito, el 89,7\% ( $n=472)$ de las personas encuestadas reconocían que se conectaban a Internet, de los cuales el 49,8\% ( $\mathrm{n}=262)$ lo hacía prácticamente a diario; asimismo, el $72,2 \% \quad(n=380)$ aseguraba que la red era importante o más o menos importante en relación con sus vidas. Pero a pesar de las diferencias en cuanto al uso de las conexiones a Internet, observamos una sorprendente homogeneidad entre las opiniones de las dos muestrasdentro del experimento que planteamos para averiguar las percepciones íntimas sobre la credibilidad de los medios:

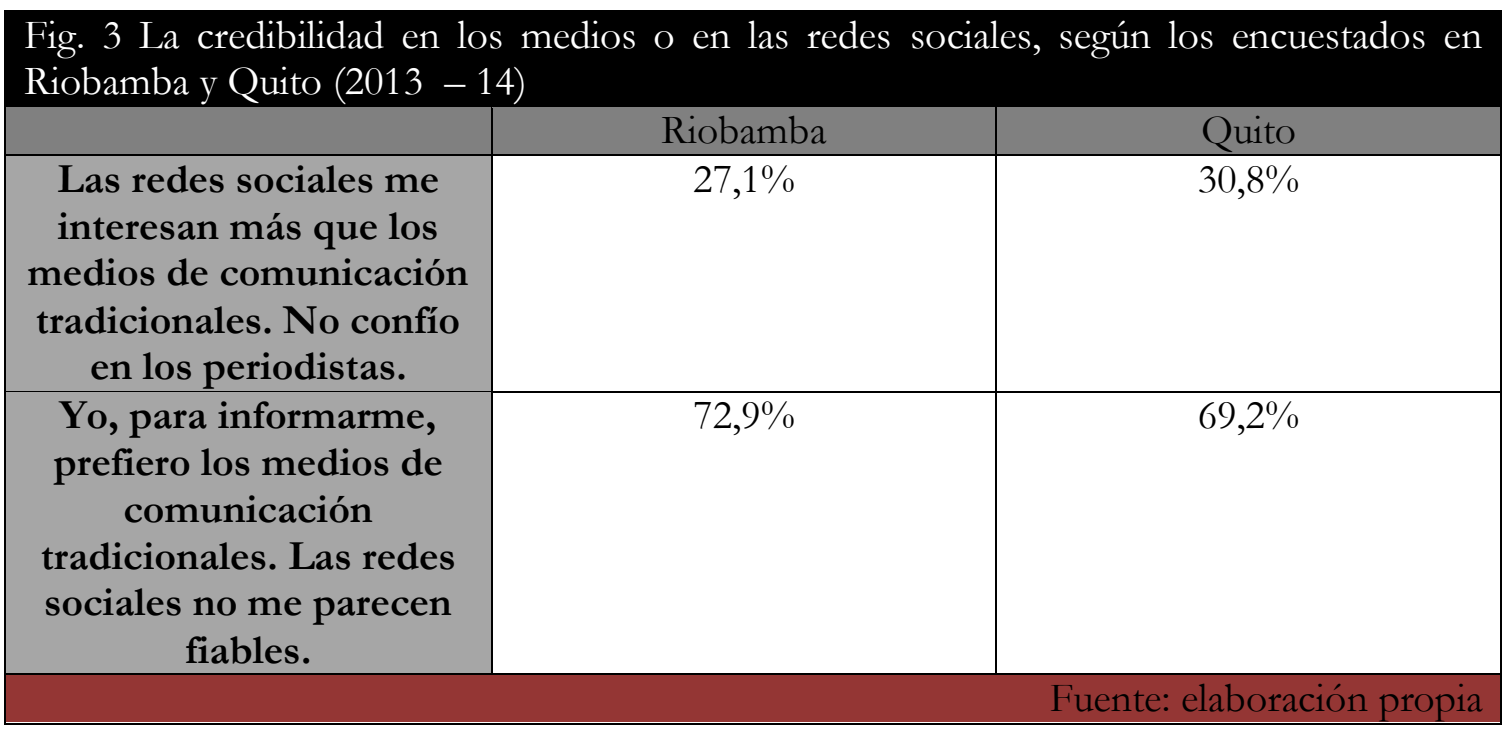

Alrededor de un tercio de las personas consultadas, según muestra la figura 3, preferían acudir a las redes sociales para informarse, tanto 
en Quito, como en Riobamba. En otro estudio a nivel nacional se determinó que solo el $55 \%$ de los ecuatorianos mantenía su confianza en los medios de comunicación (Andes, 2014, 29 de septiembre). Al examinar a las personas que marcaron la opción favorable a las redes sociales, anotamos la importancia de un importante factor como la edad de los encuestados:

Fig. 4 La credibilidad (en \%) en las redes sociales por estratos etarios, según los encuestados en Riobamba y Quito (2013 - 14)

Las redes sociales me interesan más que los medios de comunicación tradicionales.

No confío en de los periodistas.

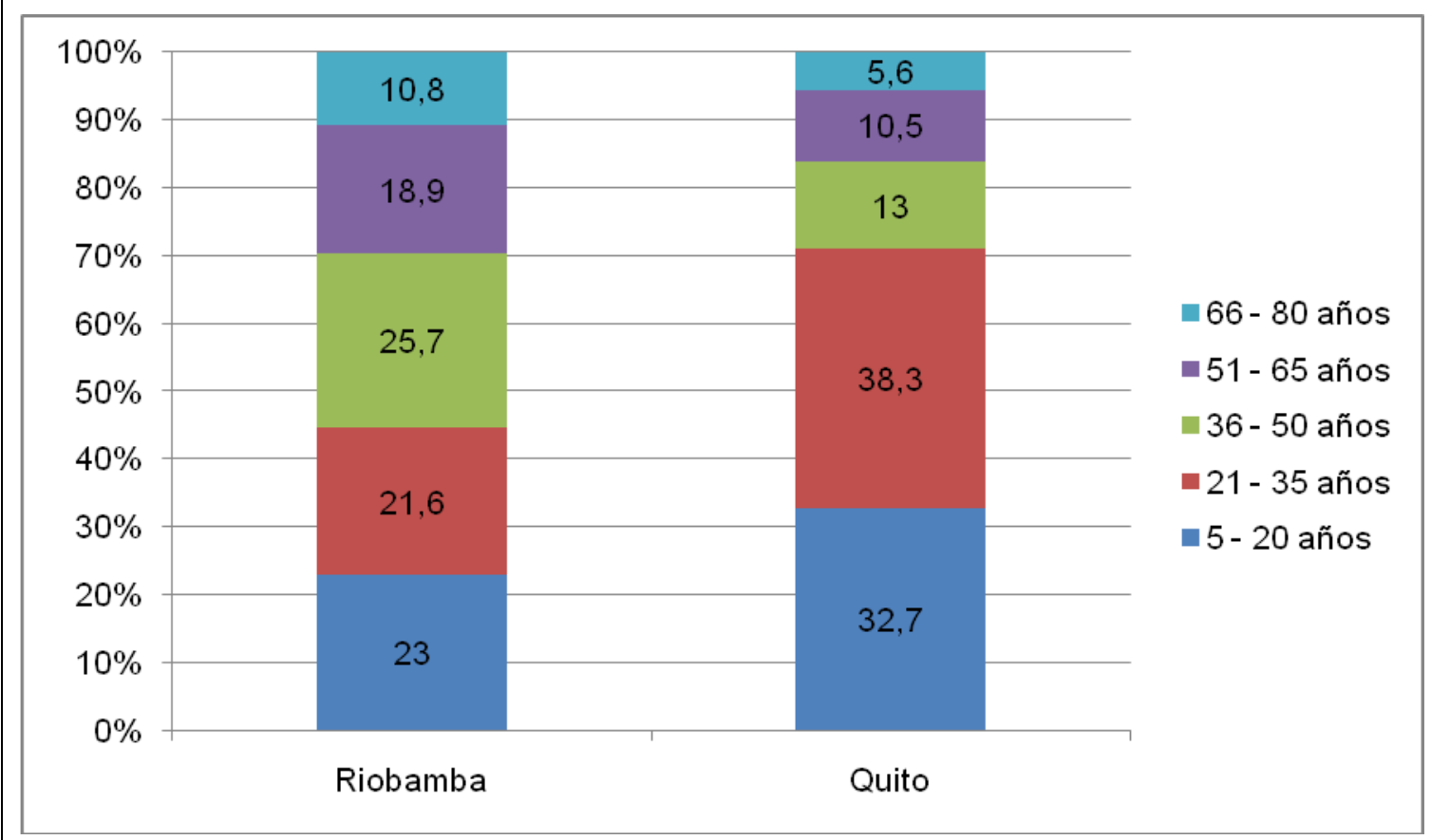

Fuente: elaboración propia

Los mayores porcentajes -más pronunciados en el caso de Quitose registraron en esos estratos poblacionales que, por cuestiones de edad, tenían un mayor manejo de la conexión a la red. Pero también encontramos que un estrato adaptado a las rutinas del ciberespacio las personas que contaban entre 36 y 50 años-, en el caso de Riobamba era el que menos confiaba en los medios de comunicación. 
También deseábamos observar si la falta de confianza en los medios de comunicación estaba vinculado al nivel de estudios de los encuestados:

Si se observa la figura anterior, la mayor credibilidad otorgada a las redes sociales frente a los medios de comunicación aparecía en personas que tenían estudios de secundaria o licenciatura, dos de los principales estratos educativos del Ecuador.

Fig. 5 La credibilidad (en \%) en las redes sociales por estratos educativos, según los encuestados en Riobamba y Quito (2013 - 14)

Las redes sociales me interesan más que los medios de comunicación tradicionales.

No confío en de los periodistas.

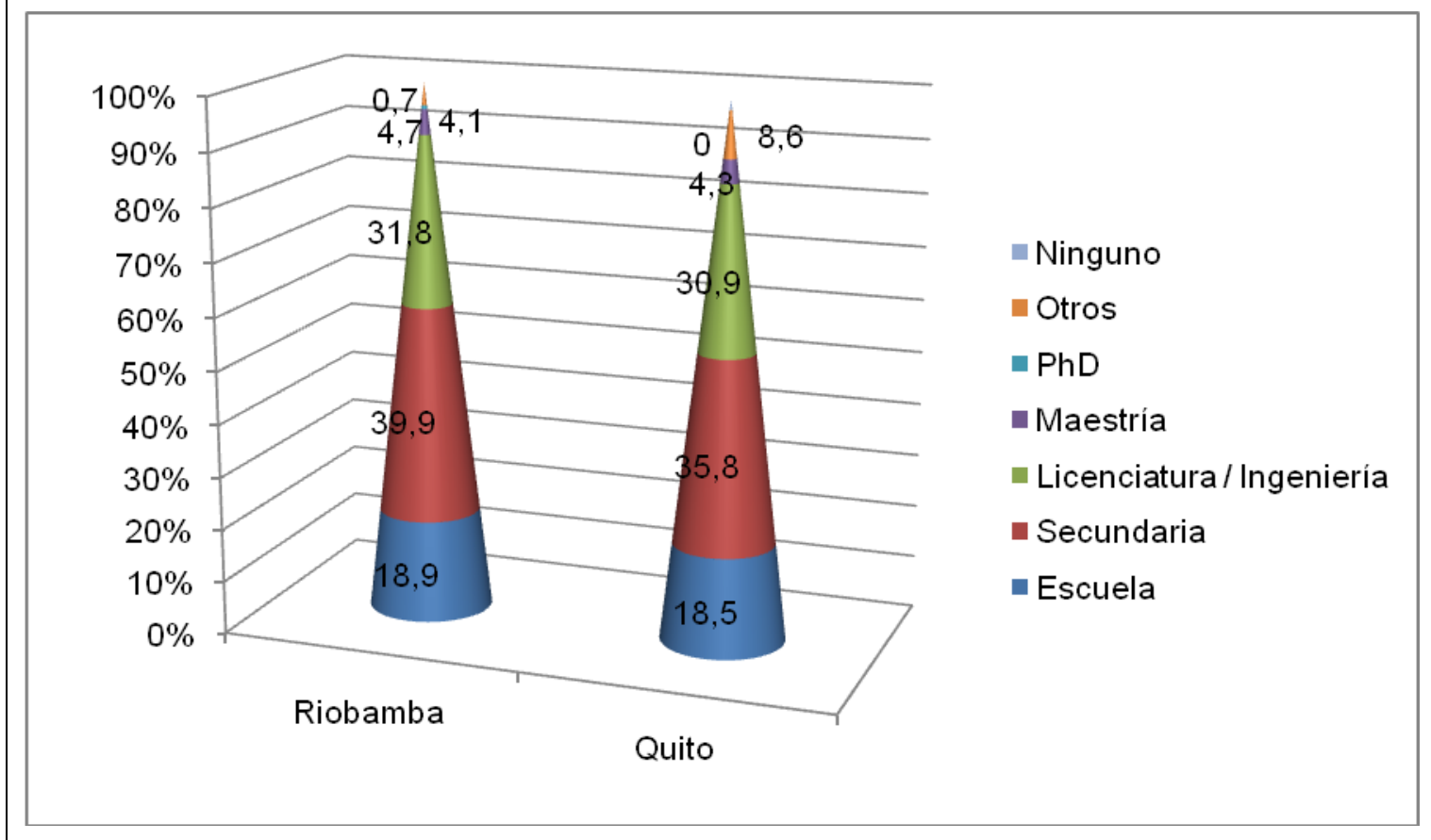

Fuente: elaboración propia

Pero a pesar de que un tercio de los ciudadanos otorgaban una mayor credibilidad a las redes sociales, en Riobamba, el 60\% $(n=328)$ de los encuestados reconocía que se había conectado alguna vez a las redes, de los cuales el 53\% ( $n=174)$ lo hacía prácticamente a diario; y, en ese sentido, el $81,4 \%(n=267)$ de las personas que se conectaban a las redes sociales, afirmaban que éstas eran importantes o más o menos importantes en relación con sus 
vidas. En Quito, por su parte, el 80\% (n=421) de los encuestados aseguraron que se habían conectado alguna vez a las redes sociales, de los cuales el 37,7\% $(\mathrm{n}=343)$ lo hacía prácticamente a diario; unas seis de cada diez personas que se conectaban a las redes -el 58\% $(n=305)$ - afirmaban que las redes eran importantes o más o menos importantes en relación con sus vidas.

Si atendemos al consumo frecuente o muy frecuente de los medios de comunicación en las localidades estudiadas, anotamos unas coincidencias estructurales muy significativas, dentro de las cuales en primer lugar se encontraban los medios nacionales no digitales, seguidos por los medios locales no digitales:

Fig. 6 Consumo frecuente o muy frecuente (en \%) de medios, según los encuestados en Riobamba y Quito (2013 - 14)

Blogs, foros y otros portales web

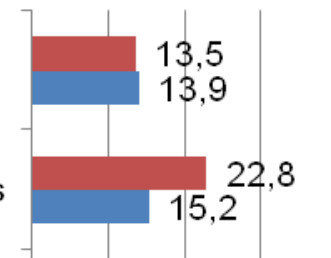

Medios digitales locales

Medios locales no digitales
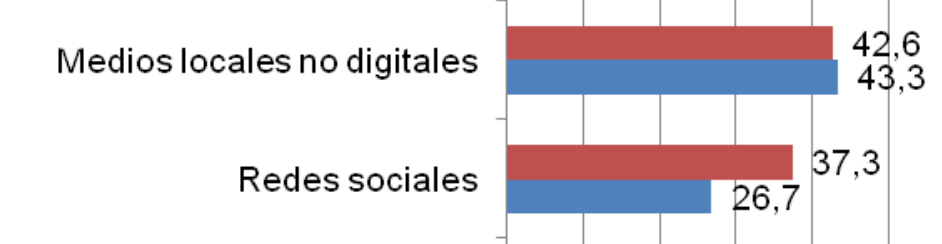

Medios digitales nacionales

Medios nacionales no digitales

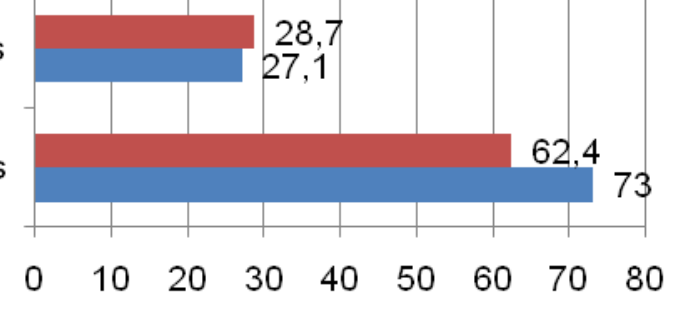

Quito

- Riobamba

Fuente: elaboración propia

El número de usuarios que frecuentaban las redes sociales para informarse era superior en Quito que en Riobamba, aunque en la figura 6 puede anotarse una escasa distancia porcentual entre los consumidores frecuentes o muy frecuentes de medios digitales nacionales o de blogs, foros y otros portales web. 
Nuevamente, como en el caso de la credibilidad, la influencia de las edades de los encuestados impactaba en la creación de tendencias dentro de los grupos:

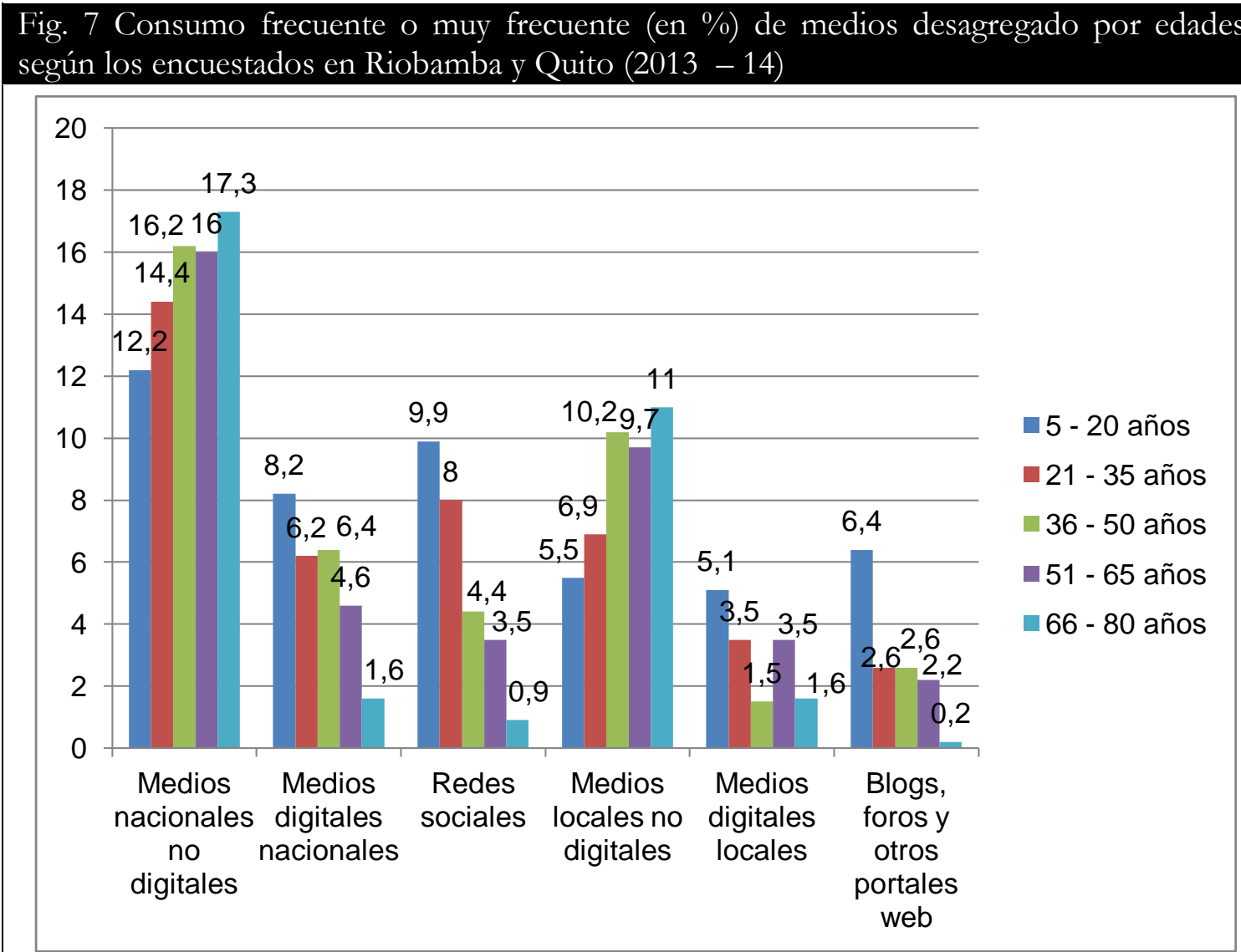

Fuente: elaboración propia

El primer grupo, integrado por personas de menores edades, frecuentaba sobre todo las plataformas digitales, mientras que un segundo grupo, de edades más avanzadas, prefería consumir medios de comunicación convencionales.

\section{Conclusiones}

En general, según ha podido percibirse en las páginas anteriores, hemos observado una corriente social crítica con los contenidos que producen los medios de comunicación convencionales; en ese sentido, casi un tercio de los ciudadanos encuestados aseguraban que las redes sociales les parecían unos canales más confiables que los medios de comunicación. Dicha falta de confianza estaba fundamentalmente marcada por variables como la edad o la 
educación de los encuestados, pero también hemos anotado otro tipo de factores vinculados sobre todo a la realidad comunicacional que se está fraguando en el país andino. La constante pérdida de credibilidad de los medios ecuatorianos tiene que contextualizarse en un emplazamiento que asiste a su segundo Plan Nacional del Buen Vivir, dentro de cuyos objetivos estratégicos se ha erigido como explicábamos en las páginas anteriores- el fortalecimiento de las capacidades críticas de la ciudadanía. Una mayor formación colectiva equivale a una ciudadanía más crítica con los mensajes que difunden los gestores simbólicos. Pero detrás de esa progresiva falta de confianza en la intermediación, hay que situar también a la activación del Estado ecuatoriano (Ramos, 2013), con la anulación parcial de los intermediarios profesionales con el fin de interactuar abiertamente con la sociedad, y las continuas campañas de desprestigio orquestadas desde la Presidencia de la República contra los mensajes originados dentro de las organizaciones periodísticas. Pero a pesar de esta corriente que desconfiaba de los medios convencionales, esos mismos medios seguían siendo responsables de la formación y la difusión, según reconocía la mayor parte de los encuestados.

Quizá el mayor inconveniente de este estudio es la imposibilidad de generalizar los resultados; sin embargo, consideramos que las ideas contenidas en las páginas anteriores pueden servir de gran ayuda para reconstruir parte de la situación de la comunicación ecuatoriana meses después de la aprobación de la LOC. Aún están por ver los efectos que tendrá esta ley en el imaginario de los ecuatorianos. En futuros estudios, será interesante afianzar los resultados mostrados, y analizar en qué medida influye la LOC en el desarrollo de una comunicación mediada más rigurosa y confiable, entre otras líneas.

\section{Referencias bibliográficas}

Abad, Gustavo (2010). Cultura periodística, censura y autocensura en Ecuador. Quito: FLACSO.

Ander -Egg, Ezequiel (1993). Técnicas de Investigación Social $<23^{\mathrm{a}}$ edición>. Buenos Aires: Magisterio del Río de La Plata. 
Andes (2014, 29 de septiembre). Aceptación de la gestión del presidente de Ecuador se mantiene en el 61\%, según estudio. Recuperado el 1 de diciembre de 2014 de http://www.andes.info.ec/es/noticias/aceptacion -gestion presidente -ecuador -mantiene -61 -segun -estudio.html

Andes (2014, 28 de noviembre). Enlace Ciudadano, un vínculo de comunicación directa y rendición de cuentas del presidente de Ecuador con la gente. Recuperado el 1 de diciembre de 2014 de http://www.andes.info.ec/es/noticias/enlace -ciudadano -vinculo -comunicacion -directa-rendicion-cuentas - presidente-ecuador -gente

Ávila, Caroline (2013). El sistema de comunicación en la Ley Orgánica de Comunicación del Ecuador: Un análisis desde el enfoque de las teorías de sociedad y masas de McQuail. Chasqui, Revista Latinoamericana de Comunicación, 124, 71 - 79.

Ayala, Alexandra y Calvache, María Belén (2009). Percepción sobre los medios públicos en Ecuador. Quito: CIESPAL.

Barredo Ibáñez, Daniel (2011). Tabús informativos individuales y organizacionales del periodismo español en el siglo XXI: un estudio Delphi. Fonseca, Journal of Communication, 3, 97 - 130.

Barredo Ibáñez, Daniel (2013a). La crisis de credibilidad de las organizaciones periodísticas: hacia la sociedad de los ideantes. Poliantea, IX (16), 101 - 126.

Barredo Ibáñez, Daniel (2013b). La crisis de credibilidad de la gestión institucional: hacia la generación de confianza en la era del ciberespacio. Chasqui, Revista Latinoamericana de Comunicación, 123, 41 $-47$.

Barredo Ibáñez, Daniel (2013c). Siglo XXI y monarquía. Propuestas para dinamizar la caracterización informativa del rey Juan Carlos I. Area Abierta, 13(3), 1 - 22.

Barredo Ibáñez, Daniel, Oller, Martín y Buenaventura, Sandra (2013). The End of the Information Society. Notes for the Configuration of the New Contemporary Public Space: the Society of Devisers. Observatorio (OBS*) Journal, 7(3), 079 - 091. 
Barredo Ibáñez, Daniel (2014). El Modelo Integrado de Evaluación de la Comunicación Organizacional en Ecuador: un estudio exploratorio a partir del diagnóstico de la ESPOCH y de CIESPAL (2013 -2014). index.communicación, 1(4), 173 - 208.

Barredo Ibáñez, Daniel y Silva, Roxana (2014). Interacción institucional, participación ciudadana y transparencia. La iniciativa del Voto Transparente en el Ecuador (2013 - 2014). Chasqui, Revista Latinoamericana de Comunicación, 126, 4 - 13.

Basabe -Serrano, Santiago y Martínez, Julián (2014). Ecuador: cada vez menos democracia, cada vez más autoritarismo... con elecciones. Revista de Ciencia Politica, 34(1). 145 - 170.

Bowman, S. y Willis, C. (2003). We media: how audiences are shaping the future of news and information. The Media Center at the American Press Institute [en línea]. Consultado el 20 de diciembre de 2012 en

<http://www.hypergene.net/wemedia/download/we_media.pdf>.

Checa - Godoy, Antonio (2012). La Banca y la propiedad de los medios: el caso de Ecuador. Revista Latina de Comunicación Social, 67, 125 - 147. Consultado el 01/09/2014 de:

http://www.revistalatinacs.org/067/art/950 Sevilla/06 Checa.html

Coronel, Gabriela y Mier, Aura (2011). Impacto del Twitter en Ecuador, caso 30S. Recuperado el 1 de diciembre de 2014 de http://www.iiis.org/CDs2011/CD2011CSC/CISCI 2011/PapersP df/CA806GT.pdf

ElComercio.com (s. f.). Enlace ciudadano No. 362. Consultado el 28/08/2014 de:

http://www.elcomercio.com/actualidad/politica/enlace-ciudadano -no -362 -quito.html

ElComercio.com (2011, 10 de diciembre). Resumen del enlace sabatino. Consultado el 28/08/2014 de:

http://www.elcomercio.com/actualidad/politica/resumen - del enlace-sabatino.html

García de Torres, E.; Yerzers'ka, L.; Rojano, M.; Azevedo, J.; Zamith, F.; Paul, N.; et al. (2009). UGC Status and levels of control 
in Argentine, Colombian, Mexican, Peruvian, Portuguese, Spanish, US and Venezuelan online newspapers. International Symposium on Online Journalism. Austin (Texas) [en línea]. Consultado el 28 de octubre de 2012 en

$<$ http://online.journalism.utexas.edu/2009/papers/Garciaetal09.pd $f>$.

Grupo Infotendencias (2012). "Media convergence". En Siapera, E. y Veglis, A. (Eds.). The handbook of global online journalism<pp. $21-$ 38>. Oxford: Wiley -Blackwell.

INEC (s.f.). Tecnologías de la Información y Comunicaciones (TIC'S) 2013. Recuperado el 1 de diciembre de 2014 de http://www.ecuadorencifras.gob.ec/documentos/web inec/Estadisticas Sociales/TIC/Resultados principales 140515.Tic .pdf

LaRepublica.pe (2011, 31 de julio). Crónica: Rafael Correa, un presidente que "mete miedo". Consultado el 27/08/2014 de: http://www.larepublica.pe/31-07-2011/cronica -rafael -correa un-presidente-que -mete-miedo

Latinobarómetro (2009). Informe 2009. Recuperado el 30 de noviembre de 2014 de https://www.oas.org/en/ser/dia/outreach/docs/INFORME LAT INOBAROMETRO 2009[1].pdf

Latinobarómetro (2013). Informe 2013. Recuperado el 30 de noviembre de http://www.latinobarometro.org/documentos/LATBD INFORM E LB 2013.pdf

Ministerio de Telecomunicaciones (2014, 19 de mayo). El 40,4\% de los Ecuatorianos utilizó internet en los últimos 12 meses.

Recuperado el 1 de diciembre de 2014 de http:/ /www.telecomunicaciones.gob.ec/el -404-de -los ecuatorianos - utilizo -internet -en -los -ultimos -12 -meses/

Noelle - Neumann, Elisabeth (1995). La espiral del silencio. Opinión pública: nuestra piel social. Barcelona: Paidós. 
Núñez, Adoración (2005). Incidencias de la entrevista personal en la investigación mediante encuesta. Revista Española de Investigaciones Sociológicas, 109, 219 - 236.

Punín, María Isabel (2011). Rafael Correa y la prensa ecuatoriana. Una relación de intrigas y odios. Razón y Palabra, 75. Consultado el 27/08/2014 de:

http://www.razonypalabra.org.mx/N/N75/varia 75/varia3parte/3 7 Punin V75.pdf

Ramos, Isabel (2012). La contienda política entre los medios privados y el gobierno de Rafael Correa. Utopia y Praxis Latinoamericana, 17(58), $65-76$.

Ramos, Isabel (2013). Trayectorias de democratización y desdemocratización de la comunicación en Ecuador. Íconos. Revista de Ciencias Sociales, 45, $67-82$.

Ramos, Juan y Gómez, Ava (2014). Sujetos, objetos, decisiones y evasiones - el proceso de aprobación de la Ley de Comunicación en Ecuador. Intercom, Revista Brasileira de Ciências da Comunicação, 37(1), $283-310$.

Rodrigo, Iván (2012). Calidad informativa: credibilidad de medios y periodistas en el Ecuador. ComHumanitas, 3(3), 53 - 69.

Senplades (2013). Plan Nacional del Buen Vivir (2013 - 2017). Quito: Senplades.

Vásconez, Irene (2011). La credibilidad de los medios de comunicación en el Ecuador: reflejo de un periodismo de calidad. ComHumanitas, 1(1), 173 - 182.

Villacís, Byron (s.f.). 3 de cada 10 ecuatorianos utilizan Internet, en dos años la cifra aumento en más de medio millón de personas. Recuperado el 1 de diciembre de 2014 de http://www.inec.gob.ec/inec/index.php?option=com content\&vie $\underline{\mathrm{w}}=$ article $\& \mathrm{id}=42 \% 3 \mathrm{~A} 3-\mathrm{de}-\mathrm{cada}-10$-ecuatorianos - utilizan internet -en -dos - anos -la - cifra -aumento -en -mas -de -medio -millon - de - personas\&catid $=63 \% 3$ Anoticias - general\&lang $=$ es 


\section{Agradecimientos}

Los autores agradecen expresamente al Proyecto Prometeo de la Secretaría de Educación Superior, Ciencia, Tecnología e Innovación de la República del Ecuador, así como a la Escuela Superior Politécnica de Chimborazo, al CIESPAL y a la Universidad Central del Ecuador, por prestar indirectamente fondos para realizar este proyecto. Asimismo, sus resultados fueron presentados en el marco del VI Congreso Internacional Latina de Comunicación Social, celebrado en Tenerife (España) en el mes de diciembre de 2014 bajo el título La crisis del periodismo ecuatoriano: algunas reflexiones a partir de una encuesta en Riobamba y Quito (2013 - 14). 


\section{iv}

\section{E1 periodismo cultural: análisis de un subcampo periodístico en el contexto del periodismo de investigación}

Pamela Cruz: Universidad Tecnológica Equinoccial, Ecuador

\section{Introducción}

— STE CAPÍTULO tiene por objeto explicar cómo el 1 periodismo cultural es un campo específico dentro del campo general del periodismo, en términos de Pierre Bourdieu, desde el cual se puede ejercer la investigación. Si bien hay una escasa producción de conocimiento alrededor del periodismo cultural en América Latina, un análisis a los contenidos de un grupo de medios de comunicación de Ecuador evidencia que lo cultural es un tema de interés público, como lo son la economía o la política, que, no obstante, se ha limitado a relatos coyunturales que reducen la cultura a lo estético, con esporádicas incursiones a lo popular, la memoria o el patrimonio. En esa dinámica, están involucrados tanto las industrias mediáticas, incluyendo los reporteros, como el público y los gestores de cultura. Desde la perspectiva del periodismo de investigación, que se diferencia de la investigación como instrumento del quehacer periodístico porque requiere de contextualizaciones y explicaciones, se propone un periodismo cultural con nuevas preocupaciones, más que recetas: la indagación de los diálogos culturales que se están produciendo, sus actores e intereses, y la difusión de productos integrales en los cuales los actores culturales sean los narradores de sus propios relatos. 


\section{El punto de partida: el periodismo de investigación como especialidad periodística}

Según George Brock, ex editor ejecutivo The Times de Londres, cuatro son las actividades que conforman la esencia del periodismo: la verificación, la lógica, el registro de los testimonios presenciales y la investigación (Dinges, 2013).

En este artículo, me centraré en la última de esas actividades porque considero que la investigación es una oportunidad para formar periodistas especializados.

Como lo sostiene José Manuel de Pablos, catedrático de la Universidad de La Laguna (Tenerife), el investigar está íntimamente unido al periodismo. Es su esencia misma porque permite conseguir los datos que darán forma a una noticia, un informe o un reportaje. Es decir, por medio de la investigación se tiene un periodismo bien hecho.

Con esta postura, coincide, por ejemplo, Gabriel García Márquez, periodista y ex Premio Nobel de Literatura (1982), quien ha afirmado que uno de los pilares de la formación periodística universitaria es que "el periodismo debe ser investigativo por definición” (El País, 20 -10 -96 en Caminos, 1997:13). Esta postura plantea que periodismo más investigación es una redundancia, como decir: avión para volar o barco para navegar (Ayala, 2010: 86).

Sin embargo, el punto de partida que planteo es ir más allá de la investigación como instrumento del quehacer periodístico, situándonos en la investigación como especialidad periodística. ¿La razón? Indagar un tema requiere de un proceso por medio del cual se contextualiza un hecho o una tendencia, se lo explica, se descubren sus causas y sus consecuencias.

Desde esa ubicación, no solo puedo referirme a la práctica del periodismo de investigación sino a cómo el periodismo cultural se constituye en un campo específico del campo general del 
periodismo, en términos de Pierre Bourdieu, desde donde ejercer la investigación como especialidad. De hecho, este es el objetivo de este documento.

Si bien el periodismo de investigación ha sido fuertemente relacionado como una práctica exclusiva de los reporteros de las secciones de política y economía, porque se ha centrado en develar temas relacionados con la corrupción política y la gestión pública, debemos reconocer que el ámbito del periodismo de investigación no se limita a esas dos secciones, ni a las llamadas "secciones fuertes" de un medio de comunicación.

Esta idea pongo sobre la mesa, a pesar de que es muy común ubicar en los libros y artículos sobre periodismo de investigación un recuento de casos investigativos sobre la corrupción política, empezando por el caso Watergate que en junio de 2013 pasado cumplió 41 años desde que el periódico Washington Post inició una investigación que terminó con la renuncia del presidente Richard Nixon.

Como lo señala José Caminos, considero que:

los textos de investigación aparecen publicados en cualquier sección del diario, y esto es así porque la investigación periodística abarca todas las áreas de la información: política, económica, social, cultural, deportiva... Su ubicación, por tanto, está siempre condicionada por el tema que aborda (1997:21).

Un tema trabajado desde el periodismo de investigación, entonces, es distinto a una nota del día no solo por el factor tiempo. Es decir, el par de horas con las que cuenta un reportero para conseguir la información, redactar los datos y registrarlos en una maqueta de diseño para periódicos o armarlo audiovisualmente para un medio radial, televisivo o el Internet.

Se constituye en un tema del periodismo de investigación porque su objetivo es profundizar en un asunto de interés social, no solo de 
carácter público sino también privado, que no era tan evidente para la sociedad en general.

Por medio de datos que se han obtenido de fuentes propias y contrastadas, el periodista investigativo es quien presenta una adecuada complementación de textos, imágenes y/o audios, contribuyendo al establecimiento sistemático de la verdad de lo que pasa en la sociedad, como lo dice el periodista Brock, del The Times. $\mathrm{Y}$ esto es válido para cualquier campo periodístico específico, como lo es el periodismo cultural.

\section{Cartografía del periodismo cultural}

Para cumplir con el objetivo de este artículo que está relacionado con la explicación de cómo el periodismo cultural es un campo específico dentro del campo general del periodismo desde el cual se puede ejercer la investigación, es preciso hacer algunos trazos, a manera de un mapa o una cartografía, que nos orienten sobre la cultura, las demandas informativas que genera, la oferta periodística que existe y lo que debería ofrecerse (Cfr. Abad, 2012: 207).

Siguiendo la propuesta del teórico francés Pierre Bourdieu, el trabajo de los periodistas responde a una lógica cuyas características lo configuran como un microcosmos particular, lo que se conoce como campo, dentro de un cosmos social (Bourdieu y Wacquant, 2005:150).

En ese campo, que se ha ido estructurando históricamente, ${ }^{37}$ hay actores que ponen en juego estrategias para conservar o incrementar su capital o la posición que han alcanzado en ese campo. Siguiendo la lógica de Bourdieu, estaría en juego, por ejemplo, el reconocimiento de un periodista por parte de sus colegas o por parte de sus lectores, oyentes o televidentes.

\footnotetext{
${ }^{37}$ Históricamente, los medios de comunicación y, específicamente, los periódicos nacieron en el sistema capitalista de la mano de las personas reunidas en la esfera de la publicidad burguesa que se apropiaron de la publicidad reglamentada desde arriba (Estado e iglesia), para concertar, a través del raciocinio (discusión, debate), la regulación de la sociedad civil (Habermas, 1994).
} 
Al igual que otros campos específicos del periodismo, como el político o el judicial, el periodismo cultural se ocupa de temas de interés público, caracterizándose porque privilegia la información de la producción, circulación y consumo de productos simbólicos o de sentidos.

Sin embargo, el periodismo cultural puede considerarse un actor en desventaja dentro del periodismo porque no ha logrado el mismo espacio y la misma importancia que otras áreas informativas (2012:207).

Para ejemplificar esto, debo señalar que en la investigación El periodismo cultural en los medios ecuatorianos, desarrollada en 2010 por Ciespal con el aval del Ministerio Coordinador de Patrimonio, se observó que en seis periódicos ecuatorianos con cobertura nacional el espacio destinado a las notas culturales no era el mismo de lunes a viernes y en fines de semana.

En los días laborables, su extensión dependió mucho de la publicidad que ingresó en las páginas, mientras que en sábados y en domingos tuvo más espacio porque el número de notas de los "temas duros" fue, en general, reducido. En ese sentido, una de las conclusiones a las cuales se llegó es que lo cultural es una información ornamental de la prensa.

Alrededor de esa situación, Pierre Bourdieu reconoce dos criterios según los cuales se jerarquiza la información que se procesa en un medio de comunicación: el mercado y la disyuntiva entre un polo cultural y uno comercial (Cruz y Rosero, 2012: 43). Sobre esas fuerzas puestas en juego, el sociólogo francés dice:

Como en el campo literario, en el periodístico la jerarquía según el criterio externo, el éxito de ventas, es prácticamente la inversa de la jerarquía según el criterio interno, la "seriedad" periodística. Y la complejidad de esta distribución según una estructura de enlaces múltiples (que también es la de los campos literario, artístico o jurídico), se ve incrementada por el hecho de que nos volvemos a 
encontrar en el seno de cada medio de comunicación con la oposición entre un polo "cultural" y un polo "comercial" que organiza el conjunto del campo, de modo que nos hallamos ante una serie de estructuras imbricadas (Bourdieu: 1995:96).

A partir de esa cita, podría decirse, entonces, que el carácter mercantil cruza las construcciones de sentido que sobre cultura produce el periodismo cultural. Y por ello, quizá, los reporteros culturales están apostando más por el desarrollo de prácticas relacionadas con lo cotidiano, lo coyuntural, más que a la investigación o la profundización de narrativas sobre las transformaciones culturales que se están dando hoy en día.

Por coyuntura, entiendo ese criterio noticiable que privilegia el seguimiento puramente fáctico de los acontecimientos culturales, y en general de los acontecimientos mediáticos, para producir un despliegue informativo breve. Lo coyuntural es, entonces, contrario a un acercamiento profundo de los temas que rondan el ámbito cultural y que permanecen en él como potenciales disparadores de debate y reflexión (Cruz y Rosero, 2012: 39).

Retomando los resultados de la investigación El periodismo cultural en los medios ecuatorianos, los temas culturales tienen presencia permanente en la agenda informativa de prensa y televisión; no obstante, los temas que más publicaciones presentan son los que tienen relación con el cine, los espectáculos y las actividades de la agenda cultural.

Por fuera, en cambio, se están dejando un catálogo de actos y expresiones culturales que no necesariamente tienen que ver con las industrias culturales (Hollywood, Team Producciones), los museos o las galerías de arte.

Otro indicador de que el periodismo cultural está privilegiando el seguimiento puramente fáctico o inmediato de los acontecimientos culturales, produciendo un despliegue breve y una enunciación parcializada, son los géneros periodísticos que está utilizando. 
Según esa misma investigación, las notas culturales más frecuentes correspondieron al género informativo - 85\% en prensa y el $65 \%$ en televisión, siendo las noticias las que más se difundieron; luego, estuvieron los cortos, las notas breves y los perfiles.

Estos datos no son solo una evidencia de un problema de tratamiento periodístico, sino de una concepción de lo que es el periodismo cultural (Cfr. Abad, 2012: 209) y su potencial para ser un espacio desde el cual se ejerza el periodismo de investigación.

\section{Las preocupaciones del periodismo cultural}

El primero de los intereses del periodismo cultural es, obviamente, la cultura. Para la Antropología, este es su concepto central. Y a ello se ha llegado a través de la etnografía, que define y vigila las fronteras del oficio del antropólogo (Cfr. Gupta y Ferguson, 1997).

A lo largo del tiempo, las ideas sobre la cultura han ido cambiado; por ejemplo, Cliford Geertz (2001) propuso que se la trate como un texto con significados mientras James Clifford (2001) sostuvo que no se puede concebir la diversidad humana como algo inscrito en culturas cerradas e independientes sino en algo multívoco donde se construye la otredad. El lugar desde donde hablar y desde donde leer a la cultura globalizada es la desterritorialización, según Arjun Appadurai. Esa desterritorialización está asociada a las transformaciones tecnológicas, financieras $y$, principalmente, mediáticas y migratorias que no implican la desaparición de las coordenadas de ubicación y localización geográficas.

En esa diversidad de propuestas, la cultura puede definirse como "un modo de hacer y producir, un modo de pensar y sentir y un modo de sentir y narrar" (Abad, 2010). En ese concepto, hay dos componentes: a) los aspectos prácticos, que están ligados a lo cotidiano y b) los aspectos imaginarios, que están relacionados con jugar, reír, soñar. Pero, ¿qué cultura es la que está narrando el periodismo cultural en América Latina y en Ecuador? 
Si hacemos una revisión histórica de la práctica del periodismo cultural, concluiremos que este campo específico del periodismo se ha enfrentado a la disyuntiva de qué aspectos de los reconocidos como culturales se deben cubrir.

Eso le llevó, por un lado, a ajustarse a la concepción ilustrada de las manifestaciones artísticas y culturales, restringiendo su labor al ámbito de las "bellas artes" (artes escénicas, plástica, música y literatura).

Desde ahí, se promovía un modelo de cultura erudita, dando cuenta de las aspiraciones de poder de determinados grupos sociales (Rivera, 1995: 15). Esto sigue vigente, reforzando así la dicotomía culto/popular que presenta una relación de dominación: lo culto es el sujeto que define y lo popular es el objeto de la definición (Cfr. Passeron y Grignon, 1978).

En la investigación citada anteriormente, el 29\% de las notas de prensa y un $21 \%$ de las notas de televisión estuvieron relacionadas con representaciones de "bellas artes" o la "cultura de élite".

A partir de la expansión de las perspectivas de la antropología cultural, el radio de enfoque del periodismo cultural se amplió. Siguiendo la propuesta de E.B. Taylor, la cultura se entendió como un conjunto complejo que incluye conocimientos, creencias, arte, moral, ley, costumbres y hábitos sociales.

Sin embargo, el periodismo cultural que acuñó esta manera de ver la cultura y amplió las prácticas de cobertura, fue criticado de inclinarse hacia la vulgarización o divulgación masiva e indiscriminada de una cultura general y difusa.

Con el tiempo, la práctica del periodismo cultural se dirigió a la perspectiva más aglutinadora y diversa, en una muestra de interés por aprehender lo extenso y lo heterogéneo del tejido social. Lo que García Canclini llamaría "culturas híbridas" en América Latina, es decir esos cruces de las herencias indígenas y coloniales con el arte contemporáneo y las culturas electrónicas. 
Pese a esa tendencia, la expansión de la cultura -en sus dimensiones culta, masiva y popular- no ocurre del mismo modo en las distintas secciones mediáticas. Aunque hay pocos estudios empíricos alrededor del periodismo cultural, uno de García Canclini (2000) en periódicos mexicanos evidenció que lo local, lo nacional y lo global se organiza de modos diversos en distintos campos culturales. Por ejemplo, lo global se limita a los espacios de espectáculos, mientras lo nacional y lo local va en las secciones etiquetadas como "cultura", donde hay más espacio para los bienes de la "alta cultura".

Trayendo a colación los resultados del estudio El periodismo cultural en los medios ecuatorianos, las representaciones de cultura en la prensa registraron un $53 \%$ de notas que correspondió a actividades culturales mediadas por la tecnología. En el caso de la televisión, un $41 \%$ de las notas estuvo relacionado con esa "cultura masiva", es decir, cine industrial, best sellers, conciertos, shows, producción de videojuegos.

A partir de esos datos, se concluye que ese énfasis de la prensa ecuatoriana en la cultura mediada por la tecnología podría trasladar una imagen sesgada de lo que es la cultura y se hace un llamado de atención para que quienes producen los contenidos culturales ensayen proyectos claros de lo que se busca que sea este complejo subcampo del periodismo.

En esa misma línea de llamados de atención, Gustavo Abad (2013) plantea que el periodismo cultural debe mirar al espacio virtual que ha potenciado las posibilidades de que cada individuo se constituya en una fuente de discursos artísticos y culturales, como creador o crítico, consumidor o promotor, ejecutante o espectador.

De allí que este periodista y académico ecuatoriano enfatice en que "el periodismo cultural tiene que replantear su trabajo de mediación, que no es otra cosa que la intervención intencional y consciente entre los hechos y los significados" (2012: 212). En ese replanteamiento, se proponen como líneas de trabajo: a) la identificación de nuevas voces que estén fuera de la institucionalidad 
y los escenarios tradicionales (instituciones públicas de cultura, museos, colectivos artísticos); b) la investigación de qué tipo de diálogos culturales se producen en la sociedad, entre qué actores y con qué intereses (Por ejemplo, qué beneficios obtienen los creadores de música electrónica de los avances del software libre), y c) el diseño de espacios de participación de esos nuevos actores en el proceso informativo, como narradores de su propia condición.

Considero que esas líneas de trabajo pueden contribuir a que los espacios que ocupa el periodismo cultural en los medios de comunicación deje de ser esa sección donde "cabe todo y nada al mismo tiempo". Es decir, todos los géneros periodísticos (notas de hechos culturales en forma de reportajes, entrevistas, crónicas, comentarios y cortos), las manifestaciones típicas de estilo ameno (cuentos, novelas, chistes, fotografías, crucigramas, pasatiempos) y las críticas de arte, de cine, de televisión...

\section{Nuevas preocupaciones para el periodismo cultural}

De lo que se ha dicho hasta el momento, queda claro, entonces, que el periodismo cultural es un campo periodístico complejo en el cual los actores -periodistas no pueden limitarse al conteo de los libros publicados en un año o las películas estrenadas en el último mes. Tampoco, pueden ceñirse a solo lo "estético", "lo culto", "lo popular" o "lo masivo".

No es un campo en el cual no se pueda visibilizar la fina línea que separa entre la información y la interpretación; es decir, el periodismo cultural se ha movido principalmente entre la reseña informativa y la crítica. Esta última entendida únicamente como la posibilidad para emitir juicios de valor bipolares: bonito - feo, bueno - malo, bien trabajado - mal trabajado.

La tarea del periodismo cultural no está en concentrarse en una producción simbólica, sino en lo que está detrás de ella: líneas de pensamiento (por ejemplo, en la historia de la literatura ecuatoriana, la creación dramatúrgica o el patrimonio material e inmaterial). 
En pocas palabras, el periodismo cultural debe dar cuenta de las características de una determinada producción simbólica $\mathrm{y}$, a partir de ellas, propiciar una reflexión para entender en qué circunstancia histórica se dio, por qué razones y cuáles son sus implicaciones.

Lo que Gustavo Abad, basándose en el planteamiento en el libro Cuestión de énfasis de Sontag, plantea: un periodismo cultural habilitado para "hacer cruces, encontrar las relaciones y proponer una manera de entender los acontecimientos culturales en su dimensión histórica y política” (2012: 216).

En ese escenario, el campo específico del periodismo cultural requiere de actores -reporteros que proyecten de un modo intencional, y no reactivo, los discursos informativos sobre la cultura que no son evidentes para la sociedad.

Aquí, entonces, queda claramente explicitado un cruce del periodismo cultural con el periodismo de investigación, entendido como:

la reportería que se realiza a través de la iniciativa y trabajo del periodista, sobre asuntos de importancia que alguna persona u organización desean mantener en secreto (Robert Greene, fundador de la Asociación de Reporteros y Editores Investigativos).

A continuación, me referiré a otros puntos de encuentro entre el periodismo cultural y el periodismo de investigación. También, me referiré a los retos que el periodismo de investigación le presenta al periodismo cultural.

\section{El periodismo cultural en el contexto del periodismo de investigación}

La determinada actitud del actor -reportero cultural, que se plantea como necesaria en ese campo específico del periodismo, es una de las entradas para relacionar al periodismo cultural con el periodismo de investigación. 
Este último, como especialidad periodística, requiere de reporteros que entiendan que la base de un trabajo periodístico bien hecho no está en los datos o hechos noticiables, sino en la manera en cómo se abordan los mismos, procurando de construir su complejidad por medio de su contextualización histórica y profundización de las relaciones que están inmersas en ellos.

Un segundo cruce está en la búsqueda de nuevas voces que están fuera de la institucionalidad y los escenarios tradicionales de lo cultural. En el periodismo de investigación, es un periodismo que no se apoya en las fuentes de información oficiales (Caminos, 1997: 24). El periodista es quien busca fuentes diversas que proporcionen información que pueda contrastarse con lo que se dice desde la institucionalidad o esos escenarios cotidianos.

En cuanto a los retos que se plantea desde el periodismo de investigación al periodismo cultural, están: la agenda informativa, la formulación de las preguntas que están detrás de una producción cultural y la mirada periodística.

Sobre la agenda informativa, el periodista investigador tiene una agenda paralela a la que cubre lo cotidiano, lo coyuntural. Es una composición trabajada en cuanto a temas de su propia iniciativa que no, necesariamente, requieren de las fuentes oficiales para ser desarrollados y sí de fuentes que aporten con datos importantes para un trabajo contextualizado.

Para el periodismo cultural, eso implica que no solo se tenga una agenda por medio de la cual se informe sino por medio de la cual se medie. Es decir, se registren hechos y se busquen sus significados en un contexto determinado (Abad, 2012: 223). La mediación es un proceso que requiere de formularse inquietudes, la aplicación de observación y recogida de datos, la sistematización y evaluación de los mismos. Estos pasos son parte del proceso que sigue el periodismo de investigación, desde la pesquisa hasta la publicación.

Para Abad, la agenda en el periodismo cultural es: 
el punto de partida para llevar a la práctica el registro de las demanda culturales y la búsqueda de respuestas tanto de la institucionalidad estatal como del conjunto de las instituciones y de los sectores sociales (2012: 223).

En la reconstrucción de la agenda, se requiere que el periodista seleccione entre todos los hechos relacionados con las producciones culturales aquellos a partir de los cuales se pueden hacer narraciones periodísticas que contribuyan a la reflexión crítica de lo que está sucediendo.

Para la selección de los hechos de producciones simbólicas, el actor -reportero debe preguntarse más allá de lo cuantitativo; por ejemplo, sobre ¿qué ha pasado con las personas o instituciones involucradas durante un corte de tiempo temporal? ¿Qué rol cumplen las políticas públicas y el marco constitucional vigente en un determinado hecho cultural, como la producción cinematográfica? ¿A qué responde el auge o la decadencia de un determinado hecho cultural?

Del estudio realizado por Ciespal, con el aval del Ministerio Coordinador de Patrimonio, se observó que hay temas culturales que están, prácticamente, excluidos de la agenda informativa del periodismo cultural. Sobre ellos, vale la pena el empezar a generar interrogantes.

Entre esos temas están, por ejemplo, el patrimonio, la memoria o el tráfico de bienes patrimoniales. Sobre el patrimonio, muy poco se conoce por los medios de comunicación que es un activo que transcurre en el tiempo y que está relacionado con la herencia de los padres y de la naturaleza, y lo que queremos heredar a nuestros hijos y a las generaciones futuras. Es muy limitada la información que se tiene de su valor simbólico (lo que representa en el presente) o el marco legal que lo protege. ${ }^{38}$

\footnotetext{
${ }^{38}$ En el caso de la Sierra Centro, por ejemplo, el patrimonio material, como las iglesias, cuenta con protección constitucional porque la protección del patrimonio es un principio fundamental para el Estado y es un objetivo del Régimen de Desarrollo.
} 
Una agenda bien estructurada permite una mirada periodística más crítica. En ese sentido, se espera que el actor -reportero se ubique en una posición determinada (explicar, promover la reflexión, denunciar) y desde ahí empiece por evidenciar esas relaciones que se dan alrededor de una producción cultural, jerarquizando lo nuevo sobre la información agotada, desechando los lugares comunes y los estereotipos.

Por ejemplo, una posición crítica sobre el Centro Histórico de Quito trabajaría porque se considere a ese espacio no solo como el relicario del arte religioso nacional sino que, desde las últimas administraciones de los alcaldes, es un espacio que está siendo re -urbanizado o re -conolizado por personas de gran poder adquisitivo, dando paso a la creación de hoteles cinco estrellas.

Ensayar esas nuevas miradas, profundizadas y contextualizadas, es otro punto de unión entre el periodismo cultural y el periodismo de investigación.

\section{Las oportunidades legales para un periodismo cultural de investigación}

En el periodismo de investigación, las referencias sobre los límites al ejercicio de esa especialidad periodística son frecuentes. Se habla, por ejemplo, de límites económicos, del propio medio de comunicación y legales.

Con la Ley Orgánica de Comunicación, considero que, más que límites o dificultades para la investigación, hay un reconocimiento a la investigación como parte de los derechos laborales de las y los trabajadores de la comunicación.

En el artículo 44 de ese articulado, numeral 4, se señala que los comunicadores tienen derecho a: 
A contar con los recursos, medios y estímulos para realizar investigación en el campo de la comunicación, necesarios para el ejercicio de sus funciones (2013).

A mi criterio, esta sección legal es significativa porque establece una obligación para que las industrias mediáticas destinen personal y dinero para la realización de investigaciones. $\mathrm{Y}$ abre la oportunidad para la institucionalización de unidades de investigación que trabajen en la diversidad de temas sobre los cuales ya me había referido antes.

Desde el periodismo cultural de investigación, considero que se puede contribuir a disminuir los ataques contra la prensa que, en muchas ocasiones con razón, ha sido criticada porque muchos de los medios de comunicación se han convertido en herramientas de intereses privados, tanto políticos como económicos.

Estoy segura que desde este campo en un contexto de periodismo de investigación no solo se pueden difundir hechos confiables y contrastados sobre producciones culturales y simbólicas, sino que se puede contribuir a una reflexión crítica sobre lo que está aconteciendo en los distintos ámbitos de la cultura actual.

\section{Referencias bibliográficas}

Abad, Gustavo (2012) "Periodismo cultural: cartografía de un campo en movimiento". En Pamela Cruz y Santiago Rosero, El periodismo cultural en los medios ecuatorianos. Quito: Editorial Quipus Ciespal. Págs. 207 - 230. (2010) Reporteros: cultura periodística, censuray autocensura. Informe de investigación. Quito: Facultad Latinoamericana de Ciencias Sociales, sede Ecuador. Disponible en: http://es.scribd.com/doc/52873827/Cultura -periodistica -censura -y-autocensura -en -Ecuador. Consultado: 20/11(2013).

Ayala Marín, Alexandra (2010) "Investigación en la comunicación y periodismo de investigación. Semejanzas y diferencias”. En Revista Chasqui 2010). Quito. Págs. 85 - 88. 
Bourdieu, Pierre y Wacqant, Loic (2005) Una invitación a la sociología reflexiva. Argentina: Siglo XXI Editores Argentina.

Bourdieu, Pierre (1990) Sociología y cultura. Argentina: editorial Grijalbo S.A.

Caminos, José María (1997) Periodismo de investigación. Teoría y práctica. España: Editorial Síntesis.

Cruz, Pamela y Rosero Santiago (2012) El periodismo cultural en los medios ecuatorianos. Quito: Editorial Quipus - Ciespal.

De Pablos, José Manuel (2004) “Ausencia de iniciativa, valor y sustancia. Las cinco "p" del Periodismo de Investigación". En Revista Mexicana de Comunicación (2004). México D.F. Págs. 30 -36.

Dinges, John (2013) "Resolución de conflictos entre los medios de comunicación y los gobiernos para el beneficio de la democracia: reflexiones sobre las preguntas que permitan definir las reglas del periodismo". En La democratización de la comunicación y la información en América Latina. Quito: Editorial Quipus - Ciespal. Pags. 63 -94.

Habermas, Jurgen (1994) Historia y crítica de la opinión pública. Editorial Gustavo Gili.

Grignon, C. y Passeron, J -C (1978/91) Lo culto y lo popular. España: La Piqueta.

Rivera, Jorge (1995) El periodismo cultural. Argentina: Paidós SAICF. 


\title{
VI
}

\section{Algunos problemas de la comunicación institucional digital. Un estudio de las instituciones educativas más prestigiosas del Ecuador}

\author{
Daniel Barredo Ibánez. Universidad de las Américas, Ecuador \\ Jenny Basantes. Escuela Superior Politécnica de Chimborazo, Ecuador \\ Ernesto Bonilla. Escuela Superior Politécnica de Chimborazo, Ecuador \\ Juan Pablo Trámpuz. Universidad Laica Eloy Alfaro de Manabi, Ecuador \\ Silvia Vega. Universidad de Cádiz, España
}

\section{Introducción}

TNTERNET estimula a las instituciones la posibilidad de 1 contactar a sus públicos estratégicos sin filtrado o intermediación, siempre y cuando se optimicen las oportunidades sugeridas por las TICs. Pero el aprovechamiento de los canales exteriores digitales depende enormemente de factores contextuales, como la tasa de conexión a Internet o algunos factores de carácter sociocultural, como el grado de interacción y transparencia. En ese sentido, en este capítulo estudiamos la gestión externa de las redes sociales de las instituciones educativas más prestigiosas del Ecuador. Los resultados señalan una gestión deficiente o infrautilización en algunos de esos centros, como también un enorme potencial para crear comunidades de usuarios alrededor de las organizaciones ecuatorianas. 


\section{Internet, el nuevo paradigma}

A nivel mundial se está produciendo un "cambio de paradigma" (en Barredo, Oller y Buenaventura, 2013: 79), el cual establece nuevas formas de aproximación social. El puesto referencial que ocupaba la televisión desde el punto de vista mediático, progresivamente, queda relegado a un segundo plano en favor de Internet, como avistara Bucy (2003) hace ya una década. Desde su nacimiento, la ciberesfera destaca por las enormes posibilidades plásticas mencionadas por Micó y Masip (2008), las cuales fusionan o integran en el lenguaje multimedia determinadas soluciones que anteriormente aparecían aisladas en cada uno de los medios. Así, la multimedialidad resulta en una mayor pluralidad informativa (Carpenter, 2010), el usuario recibe la oportunidad de adentrarse en una mayor variedad de recursos, y se produce una mayor flexibilidad general en los contenidos (Sundar, 2000).

La red, para el usuario, no solo ofrece ventajas, sino que hay determinadas problemáticas asociadas a su emergencia, como una relativa ausencia de representatividad social en determinados contextos, un desequilibrio regional o internacional, un desperdicio de los canales en formas de entretenimiento o el advenimiento de la llamada "publicidad encubierta", como explicábamos en un trabajo anterior (Barredo, 2013: 109). Una de las respuestas de las organizaciones periodísticas -principales afectadas por el resurgimiento de esta comunicación no profesionalizada- ha sido la hibridación de las redacciones a través de fórmulas como el periodismo ciudadano (Bowman y Willis, 2003). Las instituciones, por su parte, no pueden permanecer ajenas a estos cambios decisivos en la forma en que se expande y se genera el conocimiento. Por el contrario, la consolidación de Internet como una prolongación del espacio público contemporáneo ha determinado la necesidad organizacional de adaptar los canales exteriores de comunicación. Internet "mejora" la difusión (Harlow y Harp, 2012: 211), en tanto que prolonga las posibilidades de promoción y/o información. Las instituciones y los ciudadanos, en ese sentido, dependen menos en estos comienzos del siglo XXI de la gestión simbólica que realizan los medios de comunicación, ya 
que en el paradigma contemporáneo se anula gran parte de la intermediación (Barredo, Oller y Buenaventura, 2013), gracias a la aparición de espacios de intercambio como los que abanderan las redes sociales.

\subsection{Claves para entender el contexto ecuatoriano}

Las Nuevas Tecnologías de la Información y Comunicación (NTIC) se extienden escalonadamente, como aseguran Howard y Muzammil (2011), sea entre países, regiones, instituciones u organizaciones. Es decir, la implementación digital depende de factores socieconómicos, como por ejemplo la consolidación de la banda ancha, la posibilidad de acceder a equipos informáticos, los niveles de educación, etcétera. A continuación, vamos a mostrar algunos datos reveladores del contexto ecuatoriano, correspondientes a 2011, los cuales permiten definir el tipo de acceso a las NTIC que se registró en el país andino ${ }^{39}$ :

- Solo el 6,6\% de la población reconocía utilizar un teléfono celular de tipo Smartphone.

- El 60,9\% de la población afirmaba no haber empleado un computador en los últimos doce meses.

- El 65,6\% de la población sostenía no haberse conectado a Internet en los últimos doce meses.

- El 14,3\% de la población se conectaba a Internet al menos una vez al día, en tanto que el 10,7\% accedía a la red al menos una vez a la semana.

Sin embargo, el dato más interesante aparece al observar cuál era el uso dado a Internet según los datos oficiales del Instituto Nacional de Estadística y Censos en 2011:

- El empleo más frecuente de la red, para el 35,5\% de la población, era la consulta de servicios de educación y aprendizaje, en tanto que el 28,5\% utilizaba Internet para obtener información, y el 28\%

\footnotetext{
${ }^{39}$ Datos elaborados el 11/11/2013 a partir de las estadísticas oficiales ofrecidas por el Instituto Nacional de Estadística y Censos en:

http://www.ecuadorencifras.gob.ec/banco -de -informacion/
} 
sostenía acceder a la ciberesfera para recabar comunicación en general.

Las cifras anteriores, según se desprende, presentan una radiografía sociológica escalonada desde el punto de vista del acceso a Internet; había, en 2011, una parte de la sociedad influenciada aún por el paradigma anterior, en tanto que un segmento poblacional aprovechaba las posibilidades de interacción y de conexión ofrecidas a partir de los canales digitales.

\section{Objetivos}

Las páginas que continúan se han fijado como objetivos:

1- Describir cuantitativamente la popularidad de las páginas oficiales de las 14 Universidades y Politécnicas de categoría A del Ecuador.

2- Determinar qué factores pueden impulsar un mayor impacto social en la ciberesfera.

3- Analizar globalmente la situación de comunicación digital de las instituciones de educación superior más importantes de la República andina.

\section{Metodología}

Este trabajo se ha operado a través del análisis de contenido manual, una metodología que busca la cuantificación sistemática de las variables de un objeto, según explica Igartua (2006). Para tal fin, se ha empleado una ficha de análisis que contenía 16 variables, la cuales recogían las propiedades visibles ${ }^{40}$ de cada una de las redes sociales. Para la confección de la muestra se han tenido en cuenta los estudios precedentes de Reina, Fernández y Noguer (2012) y Guzmán, Del Moral, González y Gil (2013). En paralelo, se ha consultado el nivel de visibilidad otorgado por Alexa.com a las

\footnotetext{
${ }^{40}$ Gaitán y Piñuel (1998: 282) afirman que el análisis de contenido ha de centrarse en el "sentido latente".
} 
páginas web del país: Facebook.com es la segunda página más vista en la República del Ecuador, en tanto que YouTube.com es la tercera, y Twitter.com la novena ${ }^{41}$. Son, por lo tanto, las principales redes sociales de la República andina.

Asimismo, se han escogido como unidades de observación las 14 Universidades y Politécnicas de clase A catalogadas por la máxima institución educativa de Ecuador, la Secretaría de Educación Superior de Ciencia, Tecnología e Innovación de la República del Ecuador (SENESCYT) ${ }^{42}$. Estos centros académicos, según este organismo regulador de la educación, destacan por su elevada calidad, un factor a tener en cuenta durante el procesamiento de los datos, ya que los resultados que van a presentarse en las páginas siguientes mostrarán la gestión digital que realizan algunas de las Universidades y Politécnicas más importantes del país. Por último, la observación se gestionó durante el mes de julio de 2013.

\section{Resultados}

\subsection{Tráfico de las web}

Según los resultados ofrecidos por el popular auditor de páginas web, Alexa.com, las principales instituciones ecuatorianas registran un elevado tiempo medio de navegación, un indicador estrechamente vinculado con factores como la utilización de recursos digitales en el transcurso de la docencia (como las aulas virtuales), los cuales consiguen una mayor permanencia del usuario y, por lo tanto, una prolongación de su estancia en el entorno virtual institucional:

\begin{tabular}{|l|l|l|l|l|}
\hline \multicolumn{4}{|l|}{ Tabla 1. Páginas de Universidades y Politécnicas ecuatorianas de clase A (2013) } \\
\hline Institución & URL & $\begin{array}{l}\text { Posición } \\
\text { Ecuador }\end{array}$ & $\begin{array}{l}\text { Páginas } \\
\text { visitadas por } \\
\text { usuario }\end{array}$ & $\begin{array}{l}\text { Tiempo medio de } \\
\text { navegación por } \\
\text { usuario }\end{array}$ \\
\hline $\begin{array}{l}\text { Universidad Técnica } \\
\text { Particular de Loja }\end{array}$ & www.utpl.edu.ec & 79 & 7,10 & $9: 31$ \\
\hline
\end{tabular}

${ }^{41}$ Datos consultados el 11/11/2013 de: http://www.alexa.com/topsites/countries/EC

${ }^{42}$ Datos consultados el 19/07/2013 de: http://www.senescyt.gob.ec/UNIVERSIDADES.pdf 


\begin{tabular}{|c|c|c|c|c|}
\hline $\begin{array}{l}\text { Escuela Politécnica del } \\
\text { Ejército }\end{array}$ & www.espe.edu.ec & 141 & 9,20 & $8: 24$ \\
\hline $\begin{array}{l}\text { Escuela Superior } \\
\text { Politécnica del Litoral }\end{array}$ & www.espol.edu.ec & 142 & 3,09 & $3: 36$ \\
\hline $\begin{array}{l}\text { Universidad Central del } \\
\text { Ecuador }\end{array}$ & www.uce.edu.ec & 271 & 4,10 & $4: 37$ \\
\hline $\begin{array}{l}\text { Escuela Superior } \\
\text { Politécnica de } \\
\text { Chimborazo }\end{array}$ & www.espoch.edu.ec & 291 & 4,10 & $5: 26$ \\
\hline Universidad de Cuenca & www.ucuenca.edu.ec & 412 & 3,50 & $3: 59$ \\
\hline $\begin{array}{l}\text { Universidad Técnica de } \\
\text { Ambato }\end{array}$ & www.uta.edu.ec & 436 & 3,50 & $5: 07$ \\
\hline $\begin{array}{l}\text { Escuela Politécnica } \\
\text { Nacional }\end{array}$ & www.epn.edu.ec & 496 & 2,60 & $3: 46$ \\
\hline $\begin{array}{l}\text { Pontificia Universidad } \\
\text { Católica del Ecuador }\end{array}$ & www.puce.edu.ec & 531 & 2,90 & $3: 21$ \\
\hline $\begin{array}{l}\text { Universidad San } \\
\text { Francisco de Quito }\end{array}$ & www.usfq.edu.ec & 610 & 4,30 & $4: 28$ \\
\hline $\begin{array}{l}\text { Universidad Andina } \\
\text { Simón Bolívar }\end{array}$ & www.uasb.edu.ec & 647 & 1,76 & $2: 25$ \\
\hline Universidad del Azuay & www.uazuay.edu.ec & 783 & 2,90 & $4: 09$ \\
\hline $\begin{array}{l}\text { Instituto de Altos } \\
\text { Estudios Nacionales }\end{array}$ & www.iaen.edu.ec & 1710 & 2,90 & $2: 57$ \\
\hline $\begin{array}{l}\text { Facultad } \\
\text { Latinoamericana de } \\
\text { Ciencias Sociales }\end{array}$ & www.flacso.org & $\begin{array}{l}\text { No } \\
\text { disponible }\end{array}$ & 1,20 & $0: 52$ \\
\hline
\end{tabular}

Pero el elevado tiempo de navegación de los usuarios revela, asimismo, otro conjunto de factores más bien relacionados con los problemas de acceso, como por ejemplo la existencia de servidores o servicios de Internet de tipo básico, dispositivos relativamente desfasados, etcétera. La media de páginas visitadas por usuario en estas importantes instituciones de Ecuador es de 3,79 páginas,

${ }^{43}$ Datos consultados el 19/07/2013 de Alexa.com 
mientras que en conjunto todas ellas consiguen una media de 4:25 minutos de navegación por usuario:

\section{Tabla 2. Media de páginas y minutos en Ecuador (2013)}

Media de páginas visitadas por usuario en Tiempo medio de navegación por usuario en U. y P. de tipo A U. y P. de tipo A

$$
3,79
$$

$4: 25$

Fuente: elaboración propia / Alexa.com

Algunos campus con un gran prestigio académico en el país derivado de sus actividades de transferencia de resultados científicos, no despiertan un elevado interés según su tráfico web, un indicativo de una pobre gestión en la ciberesfera.

\subsection{Facebook}

Al observar los resultados relativos a las cuentas de Facebook anotamos un hecho recurrente: las cuentas con un mayor número de Me gusta (un indicador de la popularidad social de las instituciones analizadas) están relacionadas con la fecha de creación. Así, esas Universidades y Politécnicas que crearon primero sus cuentas en esta conocida red de contactos, tienden a recibir un mayor aplauso colectivo $^{45}$ :

\begin{tabular}{|l|l|l|l|l|l|l|l|}
\hline \multicolumn{2}{|l|}{ Tabla 3. Facebook de Universidades y Politécnicas ecuatorianas de tipo A (2013) } \\
\hline Institución & Creación & $\begin{array}{l}\text { Me } \\
\text { gusta }\end{array}$ & $\begin{array}{l}\text { Personas } \\
\text { hablando }\end{array}$ & $\begin{array}{l}\text { Eventos } \\
\text { pasados }\end{array}$ & Fotografías & Vídeos & Carpetas \\
\hline $\begin{array}{l}\text { Universidad San } \\
\text { Francisco de } \\
\text { Quito }\end{array}$ & $17 / 06 / 2008$ & 198229 & 3362 & 6 & 1945 & 2 & 53 \\
\hline $\begin{array}{l}\text { Escuela Superior } \\
\text { Politécnica del } \\
\text { Litoral }\end{array}$ & $08 / 09 / 2008$ & 39845 & 473 & 6 & 1289 & 2 & 22 \\
\hline $\begin{array}{l}\text { Universidad } \\
\text { Técnica }\end{array}$ & $02 / 10 / 2008$ & 27760 & 590 & 13 & 945 & 14 & 35 \\
\hline
\end{tabular}

\footnotetext{
${ }^{44}$ Datos consultados el 19/07/2013 de Alexa.com

${ }^{45} \mathrm{La}$ relación de direcciones consultadas de las páginas oficiales de Facebook se entrega en el anexo 6.1. de este trabajo.
} 


\begin{tabular}{|c|c|c|c|c|c|c|c|}
\hline Particular de Loja & & & & & & & \\
\hline $\begin{array}{l}\text { Escuela } \\
\text { Politécnica del } \\
\text { Ejército }\end{array}$ & $17 / 11 / 2009$ & 25126 & 386 & 18 & 587 & 4 & 19 \\
\hline $\begin{array}{l}\text { Pontificia } \\
\text { Universidad } \\
\text { Católica del } \\
\text { Ecuador }\end{array}$ & $01 / 03 / 2010$ & 22940 & 111 & 2 & 713 & 0 & 34 \\
\hline $\begin{array}{l}\text { Universidad del } \\
\text { Azuay }\end{array}$ & $23 / 02 / 2010$ & 13651 & 874 & 26 & +4000 & 5 & +200 \\
\hline $\begin{array}{l}\text { Escuela Superior } \\
\text { Politécnica de } \\
\text { Chimborazo }\end{array}$ & $17 / 03 / 2011$ & 9850 & 56 & 0 & 242 & 0 & 4 \\
\hline $\begin{array}{l}\text { Instituto de Altos } \\
\text { Estudios } \\
\text { Nacionales }\end{array}$ & $14 / 03 / 2012$ & 9337 & 193 & 12 & 188 & 0 & 13 \\
\hline $\begin{array}{l}\text { Universidad de } \\
\text { Cuenca }\end{array}$ & 09/03/2011 & 8852 & 252 & 2 & 514 & 1 & 48 \\
\hline $\begin{array}{l}\text { Universidad } \\
\text { Técnica de } \\
\text { Ambato }\end{array}$ & $28 / 02 / 2011$ & 5337 & 37 & 0 & 26 & 0 & 4 \\
\hline $\begin{array}{l}\text { Universidad } \\
\text { Central del } \\
\text { Ecuador }\end{array}$ & 2009 & 5000 & $\mathrm{NO}$ & +100 & 190 & 3 & 7 \\
\hline $\begin{array}{l}\text { Universidad } \\
\text { Andina Simón } \\
\text { Bolívar }\end{array}$ & $10 / 12 / 2010$ & 2898 & 124 & +100 & 1345 & 2 & 95 \\
\hline $\begin{array}{l}\text { Facultad } \\
\text { Latinoamericana } \\
\text { de Ciencias } \\
\text { Sociales }\end{array}$ & 05/03/2009 & 2829 & 110 & 14 & 918 & 0 & 6 \\
\hline $\begin{array}{l}\text { Escuela } \\
\text { Politécnica } \\
\text { Nacional }\end{array}$ & $26 / 10 / 2012$ & 2440 & 39 & 0 & 157 & 0 & 17 \\
\hline
\end{tabular}

El ítem Personas hablando no dependía, en cambio, del número de personas registradas en los diferentes Me gusta, sino que estaba

${ }^{46}$ Datos consultados el 22/07/2013 de Facebook.com 
vinculado a factores cualitativos como por ejemplo la frecuencia de actualización de los estados. En ese sentido, la Universidad Técnica Particular de Loja, a pesar de tener en su cuenta alrededor de doce mil usuarios menos que la Escuela Superior Politécnica del Litoral, contaba con más de cien personas interactuando con los contenidos institucionales.

El número de eventos, en general, denotaba una organización muy irregular; en tanto que la universidad más popular del país, la Universidad San Francisco de Quito, únicamente había invitado a sus usuarios a seis eventos (el día, obviamente, de la consulta), algunas universidades con un menor índice de aceptación (como la Universidad Central del Ecuador o la Universidad Andina Simón Bolívar) habían generado más de cien eventos.

Según los resultados de la tabla 3, había muy pocos vídeos implementados en los Facebook oficiales, a pesar de que muchas de estas instituciones poseen importantes departamento de Comunicación Social o de Relaciones Públicas, así como canales específicos de YouTube.

Más utilizadas fueron las fotografías, si bien algunos centros académicos como la Universidad Técnica de Ambato apenas mostraron 26 imágenes en más de dos años de existencia del espacio social.

En la observación contabilizamos asimismo el número de carpetas, una variable que podía determinar el nivel de gestión digital de estas páginas institucionales. Solo una de las universidades, la Universidad del Azuay, poseía más de doscientas carpetas, o sea, tendía a segmentar y a ordenar la información para facilitar la navegación del usuario. La Escuela Superior Politécnica de Chimborazo, en cambio, agrupaba en solo 4 carpetas un total de 242 fotografías, lo que dificultaba enormemente la localización de contenidos específicos y, con ello, la difusión de los hechos pasados. 


\subsection{Twitter}

En cuanto a Twitter, anotamos un escalonamiento en la gestión de las cuentas de las principales instituciones de educación superior del Ecuador:

\begin{tabular}{|c|c|c|c|c|}
\hline Institución & Cuenta & Seguidores & Tweets & Siguiendo \\
\hline $\begin{array}{l}\text { Universidad San Francisco de } \\
\text { Quito }\end{array}$ & @USFQ_Ecuador & 13075 & 14107 & 3595 \\
\hline $\begin{array}{l}\text { Universidad Técnica Particular de } \\
\text { Loja }\end{array}$ & @utpl & 12530 & 8402 & 306 \\
\hline $\begin{array}{l}\text { Escuela Superior Politécnica del } \\
\text { Litoral }\end{array}$ & @espol & 11904 & 7737 & 45 \\
\hline $\begin{array}{l}\text { Facultad Latinoamericana de } \\
\text { Ciencias Sociales }\end{array}$ & @FLACSOec & 8370 & 4729 & 79 \\
\hline Universidad del Azuay & @uazuay & 6118 & 6677 & 56 \\
\hline $\begin{array}{l}\text { Pontificia Universidad Católica } \\
\text { del Ecuador }\end{array}$ & @NoticiasPUCE & 5270 & 948 & 3092 \\
\hline Universidad de Cuenca & @udecuenca & 3546 & 1383 & 123 \\
\hline $\begin{array}{l}\text { Instituto de Altos Estudios } \\
\text { Nacionales }\end{array}$ & @IAENEDU & 2376 & 1489 & 282 \\
\hline Escuela Politécnica Nacional & @EPNEcuador & 1598 & 790 & 744 \\
\hline Universidad Central del Ecuador & @UCentralEcuador & 944 & 50 & 101 \\
\hline $\begin{array}{l}\text { Escuela Superior Politécnica de } \\
\text { Chimborazo }\end{array}$ & @EspochRio & 734 & 201 & 128 \\
\hline $\begin{array}{l}\text { Universidad Andina Simón } \\
\text { Bolívar }\end{array}$ & @u_andina & 117 & 157 & 18 \\
\hline Escuela Politécnica del Ejército ${ }^{47}$ & & & & \\
\hline Universidad Técnica de Ambato & \multicolumn{4}{|l|}{ NO ENCONTRADA } \\
\hline
\end{tabular}

${ }^{47}$ El día de la consulta, 23/07/2013, la cuenta de esta institución había sido suspendida.

${ }^{48}$ Datos consultados el 23/07/2013 de Twitter.com 
Así, según la tabla anterior, las instituciones que producen una mayor cantidad de tweets tienden a su vez a acaparar un mayor número de seguidores. Es esta una particularidad que se mantiene invariable al menos en el análisis de las cinco instituciones más populares del Ecuador. A medida que desciende el número de seguidores $-\mathrm{y}$ en concreto a partir de la Pontificia Universidad Católica del Ecuador - el número de tweets no equivale a una mayor popularidad, sino que aspectos como el tamaño del campus o el prestigio consolidado offline parecen introducir una dispersión en el fenómeno observado en los primeros tramos.

Muchos de los principales centros académicos ecuatorianos son renuentes a seguir a otros usuarios, es decir, blindan sus cuentas e introducen porcentajes de interacción cercanos o inferiores al 1\% del global de sus seguidores.

\subsection{YouTube}

Al revisar los resultados correspondientes a YouTube observamos que la popularidad en esta red no está vinculada a la fecha de creación del canal o a la cantidad de vídeos publicados ${ }^{49}$ :

\begin{tabular}{|l|l|l|l|l|l|}
\hline \multicolumn{5}{|c|}{ Tabla 5. YouTube de Universidades y Politécnicas ecuatorianas de tipo A (2013) } \\
\hline Institución & Fechas & $\begin{array}{l}N^{0} \text { de } \\
\text { visitas } \\
\text { globales }\end{array}$ & $\begin{array}{l}N^{0} \text { de } \\
\text { vídeos }\end{array}$ & $\begin{array}{l}N^{0} \\
\text { suscriptores de }\end{array}$ & $\begin{array}{l}\text { Última } \\
\text { actividad }\end{array}$ \\
\hline $\begin{array}{l}\text { Escuela Superior } \\
\text { Politécnica del Litoral }\end{array}$ & $03 / 09 / 2008$ & 5674720 & 1587 & 12268 & 1 semana \\
\hline $\begin{array}{l}\text { Universidad Técnica } \\
\text { Particular de Loja }\end{array}$ & $08 / 11 / 2006$ & 2727858 & 1881 & 2400 & 3 días \\
\hline $\begin{array}{l}\text { Escuela Politécnica } \\
\text { Nacional }\end{array}$ & $12 / 03 / 2010$ & 333411 & 351 & 521 & 4 semanas \\
\hline $\begin{array}{l}\text { Universidad Andina } \\
\text { Simón Bolívar }\end{array}$ & $28 / 01 / 2009$ & 70239 & 113 & 170 & 18 horas \\
\hline
\end{tabular}

${ }^{49}$ La lista completa de las direcciones consultadas de las páginas institucionales de YouTubese adjunta como anexo 6.2. de este trabajo. 


\begin{tabular}{|c|c|c|c|c|c|}
\hline $\begin{array}{l}\text { Pontificia Universidad } \\
\text { Católica del Ecuador }\end{array}$ & $04 / 11 / 2009$ & 70048 & 101 & 264 & 2 meses \\
\hline $\begin{array}{l}\text { Universidad San } \\
\text { Francisco de Quito }\end{array}$ & $01 / 04 / 2012$ & 47906 & 50 & 238 & 1 semana \\
\hline $\begin{array}{l}\text { Instituto de Altos } \\
\text { Estudios Nacionales }\end{array}$ & $06 / 07 / 2011$ & 30172 & 90 & 116 & 5 días \\
\hline $\begin{array}{l}\text { Universidad Central del } \\
\text { Ecuador }\end{array}$ & $30 / 04 / 2010$ & 22984 & 31 & 62 & 2 semanas \\
\hline $\begin{array}{l}\text { Escuela Politécnica del } \\
\text { Ejército }\end{array}$ & $14 / 05 / 2010$ & 21450 & 24 & 87 & 3 meses \\
\hline Universidad del Azuay & $24 / 08 / 2010$ & 9209 & 34 & 34 & 2 meses \\
\hline $\begin{array}{l}\text { Escuela Superior } \\
\text { Politécnica de } \\
\text { Chimborazo }\end{array}$ & $24 / 06 / 2011$ & 2634 & 8 & 36 & 11 meses \\
\hline $\begin{array}{l}\text { Facultad } \\
\text { Latinoamericana de } \\
\text { Ciencias Sociales }\end{array}$ & $22 / 04 / 2008$ & 868 & 2 & 11 & 5 años \\
\hline Universidad de Cuenca & \multicolumn{5}{|c|}{ NO ENCONTRADO } \\
\hline $\begin{array}{l}\text { Universidad Técnica de } \\
\text { Ambato }\end{array}$ & \multicolumn{5}{|c|}{ NO ENCONTRADO } \\
\hline
\end{tabular}

Es muy indicativo del funcionamiento de esta red que, por ejemplo, la Escuela Superior Politécnica del Litoral, con casi trescientos vídeos menos que la Universidad Técnica Particular de Loja, posee casi tres millones de visitas más. Las retóricas persuasivas, distintivas de los momentos audiovisuales anteriores, resultan contraproducentes en la esfera digital en tanto que socavan "credibilidad y expectación" a la imagen corporativa (en Barredo, 2013: 118).

Nuevamente, como en otros apartados de este trabajo, apuntamos la existencia de un escalonamiento digital entre las dos primeras instituciones y el resto. Entre la Escuela Superior Politécnica del Litoral (primera clasificada, por número de usuarios) y la Escuela Politécnica Nacional (tercera clasificada), hay una diferencia de más

${ }^{50}$ Datos consultados el 23/07/2013 de YouTube.com 
de cinco millones de usuarios. Las universidades mejor clasificadas, por número global de visitas, concentraban también una mayor actividad general, en tanto que había centros que, como la Facultad Latinoamericana de Ciencias Sociales, parecían haber abandonado su cuenta en esta conocida red de intercambio de vídeos.

\section{Conclusiones}

Las principales instituciones de educación superior en el Ecuador, según los resultados precedentes, están escalonadas desde el punto de vista de su gestión digital. Hay instituciones que, como la Escuela Superior Politécnica del Litoral o la Universidad San Francisco de Quito, mantienen unos altos niveles de gestión en sus canales de la ciberesfera. Otras instituciones, sin embargo, mantienen perfiles bajos de adaptación al lenguaje de Internet. Es esta una conclusión relacionada con la escasa importancia otorgada a los canales digitales, en tanto que aún no se perciben como los principales generadores de impacto mediático en la República.

En las redes sociales, según se desprende de los resultados mostrados en las páginas precedentes, una mayor participación institucional en general equivale a una mayor activación de las audiencias. Por participación, en concreto, entendemos el nivel de integración de los recursos multimedia; la organización de los recursos mediante la utilización de carpetas clasificadoras u otros instrumentos de gestión; la complementación de la presencia de la institución en otras redes sociales, o las frecuencias de actualización, factores que inciden directamente en el nivel de popularidad de la comunicación digital.

Según Barredo, Oller y Buenaventura (2013: 83) el paradigma contemporáneo " $<\ldots>$ posee un sistema nervioso central propio, en conexión cercana con el de nuestros cuerpos". Es esta una particularidad que distingue entre los usuarios pasivos, característicos de las sociedades anteriores a la revolución digital, y los usuarios activos, característicos del actual periodo:

“< ..> esa actividad generalizada estimula la aparición de unos nuevos emisores, no ya específicamente profesionales, 
encargados de distribuir y de manipular el conocimiento. Los nuevos emisores trascienden el sentido de la distinción clásica entre emisores/receptores"

Por el contrario, una menor participación introduce sensaciones de decaimiento, hasta el punto de que algunas instituciones -muy conocidas por su prestigio académico- son incapaces de establecer un contacto con sus públicos internos y externos.

Cada una de las redes sociales descritas presenta unas particularidades definidas por unos valores de uso y unas tradiciones propias. Así, en el caso de las cuentas de YouTube, el número global de vídeos publicados no es un factor que determina el mayor número de visitas. En este caso, una mayor popularidad parece estar relacionada con factores cualitativos, como el interés o el aspecto atractivo de las contribuciones audiovisuales.

La popularidad en la red no se consigue únicamente mediante la inyección económica, sino que como afirmamos anteriormente está íntimamente relacionada con factores de calidad. Así, durante el trabajo de campo, hemos visibilizado algunas instituciones que, con un menor número de contribuciones, cosecharon un mayor número de visitas globales en sus redes sociales. Curiosamente, las instituciones con menores presupuestos pueden obtener un mayor impacto que esas otras instituciones con mayores ingresos económicos y, por tanto, una mayor facilidad de difusión en los canales tradicionales a través de soluciones de marketing directo. En trabajos posteriores, convendría realizar un análisis de perfil cualitativo de los canales analizados, así como una revisión temática de los contenidos producidos desde las instituciones. Cuestiones estas que, lejos de plantearse como un déficit de esta contribución, se fijan como complementos que desarrollaremos en siguientes etapas. 


\section{Referencias bibliográficas}

Barredo Ibáñez, Daniel (2013). La crisis de credibilidad de las organizaciones periodísticas: hacia la Sociedad de los Ideantes. Poliantea, IX(16), 101 - 126.

Barredo, Daniel; Oller, Martín y Buenaventura, Sandra (2013). The End of the Information Society. Notes for the Configuration of the New Contemporary Public Space: the Society of Devisers. Observatorio (OBS*) Journal, 7(3), 079 - 091.

Bowman, Shayne y Willis, Chris (2003). We Media: How Audiences Are Shaping the Future of News and Information. The Media Center at the American Press Institute. Recuperado el día 20 de mayo de 2013 de : http://www.hypergene.net/wemedia/download/we_media.pdf

Bucy, Erik P. (2003). Media Credibility Reconsidered: Synergy Effects between On - Air and Online News. Journalism \& Mass Communication Quarterly, 80(2), 247 - 264.

Carpenter, Serena (2010). A study of content diversity in online citizen journalism and online newspaper articles. New Media Society, $12,1064-1084$.

Guzmán, Alba; Del Moral, María Esther; González, Fernando y Gil, Hermenegildo (2013). Impacto de Twitter en la comunicación y promoción institucional de las universidades. Píxel - Bit. Revista de Medios y Educación, 43, 139 - 153.

Harlow, Summer y Harp, Dustin (2012). Collective action on the Web. Information, Communication \& Society, 15(2), 196 - 216.

Howard, Philip N. y Hussain, Muzammil M. (2011). The role of Digital Media. Journal of Democracy, 22(3), 35 - 48.

Gaitán, Juan A. y Piñuel, José Luis (1998). Técnicas de investigación en Comunicación Social. Madrid: Síntesis.

Igartua, Juan José (2006). Métodos cuantitativos de investigación en comunicación. Barcelona: Bosch.

Micó, Josep Lluís y Masip, Pere (2008). Recursos multimedia en los 
cibermedios españoles. Análisis del uso del vídeo en El País.com, El Mundo.es, La Vanguardia.es y Libertad Digital. Trípodos, 23, 89 105.

Reina, José; Fernández, Iris y Noguer, Álvaro (2012). El Uso de las Redes Sociales en las Universidades Andaluzas: El caso de Facebook y Twitter. Revista Internacional de Relaciones Públicas, 4(II), 123 - 144.

Sundar, S. Shyam (2000). Multimedia Effects on Processing and Perception of Online News: A Study of Picture, Audio, and Video Downloads. Journalism \& Mass Communication Quarterly, 77(3), 480 499.

\section{Anexos \\ Anexo 1: direcciones de Facebook}

\begin{tabular}{|l|l|}
\hline \multicolumn{2}{|l|}{ Anexo 1. Facebook de Universidades y Politécnicas ecuatorianas de tipo A (2013) } \\
\hline Institución & Dirección \\
\hline $\begin{array}{l}\text { Universidad } \\
\text { Técnica Particular } \\
\text { de Loja }\end{array}$ & https://www.facebook.com/utpl.loja?fref=ts \\
\hline $\begin{array}{l}\text { Escuela } \\
\text { Politécnica del } \\
\text { Ejército }\end{array}$ & https://www.facebook.com/ESPE.U?fref=ts \\
\hline $\begin{array}{l}\text { Escuela Superior } \\
\text { Politécnica del } \\
\text { Litoral }\end{array}$ & https://www.facebook.com/espol?fref=ts \\
\hline $\begin{array}{l}\text { Universidad } \\
\text { Central del } \\
\text { Ecuador }\end{array}$ & https://www.facebook.com/universidadcentral.delecuador.9 \\
\hline $\begin{array}{l}\text { Escuela Superior } \\
\text { Politécnica de } \\
\text { Chimborazo }\end{array}$ & https://www.facebook.com/eduespoch?fref=ts \\
\hline $\begin{array}{l}\text { Universidad de } \\
\text { Cuenca }\end{array}$ & https://www.facebook.com/ucuenca?fref=ts \\
\hline $\begin{array}{l}\text { Universidad } \\
\text { Técnica de } \\
\text { Ambato } \\
\text { Pscuela }\end{array}$ & $\begin{array}{l}\text { https://www.facebook.com/pages/Universidad -T\%C3\%A9cnica - - } \\
\text { de -Ambato -UTA/106026499473091 }\end{array}$ \\
\hline holtps://www.facebook.com/pages/EPN $\%$ C3\%A9cnica -Nacional/435216793209022 -Escuela \\
\hline
\end{tabular}




\begin{tabular}{|l|l|}
\hline Nacional & \\
\hline $\begin{array}{l}\text { Pontificia } \\
\text { Universidad } \\
\text { Católica del } \\
\text { Ecuador }\end{array}$ & https://www.facebook.com/pontificiauniversidadcatolicadelecuador \\
\hline $\begin{array}{l}\text { Universidad San } \\
\text { Francisco de } \\
\text { Quito }\end{array}$ & https://www.facebook.com/USFQEcuador?fref=ts \\
\hline $\begin{array}{l}\text { Universidad } \\
\text { Andina Simón } \\
\text { Bolívar }\end{array}$ & https://www.facebook.com/universidadandinasimonbolivar?fref=ts \\
\hline $\begin{array}{l}\text { Universidad del } \\
\text { Azuay }\end{array}$ & https://www.facebook.com/uazuay?fref=ts \\
\hline $\begin{array}{l}\text { Instituto de Altos } \\
\text { Estudios } \\
\text { Nacionales }\end{array}$ & https://www.facebook.com/IAENUNIVERSIDAD?fref=ts \\
\hline $\begin{array}{l}\text { Facultad } \\
\text { Latinoamericana } \\
\text { de Ciencias } \\
\text { Sociales }\end{array}$ & https://www.facebook.com/pages/FLACSO -Sede -Ecuador \\
\hline
\end{tabular}

\section{Anexo 2: direcciones de YouTube}

\section{Anexo 2. YouTube de Universidades y Politécnicas ecuatorianas de tipo A (2013)}

\begin{tabular}{|l|l|}
\hline Institución & URL \\
\hline $\begin{array}{l}\text { Escuela Superior Politécnica del } \\
\text { Litoral }\end{array}$ & http://www.youtube.com/user/espol50/ \\
\hline $\begin{array}{l}\text { Universidad Técnica Particular de } \\
\text { Loja }\end{array}$ & http://www.youtube.com/user/utpl \\
\hline Escuela Politécnica Nacional & http://www.youtube.com/user/EPNEcuador \\
\hline Universidad Andina Simón Bolívar & http://www.youtube.com/user/uasbecuador \\
\hline $\begin{array}{l}\text { Pontificia Universidad Católica del } \\
\text { Ecuador }\end{array}$ & http://www.youtube.com/user/videosPUCE \\
\hline Universidad San Francisco de Quito & http://www.youtube.com/user/USFQEcuador \\
\hline
\end{tabular}

${ }^{51}$ Datos consultados el 22/07/2013 de Facebook.com 


\begin{tabular}{|l|l|}
\hline $\begin{array}{l}\text { Instituto de Altos Estudios } \\
\text { Nacionales }\end{array}$ & http://www.youtube.com/user/iaenuniversidad \\
\hline Universidad Central del Ecuador & http://www.youtube.com/user/UCEVideo \\
\hline Escuela Politécnica del Ejército & http://www.youtube.com/user/espe2web \\
\hline Universidad del Azuay & http://www.youtube.com/user/uazuay \\
\hline $\begin{array}{l}\text { Escuela Superior Politécnica de } \\
\text { Chimborazo }\end{array}$ & http://www.youtube.com/user/ESPOCHCLASEA \\
\hline $\begin{array}{l}\text { Facultad Latinoamericana de } \\
\text { Ciencias Sociales }\end{array}$ & http://www.youtube.com/user/Flacsoecuador \\
\hline Universidad de Cuenca & NO ENCONTRADO \\
\hline Universidad Técnica de Ambato & NO ENCONTRADO \\
\hline & \multicolumn{1}{|c|}{ Fuente: elaboración propia / YouTube.com ${ }^{52}$} \\
\hline
\end{tabular}

\section{Agradecimientos}

Los autores agradecen expresamente al Proyecto Prometeo de la Secretaría de Educación Superior, Ciencia, Tecnología e Innovación de la República del Ecuador por prestar indirectamente fondos para realizar este proyecto. Asimismo, sus resultados fueron presentados en el marco del V Congreso Internacional Latina de Comunicación Social, celebrado en Tenerife (España) en el mes de diciembre de 2013 bajo el título La importancia de la comunicación digital en las instituciones: un estudio a partir de las Universidades y Politécnicas ecuatorianas de clase $A$ (2013).

${ }^{52}$ Datos consultados el 23/07/2013 de YouTube.com 


\title{
VII
}

\section{La comunicación y la vinculación en la universidad ecuatoriana. Propuesta de creación del Centro Universitario de Jóvenes Emprendedores (CUJE) en la Universidad de las Américas (UDLA), Ecuador}

\author{
Martin Oller. Universidad de las Américas, Ecuador \\ Palmira Chavero. Facultad Latinoamericana de Ciencias Sociales, Ecuador \\ Rafael Jorda. Universidad de las Américas, Ecuador \\ Xavier Oviedo. Universidad de las Américas, Ecuador
}

\section{Introducción}

— N ESTE CAPÍTULO se propone la creación del Centro 1 Universitario de Jóvenes Emprendedores (CUJE) en la Universidad de las Américas (UDLA). El CUJE es creado como estrategia de vinculación con el mercado laboral, el cual permite realizar prácticas pre -profesionales a los estudiantes dentro de la universidad, cumpliendo con lo citado en el Art. 350 de la Constitución de la República del Ecuador donde señala que "son fines de la Educación Superior la formación académica y profesional con visión científica y humanista; la innovación científica y tecnológica; la innovación, promoción, desarrollo y difusión de los saberes y las culturas; la construcción de soluciones para los problemas del país y la relación con los objetivos del régimen de desarrollo". 
Además el CUJE busca capacitar a universitarios capaces de ejercer todas las responsabilidades que se presentan en el mercado laboral de hoy en día. De esta manera se incentiva que los estudiantes desarrollen un criterio propio, analítico y profesional según lo cita el Art. 8 de la LOES en su literal b) donde indica que "uno de los fines de la Educación Superior es fortalecer en las y los estudiantes un espíritu reflexivo orientado al logro de la autonomía personal, en un marco de libertad de pensamiento y de pluralismo ideológico".

La UDLA nació en el año 1995, actualmente está compuesta por las Facultades de Ciencias Económicas y Administrativas (FACEA), Arquitectura, Comunicación, Derecho, Ingeniería y Ciencias Agropecuarias; la Escuela de Ciencias Sociales, las Facultades de Turismo y Hospitalidad, Ciencias de la Salud, Odontología y Medicina, las Escuelas de Música y Cine y la Facultad de Formación General. La UDLA es una de las universidades privadas más grandes del país con casi 16.000 estudiantes y ofrece 41 carreras de pregrado distribuidas en modalidades presenciales $y$ semipresenciales en horarios diurno, vespertino y nocturno. En 2005 crea la Escuela de Tecnologías y se incorpora a la Red Laureate International Universities; en 2006 aparece la oferta de posgrados.

La FACEA está integrada en la UDLA y cuenta con las carreras de 1) Administración de empresas, 2) Economía, 3) Finanzas, 4) Negocios Internacionales, 5) Marketing, 6) Negocios y marketing deportivo ${ }^{53}$.

Los estudiantes de la UDLA, en los últimos años han venido investigando y desarrollando una serie de ideas de negocio y productos que han recibido el reconocimiento a nivel nacional e internacional ${ }^{54}$. Sin embargo, estos aún adolecen de algunos de los mecanismos necesarios para que sus propuestas obtengan el efecto

\footnotetext{
${ }^{53}$ Datos consultados el 10/12/2014:

http://www.udla.edu.ec/carreras/programas -

academicos/pregrados/facultad - de - ciencias - economicas - y administrativas/

${ }^{54}$ P.E. Un grupo de estudiantes de la FACEA fueron seleccionados por la Red Laureate para participar en el concurso James McGuire.
} 
social deseado y ayudar, de este modo, a la acreditación ${ }^{55}$ de la universidad según estipula el Gobierno y el Consejo de Evaluación, Acreditación y Aseguramiento de la Calidad de la Educación Superior (CEAACES).

La finalidad de este proyecto es la creación de una organización de servicios empresariales dentro de la universidad gestionada a nivel operativo íntegramente por estudiantes y que permita contribuir a su formación integral y a su vinculación con la sociedad.

\section{La comunicación y la vinculación en la universidad de Ecuador}

Las funciones principales de la universidad son la formación odocencia, la investigación y la extensión(Castro y col., 2009; Gutiérrez, 2007;Moncada, 2008; Revelo, 2004). Esta, como principal institución de educación superior, debe fomentar: en primer lugar, la educación que posibilite a la ciudadanía obtener los recursos y la formación necesaria para acceder a una profesión. Gutiérrez (2007) señala que la función de formación permite a los individuos el refinamiento de sus capacidades y el acceso a las expresiones más elaboradas de la cultura, haciéndolos partícipes y, a la vez, constructores de esta. En segundo lugar, la investigación orientada al desarrollo de procesos complejos que permita llegar a nuevos conocimientos. Por último, en tercer lugar, la vinculación que desarrolle un proceso comunicacional efectivo y eficiente entre la universidad, la comunidad y la sociedad.

En la medida en que las inquietudes y necesidades de las sociedades se han transformado, las funciones de las universidades igualmente lo han hecho, redefiniendo sus características y principios, para responder a su entorno (Pineda, Morales y Ortiz, 2011). Sin embargo, la vinculación entre la Universidad y la Empresa todavía es muy débil en Latinoamérica. Según Jiménez y Castellanos (2008), las

\footnotetext{
${ }^{55}$ Es un proceso de evaluación institucional de la calidad de la educación superior de las universidades de Ecuador llevado a cabo por el CEAACES que se inició en abril de 2012.
} 
limitaciones más destacadas son: a) la falta de claridad en la normatividad estatal e institucional, que responda a las necesidades en investigación, desarrollo científico y tecnológico y propiedad intelectual y patentes, lo cual ha causado una inadecuada definición de las funciones de estos organismos y b) las condiciones socioculturales adversas que se han visto reflejadas en las fuertes separaciones entre la academia y la industria.

Una de las principales falencias de la universidad en América Latina radica en la falta de construcción de estrategias de desarrollo de los canales de comunicación que proporcionen un mayor aperturismo de la comunidad académica y de los estudiantes. Por este motivo, las universidades, conscientes del limitado aporte que han hecho hasta ahora a la cultura emprendedora, están iniciando programas de nuevos emprendimientos, introduciendo materias relacionadas en los programas de estudio de otras carreras profesionales y desarrollando trabajos de investigación sobre múltiples aspectos del fenómeno de la creación de empresas. También están aumentando las conferencias y los congresos - varios de ellos con convocatoria internacional - en muchos de los países de la región, muestra del renovado interés que despierta el tema en la sociedad civil y la académica (Kantis y col., 2004).

A través de la implantación del Centro Universitario de Jóvenes Emprendedores en la UDLA se pretende intensificar los procesos de vinculación en esta institución, tanto a nivel interno como externo. A pesar de que se ha teorizado acerca de la necesidad de una relación mucho más dinámica entre la universidad y la sociedad, en la praxis, aún debe generarse un plan que fomente nexos comunes que lleven, en primer lugar, a los estudiantes a aumentar su capacidad competitiva e innovadora dirigida a una mayor y más efectiva inserción en el mundo profesional, tanto a nivel nacional como internacional y, en segundo lugar, a la sociedad para que a partir de la transferencia de los conocimientos profesionales y técnicos generados en la universidad se palie las demandas, las necesidades y los problemas de la sociedad ecuatoriana. La función de extensión, también llamada la tercera misión de las universidades, se refiere a todas aquellas actividades a través de las cuales la 
Universidad se relaciona con su entorno, es decir, con la sociedad, las empresas y el Estado (Bueno, 2007).

Hoy en día es necesario para las instituciones educativas influir en su entorno de una forma más activa, pasando de un estado inicial, en donde el incentivo era básicamente académico, a un estado en el que se aplica el conocimiento a la satisfacción de necesidades o a la resolución de problemas del medio. A partir de la formación en áreas como el emprendimiento, la innovación, el liderazgo y la responsabilidad social, los conocimientos no solo se producen y transmiten, sino que se registran, se aplican, se patentan, se comercializan, se asocian, se exportan y se importan (Moncada, 2008).

La creación de estructuras como el CUJE dentro de la colectividad académica articula distintos campos de trabajo académicos, investigativos y profesionales en busca de un proceso de vinculación que implemente formulas colaborativas efectivas. Para ello, estos procesos de vinculación se formulan como acciones dirigidas a la inserción de la comunidad universitaria ecuatoriana en la economía social -global- del conocimiento y en la construcción de nuevos servicios sociales y procesos productivos que permitan un desarrollo integral y proporcionado de Ecuador.

\section{La regulación de las universidades en Ecuador}

La universidad ecuatoriana se sustenta en la base legal que regula sus procesos y estructuras, permitiendo su homologación. Estas normativas favorecen el carácter innovador y vinculante de esta respecto al resto de instituciones y la sociedad. Así lo estipula la legislación vigente:

CONSTITUCIÓN. - El Art. 350 de la constitución señala que "son fines de la Educación Superior: Formación académica y profesional con visión científica y humanista; la innovación científica y tecnológica; la innovación, promoción, desarrollo y difusión de los saberes y las culturas; la construcción de soluciones para los problemas del país, el relación con los objetivos del régimen de desarrollo". 
LEY ORGÁNICA DE EDUCACIÓN SUPERIOR. - El Art. 3 señala: "Fines de la Educación Superior. - La educación superior de carácter humanista, cultural y científica constituye un derechos de las personas y un bien público social que, de conformidad con la Constitución de la República, responderá al interés público y no estará al servicio de intereses individuales y corporativos".

El Art. 8 señala: "Son fines de la Educación Superior. - La educación superior tendrá los siguientes fines:

Aportar al desarrollo del pensamiento universal, al despliegue de la producción científica y a la producción de las transferencias e innovaciones tecnológicas.

Fortalecer en las y los estudiantes un espíritu reflexivo orientado al logro de la autonomía personal, en un marco de libertad de pensamiento y de pluralismo ideológico.

Fomentar y ejecutar programas de investigación de carácter científico, tecnológico y pedagógico que coadyuven al mejoramiento y protección del ambiente y promuevan el desarrollo sustentable nacional.

Contribuir al desarrollo local y nacional de manera permanente, a través del trabajo comunitario y extensión universitaria".

Art. 13, literal b señala: "Funciones del sistema de educación superior. - Son funciones del sistema de educación superior:

Promover la creación, desarrollo, transmisión y difusión de la ciencia, la técnica, la tecnología y la cultura".

REGLAMENTO GENERAL A LA LEY ORGÁNICA DE EDUCACIÓN SUPERIOR. - El Art. 7 señala: "De los servicios a la comunidad. -Los servicios a la comunidad se realizarán mediante prácticas y pasantías pre profesionales, en los ámbitos urbano y rural, según las propias características de la carrera y las necesidades de la sociedad". 


\subsection{Los estatutos de la Universidad de las Américas ${ }^{56}$}

Aunque existe una regulación externa a las universidades de Ecuador, todas las instituciones académicas de educación superior del país cuentan con sus propias normas de funcionamiento, las cuales tienen que pasar por la aprobación del Consejo de Educación Superior (CES). Estas normas internas actúan como punto de partida para el correcto funcionamiento de la institución basado en parámetros como el de responsabilidad, eficiencia, utilidad y eficacia. Concretamente, el artículo sexto de los estatutos de la UDLA apoya la incorporación de organizaciones con las características del Centro Universitario de Jóvenes Emprendedores (CUJE) a partir de los siguientes literales:

Literal A: Aportar a la sociedad mediante el cultivo, el progreso creativo y la transmisión del saber superior;

Literal B: Aportar a la sociedad a través de la formación de personas que, de conformidad con los principios morales propios de nuestra cultura, alcancen la capacidad física e intelectual que les permita hacer prosperar a la comunidad, contribuir positivamente al desarrollo de las ciencias, las artes, las letras y las técnicas o en el desempeño de una actividad técnica o profesional;

Literal C: Contribuir al desarrollo del raciocinio, la cultura y el saber superior, para atender adecuadamente los intereses y necesidades de la comunidad y sus miembros, con el más alto nivel de excelencia;

Literal D: Contribuir al desarrollo espiritual y cultural de la sociedad y sus integrantes y a la difusión de los principios de libertad, espiritualidad, moralidad y solidaridad social;

El artículo séptimo señala que para el cumplimiento de sus objetivos, la Universidad desarrollará durante su existencia las siguientes actividades:

${ }^{56} \mathrm{El}$ documento citado ha sido extraído del informe que realiza el Consejo de Educación Superior de Ecuador (CES) acerca de los estatutos presentados por la UDLA para su aprobación final. Este se encuentra disponible en su web: http://www.ces.gob.ec/ 
Literal C: Cormará, capacitará, especializará a graduados y profesionales idóneos y actualizará los conocimientos de estudiantes y profesionales en los niveles de pre -grado y postgrado, en las diversas especialidades y modalidades para el cabal y correcto ejercicio de sus respectivas actividades;

Literal F: Convendrá con otros establecimientos educacionales nacionales y extranjeros, en especial con las universidades y escuelas politécnicas, actividades de colaboración mutua;

Literal H: Organizará y pondrá en funcionamiento programas de formación profesional en las distintas áreas del saber;

Literal I: Se relacionará con el Estado, entidades públicas, empresas públicas, mixtas, colegios profesionales, entidades gremiales, establecimientos educacionales, empresas privadas y con los particulares en general;

Literal M: Realizará cualquier otra actividad destinada a lograr, directa o indirectamente, sus propios objetivos;

Literal Ñ: Organizará y dictará cursos, seminarios, simposios, mesas redondas y otros, en las distintas áreas del saber;

Literal P: Garantizará el ejercicio de los derechos de los miembros de la comunidad con capacidades especiales previstos en la Constitución y en Ley Orgánica de Educación Superior, incluyendo el cumplimiento de la accesibilidad a servicios de interpretación y los apoyos técnicos necesarios.

\section{E1 concepto de Centro Universitario de Jóvenes Emprendedores (CUJE)}

Según Etzkowitz (1995 y 2000), para maximizar la capitalización del conocimiento, la academia debe integrarse estrechamente con las firmas industriales.El Centro Universitario de Jóvenes Emprendedores es una organización de estudiantes universitarios sin ánimo de lucro, que nace con la idea de mejorar la formación 
académica y la vinculación profesional de los estudiantes universitarios. Se trata de un concepto relativamente nuevo en el país, creado con el objetivo de ser un complemento práctico de la enseñanza teórica que los universitarios adquieren en sus estudios y como iniciativa de mejora de la relación entre el mundo universitario y el empresarial.

En algunos países desarrollados existe una tendencia creciente, de las corporaciones privadas, a desarrollar alianzas estratégicas con universidades. Muchos de estos países están aprobandonuevas legislaciones y llevando a cabo innovaciones institucionales de diferentes tipos, así como descubriendo sus propios caminos de interacción y desarrollo. Algunos de los mecanismos empleados son las incubadoras de empresas, los parques científicos y tecnológicos, las pasantías y prácticas profesionales, las consultorías, los programas de educación continuada, los centros de investigación cooperativa y de tecnología, las organizaciones regionales de innovación, las alianzas estratégicas o consorcios, los centros o unidades empresariales y las políticas institucionales y nacionales, entre otros (Pineda, Morales y Ortíz, 2011).

El CUJE es dirigido y gestionado por y para estudiantes en busca de la diversificación de la oferta/demanda educativa y profesional de la universidad. Para ello, los estudiantes trabajarían en colaboración con organizaciones públicas y privadas, adquiriendo de este modo la preparación práctica que les facilitaría su incorporación al mundo laborala través de algunos de los mecanismos vistos anteriormente.

Los proyectos llevados a cabo en el centro estarán relacionados con la formación y las áreas de estudio de los estudiantes dentro de sus carreras universitarias. Para facilitar el trabajo de los estudiantes que forman parte del CUJE, este cuenta con la infraestructura necesaria dentro de la universidad: un espacio físico, material informático, acceso a los distintos servicios ofertados (biblioteca, bases de datos, etc.) y el asesoramiento y orientación por parte de un equipo de profesores de la facultad.

Una parte de los ingresos por servicios prestados revierte en los propios integrantes de cada uno de los proyecto en concepto de 
becas compensatorias. Otra parte se integra en el fondo social del CUJE, destinado a la propia sostenibilidad del centro y los proyectos de formación continua de los asociados y del resto de la comunidad universitaria.

En Latinoamérica, son muy recientes y reducidos los esfuerzos para el establecimiento de una infraestructura física y social para el fortalecimiento de la relación Universidad -Empresa (Pineda y Morales, 2010), parte de ello se evidencia en los escasos proyectos de investigación, realizados a partir de alianzas entre el sector productivo y académico, la falta de claridad sobre el manejo de propiedad intelectual y patentes, niveles de emprendimiento bajos, que en su mayoría son por necesidad y no por oportunidad (Arraut y col., 2009).

El CUJE a través de su actividad pretende conseguir tres grandes objetivos:

1) Generar un espacio permanente dentro de la UDLA en el que los universitarios puedan crear y generar, a partir de su auto organización, insumos y dinámicas -planificación, gestión y evaluación- propios de una empresa; favoreciendo la interacción y la comunicación entre ellos, los distintos estamentos universitarios, el mundo empresarial y la sociedad.

2) Optimizar los sistemas de vinculación entre la universidad y la sociedad a partir del fortalecimiento de estrategias y políticas educativas que impulsen el trabajo colaborativo, dinámico y profesional de los estudiantes.

3) Crear redes y políticas universitarias de inclusión para llegar a lo propuesto por el Plan Nacional del Buen Vivir, contribuyendo al aumento de oportunidades y posibilidades de los estudiantes y de la sociedad ecuatoriana.

La razón de ser del CUJE es la formación, la capacitación y la vinculación de los estudiantes con el tejido empresarial de la región en las distintas áreas de estudio que conforman la FACEA -área de 
Marketing, Gestión Deportiva, Administración de Empresas, Finanzas y Negocios internacionales-.

Existen actores en la Universidad que contribuyen a alcanzar estos objetivos y que se complementarían al trabajo del CUJE: 1) la Asociación de Estudiantes de la UDLA (ASEUDLA), encargada de organizar eventos de vinculación, como conferencias, que complementan la formación de las carreras de la FACEA y 2) el departamento de Bolsa de Empleo, que mantiene el compromiso de vincular a los estudiantes con las necesidades de las empresas. Sin embargo, se observa que no existe ningún actor que ofrezca servicios profesionales a la comunidad, ya sea a organizaciones públicas, privadas o sin ánimo de lucro. Por lo que la principal propuesta del CUJE es ofrecer servicios profesionales relacionados con el área de 1) marketing, 2) finanzas personales, 3) finanzas corporativas, 4) estudios sectoriales, 5) planes de exportación/importación, 6) logística, 7) gestión deportiva y 8) responsabilidad social.

\subsection{El Centro de Investigación Económica (CIE) de la UDLA}

El Centro de Investigación Económica (CIE) está conformado por profesores de la FACEA que busca desarrollar para el Ecuador y para América Latina análisis sobre algunos de los principales temas de economía y finanzas para incentivar el desarrollo de personas, empresas y países en la región.

En el CIE se llevan a cabo proyectos de investigación y análisis económico del Ecuador y la región con organismos internacionales como el Banco Mundial, la Comunidad Andina (CAN), el Banco Interamericano de Desarrollo (BID), la Organización de Estados Americanos (OEA), entre otros. Estos estudios buscan profundizar el conocimiento sobre la economía ecuatoriana y latinoamericana, así como contribuir al desarrollo de mejores políticas y programas económicos para el país y la región. También prestan servicios de consultoría económica y financiera a importantes empresas ecuatorianas. Estas consultorías buscan desarrollar herramientas 
analíticas que permitan un mejor entendimiento de los mercados, sus fortalezas, debilidades y acciones destinadas a mitigar riesgos y aprovechar oportunidades de negocio con la finalidad de mejorar la calidad y la interpretación de la información disponible para la toma de decisiones de negocio.

Un importante objetivo del CIE es fusionar las dos facetas claves de la formación universitaria: la academia y la investigación. En esta dirección, sus proyectos combinan la experiencia del equipo de investigación, formado por profesores investigadores de la FACEA, con las capacidades y el deseo de aprender de destacados estudiantes de la UDLA. Adicionalmente, a través de la publicación de una serie de working papers, el CIE auspicia la investigación académica en economía, negocios y finanzas en el país. Estos trabajos de investigación académica contribuyen a incrementar el entendimiento de la sociedad sobre el desarrollo de la economía ecuatoriana y de la ciencia económica en general ${ }^{57}$.

\subsection{Relación entre el Centro Universitario de Jóvenes Emprendedores (CUJE) y el Centro de Investigación Económica (CIE)}

El CUJE es una organización sin ánimo de lucro formada por estudiantes universitarios con el objetivo de ser un complemento práctico de la enseñanza teórica que los universitarios adquieren en su formación. Se pretende con esta iniciativa conseguir un mayor acercamiento del mundo universitario al mundo empresarial. Por su parte, El CIE busca estimular la investigación científica, en especial aquella que contribuya al progreso económico y social del país, promoviendo una interacción entre los sectores público y privado con la universidad.

La relación entre un CUJE y el CIE en la Universidad de las Américas (UDLA) se basa en el planteamiento de propuestas y estrategias de progreso en distintos ámbitos como consultoría y asesoría empresarial, promoción de la investigación académica, etc.

\footnotetext{
${ }^{57}$ Datos consultados el 10/12/2014: http://cie.udla.edu.ec/ElCIE.aspx
} 
Con lo cual, se pretende brindar soluciones a las necesidades y requerimientos que se presentan en los sectores productivos y sociales; ayudando así, al progreso económico y social del país.

La puesta en marcha del CUJE se apoya en el CIE, ya que es una organización que está consolidada en el mercado y acumula más de 5 años de experiencia llevando a cabo proyectos de consultoría en el ámbito de la economía y los negocios en Ecuador. Los profesores investigadores que trabajan en este centro son los mentores de los estudiantes que conforman el CUJE, actuando como supervisores. Además se comparte el networking del CIE con el CUJE, generando sinergias entre ambos centros. El trabajo conjunto entre el CIE y el CUJE ofrecere un servicio de consultoría en el ámbito empresarial a pequeñas y medianas empresas del Ecuador, lo cual permite a los estudiantes acumular experiencia laboral antes de graduarse e incluso supone la oportunidad para incorporarse en algunas de las empresas colaboradoras. El CUJE se convierte en un sólido puente entre la Universidad y la Empresa, acercando a los alumnos al tejido empresarial de la zona. Además, los servicios ofrecidos por el CUJE son muy atractivos para las empresas debido a que obtienen un servicio de calidad en unas condiciones económicas muy favorables y competitivas basadas en parámetros profesionales de alta calidad.

\section{Propuesta de creación del Centro Universitario de Jóvenes Emprendedores (CUJE)}

\subsection{Denominación}

El Centro Universitario de Jóvenes Emprendedores (CUJE) es una asociación de carácter no lucrativo constituido y gestionado por estudiantes que opera dentro de la FACEA, desde el que ofrece sus servicios a las empresas y a la comunidad estudiantil en materias relacionadas con sus estudios y capacitaciones.

Conviene destacar el hecho de que al estar encuadrado dentro de la Universidad, obtiene un apoyo en forma de asesoramiento técnico por parte de sus departamentos, lo cual, junto con el soporte de las diferentes áreas, garantiza la calidad de sus servicios. 
Los beneficios obtenidos son destinados a otras actividades que complementan la formación de los estudiantes del centro a través de cursos, seminarios, conferencias, mesas redondas; así como a fomentar el contacto con las otras instituciones académicas, tanto de Ecuador como del resto de Latinoamérica.

El CUJE es una organización dinámica, encontrándose sus asociados en permanente renovación, puesto que es condición indispensable para pertenecer al CUJE estar matriculado en una de las 6 carreras de las que se compone la FACEA.

\subsection{Visión}

- Romper el tradicional circulo en el que para conseguir trabajo hace falta experiencia. Este objetivo se consigue a partir de la propia creación del CUJE, pues es una forma de generar trabajo, y por tanto experiencia, que parte de la iniciativa de los propios estudiantes.

- Conseguir una formación práctica y real que complemente a la formación académica. Este objetivo de perfeccionamiento formativo se consigue a través de la realización de los trabajos encargados por las empresas, así como la reinversión en formación que realiza el CUJE con los beneficios obtenidos a partir de la realización de trabajos, cursos, capacitaciones, etc.

- Llegar a ser un sólido puente entre la Universidad y la Empresa, incrustando el mercado y la estructura empresarial dentro de la propia vida académica y universitaria; acercando así el mundo universitario al tejido empresarial, produciéndose grandes efectos sinérgicos en esta necesaria interacción "Universidad-Empresa".

- Conseguir una cantera de jóvenes emprendedores y de futuros directivos que asuman todas las responsabilidades que se les exigirán cuando estén inmersos en el mundo laboral de Ecuador u otros países. Este objetivo se consigue cuando todo el personal dentro del CUJE asume esas responsabilidades, como en cualquier otra empresa en la que ellos trabajarán en un futuro inmediato. 


\subsection{Misión}

La misión del Centro Universitario de Jóvenes Emprendedores (CUJE) es solucionar una de las asignaturas pendientes de la UDLA; proyectar a sus estudiantes hacia el mundo laboral y profesional. El problema que encontramos en las universidades ecuatorianas es que existe una profunda formación teórica, obviando la capacitación práctica y la integración de los estudiantes en el mundo laboral a partir de una vinculación profesional sólida.

\subsection{Fines}

Los fines a los que se pretende llegar son:

- Ofertar y ofrecer al alumno todas las posibilidades educativas y profesionales que existen hoy en día.

- Preparar al alumno de forma integral, con una capacitación tanto teórica como práctica.

- Canalizar toda la información, tanto profesional como académica, que le llega a los alumnos.

- Gestionar y fomentar la relación entre el binomio profesor/alumno para conseguir el mayor número de ventajas para ambos.

- Completar la formación de los estudiantes.

- Fomentar la relación y la integración de la UDLA con y dentro del entorno social, político y económico de Ecuador.

\section{Los estatutos del Centro Universitario de Jóvenes Emprendedores (CUJE)}

\section{CAPITULO PRIMERO}

\section{DENOMINACION}

Artículo1. -Estatutos del Centro Universitario de Jóvenes Emprendedores (CUJE) de la Universidad de las Américas.

El Centro Universitario de Jóvenes Emprendedores se regirá por los preceptos de las citadas Leyes de Asociaciones, por los presentes 
Estatutos en cuanto no estén en contradicción con la Ley, por los acuerdos válidamente adoptados por sus órganos de gobierno, siempre que no sean contrarios a la Ley y/o a los Estatutos, y por las disposiciones reglamentarias que apruebe el Gobierno Ecuatoriano, que solamente tendrán carácter supletorio.

\section{FINES QUE SE PROPONE}

Artículo2. - Los fines de (CUJE) son:

- Coordinar las actividades de los miembros, velando por la observación de las obligaciones impuestas por la legislación vigente y sus respectivos Estatutos.

- Potenciar los vínculos de unión entre las distintas instituciones de la UDLA con el fin de mantener contactos e intercambiar información sobre las respectivas actividades.

- Tratar de que cada uno de los departamentos desarrollen al máximo los fines previstos en sus Estatutos.

- Promocionar, expandir y consolidar el Centro Universitario de Jóvenes Emprendedores en el ámbito universitario ecuatoriano.

- Defender los intereses de los miembros.

- Representar a los miembros.

- Constituirse como juez ante litigios que se presenten entre los miembros.

- Controlar las actuaciones de las Asociaciones miembros de manera que se ciñan al espíritu del Centro Universitario de Jóvenes Emprendedores.

Sin perjuicio de las actividades descritas en el apartado anterior, el Centro, para el cumplimiento de sus fines podrá:

- Desarrollar actividades económicas de todo tipo, encaminadas a la realización de sus fines o a allegar recursos con ese objetivo.

- Adquirir y poseer bienes de todas clases y por cualquier título, así como celebrar actos y contratos de todo género.

- Ejercitar toda clase de acciones conforme a las Leyes o a sus Estatutos. 


\section{a. DOMICILIO SOCIAL}

Artículo 3. - El domicilio principal de este centro estará ubicado en la Facultad de Ciencias Económicas y Administrativas, Av. Granados y esq. Colimes. Quito, Ecuador.

b. AMBITO TERRITORIAL

Artículo 4. - El ámbito territorial en el que desarrollara principalmente sus funciones, será en la cuidad de Quito, provincia de Pichincha, región sierra norte del Ecuador.

\section{c. DURACIÓN Y CARÁCTER DEMOCRÁTICO}

Artículo 5. - El centro se constituye con carácter permanente, y solo se disolverá por acuerdo de los miembros integrantes del (CUJE) dispuesto en el Capítulo VI o por cualquiera de las causas previstas en las Leyes.

La organización interna y el funcionamiento del (CUJE), deberán ser democráticos, con pleno respeto al pluralismo. Serán nulos de pleno derecho los pactos, disposiciones estatutarias y acuerdos que desconozcan cualquiera de los aspectos del derecho fundamental del centro.

\section{CAPÍTULO SEGUNDO}

\section{1. ÓRGANOS DE GOBIERNO Y ADMINISTRACIÓN}

Artículo 6. - El gobierno y administración del CUJE estarán a cargo de los siguientes órganos colegiados:

- La Asamblea General de Socios, como órgano supremo.

- La Junta Directiva, como órgano colegiado de dirección permanente.

a. LA ASAMBLEA GENERAL

Artículo 7. - La Asamblea General, integrada por los representantes de todas las instituciones asociadas, es el órgano de expresión de la voluntad de estos. Se reunirá en sesiones ordinarias y extraordinarias.

Son facultades de la Asamblea General los acuerdos relativos a: 
- La aprobación del plan general de actuación del CUJE.

- El examen y aprobación de las cuentas anuales.

- El examen y aprobación del presupuesto del ejercicio siguiente.

- El examen y aprobación del informe de gestión de la Junta Directiva.

- La elección de los miembros de la Junta Directiva.

- La Fijación de las cuotas ordinarias o extraordinarias.

- La modificación de Estatutos.

- La disolución del centro.

- La asociación con otros centros, o el abandono de algunas de ellos.

- La disposición o enajenación de bienes.

- La elección y el cese del presidente o la presidenta, el secretario o la secretaria, del tesorero o la tesorera, el o los vicepresidentes o vicepresidentas y, si lo hubiere, de los demás miembros del órgano de gobierno colegiado, así como su supervisión y control.

- El acuerdo de remuneración de los miembros del órgano de gobierno, en su caso.

- La adopción del acuerdo de separación definitiva de las personas asociadas.

Cualquier otra competencia no atribuida a otro órgano social. Artículo 8. - La Asamblea General se reunirá en sesiones ordinarias y extraordinarias.

Articulo 9. - La Asamblea General deberá ser convocada en sesión ordinaria, al menos una vez al año, dentro del último trimestre, a fin de adoptar los Acuerdos previstos en el artículo 7 -a), b), c), d) y e). Articulo 10. - La Asamblea General se reunirá en sesión extraordinaria cuando así lo acuerde la Junta Directiva, bien por propia iniciativa, o porque lo soliciten más del 50\% de los asociados, indicando los motivos y fin de la reunión y, en todo caso, para conocer y decidir sobre las siguientes materias: 
- La modificación de Estatutos.

- La disolución del centro.

- La asociación con otros centros, o el abandono de algunas de ellas.

- La disposición o enajenación de bienes.

Artículo 11. - Las convocatorias de las Asambleas Generales se realizaran por escrito expresando el lugar, día y hora de la reunión, así como el orden del día con expresión concreta de los asuntos a tratar. Entre la convocatoria y el día señalado para la celebración de la Asamblea en primera convocatoria habrán de mediar al menos siete días naturales, pudiendo así mismo hacerse constar si procediera, la fecha y hora en que se reunirá la Asamblea en segunda convocatoria, sin que entre una y otra pueda mediar un plazo inferior a media hora.

Junto a la convocatoria de la Asamblea General se deberá hacer llegar a los socios la documentación necesaria sobre los puntos a tratar en el orden del día.

Las Asambleas Generales, tanto ordinarias como extraordinarias, quedaran válidamente constituidas en primera convocatoria, cuando concurran a ella la mitad más uno de los asociados con derecho a voto, y en segunda convocatoria cualquiera que sea el número de asociados con derecho a voto presente.

Podrá asistir, con voz pero sin voto, a las Asambleas cualquier miembro del movimiento CUJE. Y a propuesta de alguno de los miembros, o por propia iniciativa, la Junta Directiva podrá invitar personas ajenas al movimiento.

Artículo 12. - Los acuerdos de la Asamblea General se adoptaran por mayoría simple de las personas presentes o representadas, cuando los votos afirmativos superen a los negativos. No obstante, requerirán mayoría cualificada de las personas presentes o representadas, que resultara cuando los votos afirmativos superen la mitad de los válidamente emitidos, los acuerdos relativos a la 
disolución del centro, la modificación de estatutos y la disposición o enajenación de bienes.

Artículo 13. - Los socios podrán otorgar su representación, a los efectos de asistir a las Asambleas Generales, en cualquier otro socio. Tal representación se otorgará por escrito, y deberá obrar en poder del Secretario de la Asamblea, al comienzo de la sesión. Los socios que residan en ciudades distintas a aquella en que tenga su domicilio social la Asociación, podrán remitir por correo electrónico el documento que acredite la representación.

b. LA JUNTA DIRECTIVA

Artículo 14. - La Junta Directiva es el órgano de representación que gestiona y representa los intereses del CUJE, de acuerdo con las disposiciones y directivas de la Asamblea General. Solo podrán formar parte del órgano de representación los asociados.

La Junta Directiva estará integrada por un Presidente, un Secretario, un Tesorero y uno o dos Vicepresidentes.

Deberán reunirse al menos una vez al trimestre y siempre que lo exija el buen desarrollo de las actividades sociales.

Artículo 15. - La falta de asistencia a las reuniones señaladas, de los miembros de la Junta Directiva, en 2 ocasiones sin causa justificada, dará lugar al cese inmediato en el cargo respectivo.

Articulo 16. - Los cargos que componen la Junta Directiva, se elegirán por la Asamblea General y duraran un periodo de un año, salvo revocación expresa de aquella, pudiendo ser objeto de reelección.

Dichos cargos se renovaran de forma total.

Artículo 17. - Para pertenecer a la Junta Directiva serán requisitos indispensables: 
- Ser mayor de edad, estar en pleno uso de los derechos civiles y no estar incurso en los motivos de incompatibilidad establecidos en la legislación vigente.

- Ser designado en la forma prevista en los Estatutos.

Articulo 18. - El cargo de miembro de la Junta Directiva se asumirá cuando, una vez designado/a por la Asamblea General, se proceda a su aceptación o toma de posesión.

La Asamblea General podrá establecer, en su caso, el abono de dietas y gastos de los miembros de la Junta Directiva.

Artículo 19. - Los miembros de la Junta Directiva cesaran en los siguientes casos:

- Expiración del plazo de mandato.

- Dimisión.

- Incursión en causa de incapacidad.

- Revocación acordada por la Asamblea General en aplicación de lo previsto en el artículo 16 de los presentes Estatutos.

- Fallecimiento.

Cuando se produzca el cese por la causa prevista en el apartado a, los miembros de la Junta Directiva continuaran en funciones hasta la celebración de la primera Asamblea General, que procederá a la elección de los nuevos cargos.

En los supuestos b), c), d) y e), la propia Junta Directiva proveerá la vacante mediante nombramiento provisional, que será sometido a la Asamblea General para su ratificación o revocación, procediéndose, en este último caso, a la designación correspondiente.

Todas las modificaciones en la composición de este órgano serán comunicadas al Registro de Asociaciones.

Artículo 20. - Las funciones de la Junta Directiva son:

- Dirigir la gestión ordinaria del centro, de acuerdo con las directrices de la Asamblea General y bajo su control.

- Programar las actividades a desarrollar por el CUJE. 
- Someter a la aprobación de la Asamblea General el presupuesto anual de gastos e ingresos.

- Someter a la aprobación de la Asamblea General el estado de cuentas del año anterior, así como el informe de gestión del año anterior.

- Confeccionar el Orden del Día de las reuniones de la Asamblea General, así como acordar la convocatoria de las Asambleas Generales ordinarias y extraordinarias.

- Atender las propuestas o sugerencias que formulen los socios/as, adoptando al respecto, las medidas necesarias.

- Interpretar los preceptos contenidos en estos Estatutos y cubrir sus lagunas, sometiéndose siempre a la normativa legal vigente en materia de asociaciones.

- Ejercitar aquellas competencias que le otorgue la Asamblea General mediante Acuerdo expreso, siempre que no sean de su exclusiva competencia.

Artículo 21. - La Junta Directiva celebrara sus sesiones cuantas veces lo determine la Presidencia, o la Vicepresidencia en su caso, bien a iniciativa propia, o a petición de cualquiera de sus componentes. Sera presidida por el Presidente, y en su ausencia, por la Vicepresidencia y, a falta de ambos, por la persona de la Junta que tenga más edad.

Para que los acuerdos de la Junta sean válidos, deberán ser adoptados por mayoría de votos de las personas asistentes, requiriéndose la presencia de la mitad de los miembros.

De las sesiones, el Secretario levantara acta que se transcribirá al Libro correspondiente.

\section{c. ÓRGANOS UNIPERSONALES}

PRESIDENTE/A

Artículo 22. - El Presidente del CUJE asume la representación legal de la misma, y ejecutara los acuerdos adoptados por la Junta Directiva y la Asamblea General, cuya presidencia ostentara respectivamente. 
Artículo 23. - Corresponderán al Presidente/a las siguientes facultades:

Convocar y levantar las sesiones que celebre la Junta Directiva y la Asamblea General, dirigir las deliberaciones de una y otra, y decidir un voto de calidad en caso de empate de votaciones.

Proponer el plan de actividades de la Federación a la Junta Directiva, impulsando y dirigiendo sus tareas.

Ordenar los pagos acordados válidamente.

Resolver las cuestiones que puedan surgir con carácter urgente, dando conocimiento de ello a la Junta Directiva en la primera sesión que se celebre.

Ejercitar aquellas competencias que le otorgue la Asamblea General mediante acuerdo expreso, siempre que no sean de su exclusiva competencia.

\section{VICEPRESIDENTE/A}

Artículo 24. - El Vicepresidente asumirá las funciones de asistir al Presidente y sustituirle en caso de imposibilidad temporal de ejercicio de su cargo. Asimismo, le corresponderán cuantas facultades le delegue expresamente la Presidencia.

\section{SECRETARIO/A}

Artículo 25. - Corresponderán al Secretario las siguientes facultades: Custodiar los libros de actas y de registro de socios, documentos y sellos del CUJE.

Recibir y tramitar las solicitudes de ingreso, además de llevar el fichero y el Libro de Registro de Socios

Atender a la custodia y redacción del Libro de Actas.

Velar por el cumplimiento de las disposiciones legales vigentes en materia del Centro, custodiando la documentación oficial de la Entidad, certificando el contenido de los Libros y archivos sociales, y haciendo que se cursen a la autoridad competente las 
comunicaciones preceptivas sobre designación de Juntas Directivas y cambios de domicilio social.

Las Actas vendrán firmadas por el Presidente y Secretario, y las correspondientes certificaciones que expida el Secretario en nombre del centro deberán ir acompañadas por el visto bueno del Presidente.

\section{TESORERO/A}

Artículo 26. - Corresponderán al Tesorero las siguientes facultades: Llevar veraz y puntualmente los libros de contabilidad del CUJE. Preparar los balances, inventarios y presupuestos del CUJE para su aprobación por la Asamblea General, tras el visto bueno de la Junta Directiva.

Custodiar, recaudar y gestionar los fondos del CUJE.

Buscar, gestionar y justificar las posibles subvenciones a las que pueda optar CUJE.

Velar por el cumplimiento fiel de las obligaciones tributarias que conciernan a CUJE.

\section{COLABORADORES}

Artículo 27. - La Junta Directiva podrá nombrar los Colaboradores que considere necesario, siempre que el número de colaboradores no sea superior al número de miembros de la Junta Directiva. Dichos Colaboradores no pertenecerán a la Junta Directiva.

Sus funciones serán definidas por la Junta Directiva en cada caso, alrededor de un área específica.

\section{CAPITULO TERCERO}

1. DE LOS SOCIOS: REQUISITOS Y PROCEDIMIENTO DE ADMISIÓN Y CLASES

Artículo 28. - La adquisición de la condición de miembro vendrá determinada por la adquisición del carácter de "Centro Universitario 
de Jóvenes Emprendedores Aspirante" o, en su defecto, por la posesión del carácter de CUJE de pleno derecho.

Articulo 29. - Aquellos miembros que pretendan adquirir el carácter de Centro Universitario de Jóvenes Emprendedores Aspirante. Deberán presentar una solicitud por escrito firmada o enviada en formato digital.

Junto con esta solicitud, deberán presentar la documentación necesaria para avalar la concurrencia del solicitante, de los requisitos abajo mencionados, así como la declaración de conocer y asumir en caso de admisión, las obligaciones propias de todo miembro del centro.

Al ser miembro del Centro Universitario de Jóvenes Emprendedores Debiendo aportar el acuerdo expreso de su órgano competente, en el que se manifestara su voluntad asociativa.

Pertenecer a la Universidad de las Américas.

Total compatibilidad de sus normas estatutarias y reglamentarias, así como de sus objetivos y métodos marcados por CUJE.

Quienes deseen pertenecer a CUJE, lo solicitaran por escrito avalado por dos miembros y dirigido al Presidente, quien, dará cuenta a la Junta Directiva, que resolverá sobre la admisión o inadmisión, pudiéndose recurrir en alzada ante la Asamblea General. Articulo 30. - A todo aquel grupo de personas con intención de ser futuros socios del CUJE, se le otorgara la condición de miembro de pleno derecho del Centro, pero da lugar a unos derechos y obligaciones distintos a los que se atienen a cumplir.

Artículo 31. - La designación como Centro Universitario de Jóvenes Emprendedores de pleno derecho corresponderá a la iniciativa como poseedor de la marca Centro Universitario de Jóvenes Emprendedores, la misma que se consolidara como red estudiantil a nivel nacional. 
Artículo 32. - El CUJE, por acuerdo de la Junta Directiva, podrá otorgar la condición de socio honorario a aquellas personas que, reuniendo los requisitos necesarios para formar parte de aquella, no puedan servir a los fines sociales con su presencia física. La calidad de estos socios es meramente honorifica y, por tanto, no otorga la condición de miembro, ni derecho a participar en los órganos de Gobierno y Administración de la misma, estando exento de toda clase de obligaciones.

La asamblea será quien decidirá si se otorga o no por mayoría simple.

El secretario/a llevara el registro de todos los miembros nombrados honorarios.

\section{a. DERECHOS Y DEBERES DE LOS SOCIOS/AS}

Artículo 33. - Toda persona asociada tiene derecho a:

Impugnar los acuerdos y actuaciones contrarios a la Ley de los Estatutos, dentro del plazo de cuarenta días naturales, contados a partir de aquel en que el/la demandante hubiera conocido, o tenido oportunidad de conocer, el contenido del acuerdo impugnado.

Conocer, en cualquier momento, la identidad de los demás miembros del centro, la composición de los órganos de gobierno y representación del CUJE, su estado de cuentas y desarrollo de su actividad.

Ejercitar el derecho de voz y voto en las Asambleas Generales, pudiendo conferir, a tal efecto, su representación a otros miembros. Participar, de acuerdo con los presentes Estatutos, en los órganos de dirección del CUJE, siendo elector para los mismos.

Figurar en el fichero de Socios previsto en la legislación vigente, y hacer uso del emblema del CUJE.

Poseer un ejemplar de los Estatutos y del Reglamento de Régimen Interno si lo hubiere, y presentar solicitudes y quejas ante los órganos directivos. 
Disfrutar de los beneficios del CUJE según sus propias normas y asistir a cuantos actos públicos organice el Centro para la promoción y consolidación.

Ser oído por escrito, con carácter previo a la adopción de medidas disciplinarias, e informado de las causas que motiven aquellas, que solo podrán fundarse en el incumplimiento de sus deberes como socios.

Darse de baja en cualquier momento, sin perjuicio de los compromisos adquiridos pendientes de cumplimiento.

Artículo 34. - Son deberes de los socios/as:

Prestar concurso activo para la consecución de los fines del CUJE, colaborando positivamente en las actividades que se organicen.

Facilitar información veraz y sin dilaciones de cuanto le sea interesado por órganos superiores en el ejercicio de sus funciones, así como informar a los mismos, a iniciativa propia, cuando se hayan producido situaciones de tal relevancia que puedan afectar al buen funcionamiento y nombre del CUJE.

Asistir, con puntualidad e interés a las Asambleas Generales.

Contribuir al sostenimiento de los gastos con el pago de las cuotas, derramas y otras aportaciones que se establezcan por la Asamblea General.

Observar una conducta leal con el CUJE y con el resto de los miembros.

Acatar y cumplir lo presentes Estatutos, así como el Reglamento de Régimen Interno del CUJE y los acuerdos válidamente adoptados por sus órganos directivos.

Artículo 35. - El carácter de "Centro Universitario de Jóvenes Emprendedores Futuro socio", pese a no suponer la titularidad como socio del Centro, también supone un vínculo en el mismo y 
dará al "Centro Universitario de Jóvenes Emprendedores Futuro socio" derecho a:

Tomar parte en las Asambleas Generales, con voz pero sin voto.

Derecho a beneficiarse de los servicios ofrecidos como miembro del Centro Universitario de Jóvenes Emprendedores.

Poseer un ejemplar de los Estatutos y del Reglamento de Régimen Interior si lo hubiera.

Artículo 36. - El carácter de "Centro Universitario de Jóvenes Emprendedores Futuro socio", pese a no suponer la titularidad como socio del Centro, también supone un vínculo entre ambas.

Por ello el "Centro Universitario de Jóvenes Emprendedores Futuro socio" adquiere las siguientes obligaciones:

- Esforzarse en la pronta consecución del carácter del Centro Universitario de Jóvenes Emprendedores de pleno derecho.

- Responder veraz y puntualmente ante el CUJE.

- Observar una conducta leal con el CUJE.

- Someterse en su actuación a los Estatutos de la Federación y a su Reglamento de Régimen Interno.

\section{b. REGIMEN SANCIONADOR}

Artículo 37. - Las personas asociadas podrán ser sancionadas por la Junta Directiva por infringir reiteradamente los Estatutos o los acuerdos de la Asamblea General o de la Junta Directiva.

Las sanciones pueden comprender desde la suspensión de los derechos, de 15 días a un mes, hasta la separación definitiva, en los términos previstos en los artículos 39 al 42, ambos inclusive.

A tales efectos, la Presidencia podrá acordar la apertura de una investigación para que se aclaren aquellas conductas que puedan ser sancionables. Las actuaciones se llevaran a cabo por la Secretaria, que propondrá a la Junta Directiva la adopción de las medidas oportunas. La imposición de sanciones será facultad de la Junta 
Directiva, y deberá ir precedida de la audiencia de la persona interesada.

Contra dicho acuerdo, que será siempre motivado, podrá recurrirse ante la Asamblea General, sin perjuicio del ejercicio de acciones previsto en el artículo 33 -(a.

En la situación particular de falta de asistencia a las reuniones, de los socios del CUJE, durante 2 veces consecutivas sin causa justificada, podrá ser considerado como suficiente para dar lugar al cese de dicha sociedad como miembro del CUJE.

c. SUPUESTO Y PERDIDA DE LA CONDICION DE $\mathrm{SOCIO} / \mathrm{A}$

Artículo 38. - La condición de socio/a se perderá en los casos siguientes:

- Por disolución del CUJE.

- Por separación voluntaria, solicitando la baja mediante escrito al Presidente/a del Centro, al que se acompañara el acuerdo adoptado por el órgano de la entidad que corresponda en tal sentido.

- Por separación por sanción, acordada por la Junta Directiva, cuando se den algunas de las siguientes circunstancias: incumplimiento grave, reiterado y deliberado, de los deberes emanados de los presentes Estatutos y de los acuerdos válidamente adoptados por la Asamblea General y Junta Directiva.

- Por egresar la carrera su respectiva unidad académica.

Articulo 39. - Por impago de la cuota en un máximo de 3 meses, el CUJE será propuesto para su expulsión ante la asamblea general. Articulo 40. - En caso de incurrir un socio en cualquiera de los supuestos regulados en el artículo 38 -(c, la Presidencia podrá ordenar a la Secretaria la práctica de determinadas diligencias previas, al objeto de obtener la oportuna información, a la vista de la cual, la Presidencia podrá mandar archivar las actuaciones o iniciar un expediente sancionador. 
Articulo 41. - Si se iniciara un expediente sancionador por cualquiera de los supuestos regulados en el artículo 38 -(c, el Secretario, previa comprobación de los hechos, remitirá a la persona interesada un escrito en el que se pondrán de manifiesto los cargos que se le imputan, a los que podrá contestar alegando en su defensa lo que estime oportuno en el plazo de 15 días transcurridos los cuales, en todo caso, se incluirá este asunto en el Orden del día de la primera sesión de la Junta Directiva, la cual acordara lo que proceda, con el "quorum" de $2 / 3$ de los componentes de la misma.

El acuerdo de separación será notificado a la persona interesada, comunicándole que, contra el mismo, podrá presentar recurso ante la primera Asamblea General Extraordinaria que se celebre, que, de no convocarse en tres meses, deberá serlo a tales efectos exclusivamente. Mientras tanto, la Junta Directiva podrá acordar que la persona inculpada sea suspendida en sus derechos como socio/a y, si formara parte de la Junta Directiva, deberá decretar la suspensión en el ejercicio del cargo.

En el supuesto de que el expediente de separación se eleve a la Asamblea General, el Secretario redactara un resumen de aquel, a fin de que la Junta Directiva pueda dar cuenta a la Asamblea General del escrito presentado por la persona inculpada, e informar debidamente de los hechos para que la Asamblea pueda adoptar el correspondiente acuerdo.

Articulo 42. - El acuerdo de separación, que será siempre motivado, deberá ser comunicado a la persona interesada, pudiendo esta recurrir a los Tribunales en ejercicio del derecho que le corresponde, cuando estimare que aquel es contrario a la Ley o a los Estatutos.

Artículo 43. - Al comunicar a un socio su separación del CUJE, ya sea con carácter voluntario o como consecuencia de sanción, se le requerirá para que cumpla con las obligaciones que tenga pendientes para con aquella, en su caso. 


\section{CAPITULO CUARTO \\ 1. PATRIMONIO FUNDACIONAL Y REGIMEN \\ PRESUPUESTARIO}

Artículo 44. - El CUJE carece de patrimonio fundacional.

Artículo 45. - Los recursos económicos previstos por el CUJE para el desarrollo de las actividades sociales, serán los siguientes:

- Las cuotas de entrada.

- Las cuotas periódicas que acuerde la misma.

- Los productos de los bienes y derechos que le correspondan, así como las subvenciones, legados y donaciones que pueda recibir en forma legal.

- Los ingresos que obtenga la Federación mediante las actividades licitas que acuerde realizar la Junta Directiva, siempre dentro de los fines estatutarios.

- El ejercicio asociativo y económico será anual y su cierre tendrá lugar el 31 de diciembre de cada año.

Los beneficios obtenidos por el CUJE, derivados del ejercicio de actividades económicas, incluidas las prestaciones de servicios, deberán destinarse, exclusivamente, al cumplimiento de sus fines.

\section{CAPITULO QUINTO \\ 1. DE LA MODIFICACION DE ESTATUTOS}

Articulo 46. - La modificación de los Estatutos habrá de acordarse en Asamblea General de socios convocada específicamente con tal objeto, cuando así lo acuerde la Junta Directiva, bien por propia iniciativa, o porque lo soliciten $2 / 3$ partes de los asociados. En cualquier caso, la Junta Directiva designara una Ponencia formada por tres personas, a fin de que redacte el proyecto de modificación, siguiendo las directrices impartidas por aquella, la cual fijara el plazo en el que tal proyecto deberá estar terminado.

Artículo 47. - Una vez redactado el proyecto de modificación en el plazo señalado, el Presidente lo incluirá en el Orden del Día de la primera Junta Directiva que se celebre, la cual lo aprobara o, en su caso, lo devolverá a la Ponencia para nuevo estudio. 
En el supuesto de que fuera aprobado, la Junta Directiva acordara incluirlo en el Orden del Día de la próxima Asamblea General que se celebre, o acordara convocarla a tales efectos.

Articulo 48. - A la convocatoria de la Asamblea se acompañara el texto de la modificación de Estatutos, a fin de que los socios puedan dirigir a la Secretaria las enmiendas que estimen oportunas, de las cuales se dará cuenta a la Asamblea General, siempre y cuando estén en poder de la Secretaria con dos días de antelación a la celebración de la sesión.

Las enmiendas podrán ser formuladas individualmente o colectivamente, se harán por escrito y contendrán la alternativa de otro texto. Tras la votación de las enmiendas, la Asamblea General adoptara el Acuerdo de modificación estatutaria, el cual solo producirá efectos ante terceros desde que se haya procedido a su inscripción en el Registro General.

\section{CAPITULO SEXTO}

\section{DE LA DISOLUCION DE LA ASOCIACIONES Y APLICACION DEL PATRIMONIO SOCIAL}

Artículo 49. - La Federación se disolverá por las siguientes causas:

- Por voluntad de los socios, expresada en Asamblea General convocada al efecto, con el voto favorable de la mayoría absoluta de los/las presentes.

- Por sentencia judicial.

- El cumplimiento del plazo o condición fijados en los estatutos.

- La absorción o fusión con otras asociaciones.

- La falta del número mínimo de personas asociadas legalmente establecido.

- La imposibilidad de cumplimiento de los fines sociales.

Artículo 50. - En caso de disolverse el CUJE, la Asamblea General que acuerde la disolución, nombrara una Comisión Liquidadora, compuesta por dos personas miembros extraídas de la Junta Directiva, la cual se hará cargo de los fondos que existan. 
Una vez satisfechas las obligaciones sociales frente a los/las socios/as y frente a terceras personas, el patrimonio social sobrante, si lo hubiere, será entregado a las asociaciones que reúnan el requisito de ser asociaciones sin ánimo de lucro.

\section{DISPOSICION FINAL}

La Asamblea General podrá aprobar un Reglamento de Régimen Interno, como desarrollo de los presentes Estatutos, que no alterara, en ningún caso, las prescripciones contenidas en los mismos.

\section{Discusión}

Esta propuesta busca implementar una nueva política en la creación de nuevos procesos de vinculación en la universidad a partir de la participación activa de los estudiantes en su formación educativa y profesional. Estos procesos parten de una mejora comunicacional, tanto interna como externa; basada en la creación de vínculos y redes que creen un colectivo profesional en periodo de aprendizaje que ofrezca sus primeros frutos durante la formación de los estudiantes.

La necesidad que se ha ido creando en las universidades ecuatorianas, de igual modo en la UDLA, está llevando a los organismos del gobierno ecuatorianos encargados de regular las instituciones de educación superior a plantear estrategias que favorezcan la vinculación. Por este motivo, en colaboración con las propuestas del Estado ecuatoriano y las necesidades creadas en la UDLA, la creación del Centro Universitario de Jóvenes Emprendedores garantiza la puesta en práctica de un mecanismo que favorece la participación de los estudiantes en el desarrollo del Sistema Nacional de Educación Superior. Como estipula la Ley de Educación Superior "las instituciones de educación superior del Ecuador tienen como misión la búsqueda de la verdad, el desarrollo de la cultura universal y ancestral ecuatoriana, de la ciencia y la tecnología, mediante la docencia, la investigación y la vinculación con la colectividad". 
Este proceso de vinculación entre los estudiantes, la comunidad universitaria y la sociedad permitirá crear contactos y relaciones duraderas, creando una imagen integral y unificada de los distintos organismos y sistemas -educativo, político, social, comunicativo y económico- que estructuran la sociedad de Ecuador. De modo que el CUJE ayudará a los estudiantes -y a la universidad- a adentrarse en un proceso de autoformación que les permitirá convertirse, en primer lugar, en profesionales emprendedores que busquen el liderazgo en su vida profesional y, en segundo lugar, en ciudadanos íntegros que contribuyan en el desarrollo del país.

\section{Referencias bibliográficas}

Arraut L.; Amar, P.; Correa, Z. y Rodríguez, I. (2009). Modelo de participación de la Universidad Tecnológica de Bolívar en la creación de empresas de base tecnológica en la ciudad de Cartagena de Indias. XIII Seminario Latino Iberoamericano de Gestión TecnológicaAltec (1 -21). Cartagena: Tecnológica de Bolívar.

Bueno, E. (2007). La tercera misión de la Universidad: el reto de la transferencia del conocimiento. Revista Electrónica de Madrid, 41, http://www.madrimasd.org/revista/revista41/tribuna/tribuna2.asp [recuperado 15/12/2014].

Castro, E.; Olmos, J.; y Manjarrés, L. (2009). Transferencia de conocimiento en los grupos de investigación de ciencias humanas y sociales: la influencia de los factores organizativos. XIII Seminario Latino-Iberoamericano de Gestión Tecnológica. Cartagena de Indias, Colombia.

Constitución del Ecuador, 2008.

Etzkowitz, H. y Leydesdorff, L. (1995). The Triple Helix University Industry Gobernment Relations: A laboratory for Knowledge based Economic Development. EASST Review, 14: 14-19.

Etzkowitz, H.; Webster, A.; Gebhardt, C. y Cantisano, B. (2000). The Future of the University and the University of the Future: Evolution of Ivory Tower to Entrepreneurial Paradigm. Elsevier Science, $313-330$. 
Gutiérrez, C. (2007). Libre comercio y autonomía universitaria, un dilema actual: el caso colombiano, Revista Latinoamericana de Ciencias Sociales, Niñezy Juventud, 5(002): 605 -636.

Jiménez, C. y Castellanos, O. (2008). Desafios en gestón ecnológica para las universidades como generadoras de conocimiento. I Congreso Internacional de Gestión Tecnológica e Innovación. Bogotá, 14 y 15 de agosto.

Kantis, H.; Angelelli, P. y Moori, V. (2004). Desarrollo emprendedor: América Latina y la experiencia internacional. Nueva York: Edit. Banco Interamericano de Desarrollo.

Ley Orgánica de Educación Superior, LOES, 2010.

Moncada, J. (2008). La Universidad: un acercamiento histórico filosófico. Ideas y V alores, 137: 131 -148.

Pineda, K.; Morales, M.; Ortiz, M. (2011). Modelos y mecanismos de interacción universidad -empresa -Estado: retos para las universidades colombianas. Revista Equidad y Desarrollo, 15: 41 -67.

Pineda, K. y Morales, M. (2010). Integración Universidad, empresa y Estado: retos para la Universidad Militar Nueva Granada. Memorias del $V$ Encuentro de Investigaciones de la UMNG. Bogotá.

Plan Nacional del Buen Vivir, SENPLADES, 2012.

Reglamento general a la Ley Orgánica de Educación Superior, 2011.

Revelo, J. (2004). Normas, reflexiones y realidades sobre la educación superior en los países miembros del Convenio Andrés Bello. Bogotá: Convenio Andrés Bello. 


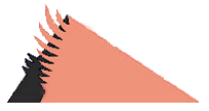 \\ Epílogo \\ Una lectura de la realidad, desde la Comunicación}

D ARA COMENZAR este epílogo permítannos una reflexión periodista, allá por los años 60 el nombre de CIESPAL era paradigma de investigación y desarrollo del conocimiento teórico en Comunicación en toda América Latina y en mi país. Uno de los sueños más preciados era estudiar en CIESPAL, lo que se convertiría en realidad hacia 1986 cuando nos becaron para estudiar el curso de Proyectos de Comunicación: Investigación y Planificación. Una experiencia inolvidable que marcó para siempre nuestra vida personal, profesional y académica, enriqueciéndonos mucho. La huella de Daniel Prieto, nuestro maestro y amigo sincero, permanece en nosotros. Hicimos allí entrañables amistades que duran hasta hoy, así como aprendimos mucho de la amable gente ecuatoriana, de sus paisajes, su arte, sus sabores y sus cantares.

Es menester ahora enfocarnos, con la brevedad que exige un epílogo, en el libro que tiene Ud. en sus manos. En esta obra que acabamos de leer con fruición encontramos el testimonio de colegas venidos de allende el océano quienes investigan acuciosamente la problemática de la comunicación y no lo hacen desde fuera, mirando del país a través de una ventana. Antes bien, sus lecturas de la realidad se nutren de las experiencias vividas en estancias de investigación al interior de instituciones académicas ecuatorianas de naturaleza diversa. Es en el marco de ese accionar que han desarrollado las actividades de investigación presentadas en las 
cuales han involucrado a especialistas de diversas instituciones ecuatorianas.

Hay un marcado tono de optimismo en el quehacer investigativo que se destila a lo largo de todo el libro así como en las reflexiones que se dan a conocer. Esto constituye a nuestro modesto entender una de sus evidentes fortalezas. Ello contradice palmariamente las que consideramos dos falacias que hemos escuchado repetir hasta la saciedad en diversos escenarios. La primera, presume que investigar "es una tarea imposible pues se requieren ingentes recursos que lamentablemente no tenemos aquí". La segunda, la podemos especificar en la pregunta "¿Para qué vamos a escribir si nadie nos lee?”. Y estas visiones pesimistas, sin base en la realidad, son siempre sostenidas por quienes ni investigan ni publican. Para investigar se requiere antes que nada voluntad, la experticia se va adquiriendo en el camino, se pueden realizar sin mayores recursos investigaciones de cátedra y es posible acceder a oportunidades de financiación de investigaciones. El escribir es una práctica que se va perfeccionando, que una vez que la iniciamos se ve fortalecida por la pasión que inspira e indudablemente siempre habrá gente interesada en leernos.

La introducción registra una serie de problemas que en líneas generales hemos observado en América Latina. Solo aludiremos a dos: La escasa ligazón de la academia con la realidad que amén de reflejarse en la adopción de paradigmas obsoletos y el teoricismo, se ha hecho evidente en la formación de profesionales de la comunicación que no siempre coinciden con las necesidades del país. Por otro lado, compartimos la percepción del desinterés por la investigación como por la integración en redes, lo cual conduce a que paradójicamente se conozca más de lo producido en el exterior que de lo investigado en otras ciudades del propio país. Somos relativamente pocos quienes investigamos, como puede colegirse del registro de expositores en certámenes nacionales e internacionales así como de las publicaciones científicas. Sin embargo, tal como Daniel y Martín lo expresan en el último párrafo de la introducción "Queda mucho camino por recorrer, pero algo se ha avanzado ya". $\mathrm{Y}$ esto se palpa en las nuevas generaciones de investigadores que 
van surgiendo en Ecuador y en América Latina así como en las publicaciones científicas que crecen día a día.

La falta de una cultura de participación, de la cual nos hablan Daniel Barredo, Roxana Silva y Cheryl Martens es una constante en diversos lugares de nuestro continente y a ello contribuye el sensacionalismo que se preocupa de lo intrascendente, lo cual conlleva a la necesidad de una comunicación con responsabilidad social, que contribuya al fortalecimiento de la democracia, a lo cual se alude en varios acápites del libro.

También se menciona la necesidad de que las universidades sean centros de producción de conocimientos con lo cual coincidimos. Es evidente, por ejemplo, que las universidades más prestigiosas del mundo se caracterizan por el desarrollo de conocimientos científicos generados por especialistas en sus propios centros de investigación.

La necesidad de la inclusión digital se manifiesta igualmente. Las posibilidades de participación y el mayor acceso a fuentes de información hacen posible que los ciudadanos comprendan mejor su realidad. Ello en la actualidad se relaciona necesariamente con la alfabetización digital, que hace posible optimizar las posibilidades de interacción en el mundo globalizado de hoy así como la de dar a conocer nuestra visión del mundo en que vivimos y hasta de aquel que verán los seres humanos de las futuras generaciones, para quienes la comunicación, como actividad cotidiana o como objeto de investigación, siempre será tarea de suma importancia.

Lima, diciembre de 2014

Amaro La Rosa

Investigador. Universidad Femenina del Sagrado Corazón, Perú 


\section{La Comunicación y el Periodismo de Ecuador frente a los desafíos contemporáneos}

\section{Los autores}

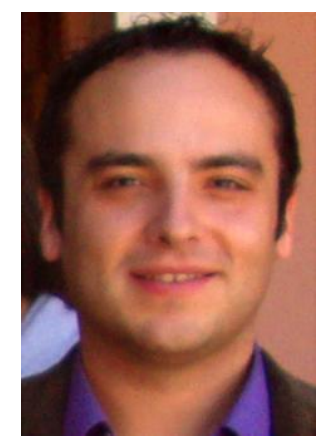

Daniel Barredo Ibáñez, doctor en Periodismo por la Universidad de Málaga (España), además de licenciado en Filología Hispánica, licenciado en Comunicación Audiovisual y máster en Comunicación por la Universidad de Granada (España).

Es autor de más de una treintena de artículos científicos, además de ocho monografías y cinco libros de creación artística. Ha impartido más de cuarenta conferencias en lugares como la Universidad de Oxford (Reino Unido), la Université Sorbonne Paris IV (Francia), la Pontificia Javeriana (Bogotá, Colombia), o la Universidad de Navarra (España), entre otras.

Su tesis doctoral fue el primer trabajo que analizó la comunicación de la monarquía española, fruto del cual publicó en 2013 "El Tabú Real. La imagen de una monarquía en crisis", un libro considerado “importante en su ámbito” según el prólogo del Dr. John Balmer, director del Grupo de Investigación en Marketing de la Brunel University de Londres (Reino Unido).

Entre 2013 y 2014, trabajó como investigador Prometeo para el Gobierno del Ecuador. En la actualidad, ejerce como investigador y docente en el departamento de Periodismo de la Universidad de las Américas (Ecuador).

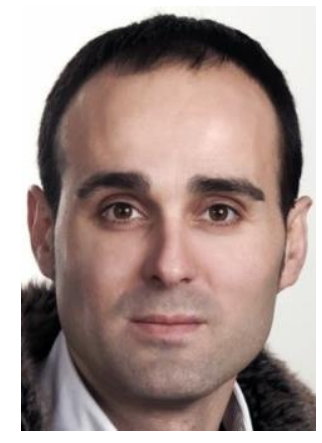

Martín Oller Alonso, doctor en Periodismo por la Universidad Rey Juan Carlos de Madrid (2012). Máster Universitario en Estudios Avanzados en Comunicación por la Universidad de Murcia (2009). Licenciado en Periodismo (2008), Publicidad y Relaciones Públicas (2011) y Ciencias de la Actividad 
Física y el Deporte (CAFD) por la Universidad de Murcia y la Universidad Católica de Murcia (UCAM).

Se encuentra involucrado en varios proyectos de investigación internacionales (World of Journalism Study, Journalistic Role Performance around the World y Cultura Periodística de Ecuador) basados en el análisis comparativo internacional del periodismo.

Además, ha escrito 10 libros científicos, colaborado en más de una docena de libros como coautor, elaborado casi una treintena de artículos científicos y participado como ponente en más de 40 congresos en varios países alrededor del mundo. Ha residido en Zúrich y St. Gallen (Suiza); Manchester (Inglaterra); París (Francia) y Murcia y Madrid (España). Actualmente reside en Quito (Ecuador) donde se desarrolla su labor docente e investigadora en la Universidad de las Américas (UDLA).

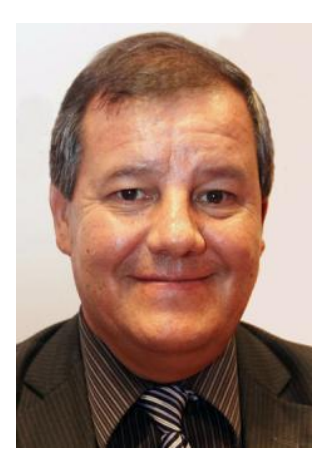

Sergio Hernández González, licenciado en Estadística por la Universidad Veracruzana, México; Maestría en Matemáticas (Mención Probabilidad y Estadística), por la Universidad de La Habana, Cuba y Ph. D. en Estadística Multivariante Aplicada, por la Universidad de Salamanca, España.

Catedrático de Tiempo Completo de la Facultad de Estadística e Informática desde hace 30 años, Profesor con Perfil PROMEP desde el año 2005 y Miembro del Sistema Nacional de Investigadores a partir del año 2012. Entre 2013 y 2014 trabajó como investigador Prometeo para el Gobierno de Ecuador.

Actualmente es investigador y docente en la Universidad Veracruzana, además de Presidente de la Asociación Mexicana de Estadística (AME). 